Eduardo Arreguy Viana

\title{
Interação Estrutura-Solo para Estruturas Aporticadas submetidas a carregamentos dinâmicos devidos a compressores alternativos
}

Dissertação de Mestrado

Dissertação apresentada ao Programa de Pós-Graduação em Engenharia Civil como requisito parcial para a obtenção do título de Mestre em Engenharia Civil.

Orientador: Deane de Mesquita Roehl

Rio de Janeiro 


\title{
Pontifícia Universidade Católlica $_{\text {an }}$

\section{Eduardo Arreguy Viana}

\author{
Interação Estrutura-Solo para Estruturas Aporticadas submetidas a \\ carregamentos dinâmicos devidos a compressores alternativos
}

Dissertação apresentada como requisito parcial para obtenção do título de Mestre pelo Programa de Pós-Graduação em Engenharia Civil da PUC-Rio. Aprovada pela Comissão Examinadora abaixo assinada.

Prof. Deane de Mesquita Roehl Orientador Departamento de Engenharia Civil - PUC-Rio

Prof. Paulo Batista Gonçalves Departamento de Engenharia Civil - PUC-Rio

Prof. Raul Rosas e Silva Departamento de Engenharia Civil - PUC-Rio

Rubenei Novais Souza PETROBRAS

Prof. José Eugênio Leal

Coordenador Setorial do Centro Técnico Científico - PUC-Rio

Rio de Janeiro, 13 de abril de 2012 
Todos os direitos reservados. É proibida a reprodução total ou parcial do trabalho sem autorização da universidade, do autor e do orientador.

\section{Eduardo Arreguy Viana}

Graduou-se em Engenharia Civil pela Universidade Federal do Espírito Santo (UFES) em 2005. Ingressou na Petrobras em 2006. Em 2006 foi lotado na gerência ENGENHARIA/IEABAST/EAB/IESC. Desde então, realiza projetos de engenharia básica nas disciplinas da engenharia civil e presta consultoria técnica aos empreendimentos do Abastecimento do sistema Petrobras.

Ficha Catalográfica

Viana, Eduardo A.

Interação Estrutura-Solo para estruturas aporticadas submetidas a carregamentos dinâmicos devidos a Compressores Alternativos / Eduardo Arreguy Vlana; orientador: Deane de Mesquita Roehl - 2012.

133 f. : il. (color.) ; $30 \mathrm{~cm}$

Dissertação (Mestrado) - Pontifícia Universidade Católica do Rio de Janeiro, Departamento de Engenharia Civil, 2012. Inclui bibliografia

1. Engenharia civil - Teses. 2. Vibração. 3. Interação estrutura-solo. 4. Coeficiente de mola. 5. Modelo de elementos finitos. 6. Modelo massa-mola. 7. Velocidade efetiva. 8. Freqüência natural. I. Roehl, Deane de Mesquita. II. Pontifícia Universidade Católica do Rio de Janeiro. Departamento de Engenharia Civil. III. Título.

CDD: 624 
Dedico esta obra ao professor João Luis Pascal Roehl (in memoriam) por ensinar-me tudo que sei sobre Dinâmica das Estruturas e, principalmente, pelo explicito prazer e dedicação à arte da Docência. 


\section{Agradecimentos}

À Deus, que me segurou e me deu forças quando nem eu mesmo achava que tinha.

À professora Deane pela orientação, apoio e motivação, fundamentais para o cumprimento desse importante objetivo de minha vida.

À professora Kátia Vanessa Bicalho da UFES, por ter me recomendado ao curso de mestrado da PUC-RIO.

À PUC-RIO por me aceitar como aluno e por me conceder bolsa de isenção de taxas.

Aos membros da banca examinadora, pela contribuição com comentários e sugestões.

Aos meus queridos pais Sérgio e Rosa, pela educação e dedicação infinita aos seus dois filhos.

Ao meu querido irmãozinho Flávio, agora doutor Flávio, pela amizade verdadeira. Valeu a pena!

Aos amigos da EAB que de alguma forma me ajudaram ao longo desse processo, especialmente ao chefe Bira por ter permitido minha ausência em certos momentos para atendimento às disciplinas e redação da minha dissertação.

À PETROBRAS por acreditar e incentivar a formação de seus funcionários, por ter me proporcionado estar hoje aqui, e por prezar pela excelência técnica e científica.

Aos amigos verdadeiros, especialmente Jô Buback e Elvídio Gavassoni, que presenciaram o começo dessa jornada. 


\section{Resumo}

Viana, Eduardo Arreguy; Roehl, Deane de Mesquita. Interação estrutura-solo para estruturas aporticadas submetidas a carregamentos dinâmicos devidos a compressores alternativos. Rio de Janeiro, 2012. 133p. Dissertação de Mestrado - Departamento de Engenharia Civil, Pontifícia Universidade Católica do Rio de Janeiro.

Compressores de gás de grande porte são componentes fundamentais em plantas industriais de refino de petróleo, atuando principalmente como agentes fornecedores de energia mecânica aos processos químicos. Dentre os tipos de compressores, destacam-se os alternativos. Devido a exigências de processo químico e arranjo industrial, é comum a instalação desses equipamentos em estruturas aporticadas, fato que, associado às características do movimento de suas partes mecânicas, não raramente as cargas dinâmicas geradas provocam vibrações inadmissíveis. Neste trabalho é avaliado o comportamento dinâmico de um sistema formado por uma estrutura aporticada, por compressor alternativo, pela fundação em estacas e finalmente pelo próprio solo. $\mathrm{O}$ estudo paramétrico realizado se desenvolve a partir de uma análise de modelos simplificados massa-mola, de um modelo em elementos finitos e de medições de campo visando a estabelecer intervalos de valores dos parâmetros do solo local dentro dos quais se identifique as características da resposta dinâmica do sistema. São avaliados os parâmetros coeficiente de mola $\left(k_{m}\right)$ e a constante do coeficiente de reação horizontal $\left(n_{h}\right)$ do solo natural típico da área abrangida pela refinaria REPAR, localizada no município de Araucária, no estado do Paraná, solo esse pertencente à formação geológica denominada Guabirotuba. A avaliação do comportamento dinâmico do sistema através dos modelos desenvolvidos é balizada por valores de medição na estrutura real de velocidades de vibração efetivas, obtidas por instrumentação. Os parâmetros do solo são obtidos por retroanálise de resultados de ensaio de campo, utilizando-se dois modelos amplamente utilizados nos escritórios de projeto: modelo proposto por Miche (1932) e modelo proposto por Hetenyi (1946). O primeiro considera que os parâmetros do solo variam com a profundidade, e o segundo os considera constante com a profundidade. Busca-se avaliar também a influência de parâmetros do solo obtidos através de ensaios de carregamento estático (ABNT NBR 12131, 2006) e obtidos através de ensaios de carregamento estático cíclico, este último se propondo a simular o efeito dinâmico sobre o solo. Finalmente, compara-se os resultados fornecidos 
pelos modelos simplificados e pelo modelo em elementos finitos em termos das freqüências naturais de vibração.

\section{Palavras-chave}

Vibração; interação estrutura-solo; coeficiente de mola; modelo de elementos finitos; modelo massa-mola; velocidade efetiva; freqüência natural. 


\section{Abstract}

Viana, Eduardo Arreguy; Roehl, Deane de Mesquita (Advisor). Structure-Soil interaction by frame structures under dynamic loads due to reciprocating compressors. Rio de Janeiro, 2012. 133p. MSc. Dissertation - Departamento de Engenharia Civil, Pontifícia Universidade Católica do Rio de Janeiro.

Gas compressors are key components of industrial plants in oil refining, mainly acting as mechanical energy suppliers to chemical processes. Among the types of compressors, the reciprocating ones is highlighted. Due to mandatory demands of chemical process and industrial arrangement, it is common to install such equipment in framed structures. This condition and the typical movement of mechanical parts of the compressors generate dynamic loads which frequently causes unacceptable vibrations. The aim of the present work is to evaluate the dynamic behavior of a system consisting of a framed structure, a reciprocating compressor, foundation in piles and the soil itself. For this purpose, parametric study is developed from simplified spring-mass models, a finite element model and field measurements. The parametric study is aimed at establish ranges of local soil parameters within which the dynamic behavior of a system can be understood and measured. The parameters so-called spring stiffness $\left(k_{m}\right)$ and the constant coefficient of horizontal reaction $\left(n_{h}\right)$ of natural soil which typically occurs in the area covered by the REPAR refinery, located in Araucaria, Paraná, are then evaluated. This type of natural soils belongs to the geological formation called Guabirotuba. The evaluation of the dynamic behavior of the system through the developed models is benchmarked by field measurements of effective velocity of vibration in the actual structure, obtained by instrumentation. The soil parameters are obtained by back analysis of tests results by using two models widely used in design offices: model proposed by Miche (1932) and model proposed by Hetenyi (1946). The first one takes in account the variation of the soil parameters with depth, and the second one considers soil parameters constant with depth. The aim is also to evaluate the influence of the soil parameters obtained by static and cyclic horizontal loading tests, the latter being proposed to simulate the dynamic effect on the soil. Finally, it is done comparisons of the results provided by simplified models and the finite element model in terms of natural frequencies of vibration. 


\section{Keywords}

Vibration; structure-soil interaction; spring stiffness; finite element model; sprigmass model; effective velocity; natural frequency. 


\section{Sumário}

1 Introdução

1.1. Objetivos gerais 23

1.2. Roteiro 24

2 Conceitos relacionados à dinâmica das máquinas 25

2.1. Propriedades do movimento harmônico 25

2.2. Modelo Massa-Mola-Amortecedor 27

2.2.1. Vibração livre $\quad 27$

2.2.2. Vibração livre não-amortecida 28

2.2.3. Vibração livre amortecida 29

2.2.4. Vibração forçada 30

2.2.4.1. Sistema não-amortecido 31

2.2.4.2. Sistema amortecido 31

2.2.4.3. Isolamento de vibrações 33

2.3. Método da superposição modal 34

2.4. Interação entre máquinas e estruturas 36

2.4.1. Procedimento do projeto de fundações de máquinas 36

2.4.2. Componentes de um problema de fundações de máquinas 37

2.4.2.1. Máquina 37

2.4.2.2. Superestrutura e fundação 38

$\begin{array}{ll}\text { 2.4.2.3. Solo } & 39\end{array}$

2.5. Sistema dinâmico Estrutura-Solo-Equipamento 39

2.5.1. Carregamento dinâmico devido a compressor alternativo 39

2.6. Interação solo-estrutura 43

3 Modelo físico 45

3.1. Descrição da estrutura 45

3.2. Descrição do equipamento 48

3.2.1. Compressor de gás 49 
3.3. Descrição do solo local 53

3.3.1. Conceitos relacionados a estacas carregadas horizontalmente $\quad 55$

3.3.2. Ensaio de carregamento horizontal 58

3.3.3. Retroanálise do resultado do ensaio de carregamento horizontal 63

3.3.3.1. Método de Miche 63

3.3.3.2. Método de Heteny 67

3.4. Instrumentação 68

4 Modelos simplificados massa-mola $\quad 71$

4.1. Método de Rausch 71

4.1.1. Freqüências naturais referentes aos modos na direção vertical 72

4.1.2. Freqüências naturais referentes aos modos na direção horizontal 72

4.1.3. Determinação das freqüências naturais do modelo estudado 73

4.2. Método de Barkan 74

4.2.1. Freqüências naturais referentes aos modos na direção horizontal 75

4.2.2. Determinação das freqüências naturais do modelo estudado 76

4.3. Modelo de interação dinâmica estrutura-solo 77

4.3.1. Freqüências naturais referentes aos modos na direção vertical 77

4.3.2. Freqüências naturais referentes aos modos na direção horizontal 79

4.3.3. Determinação das freqüências naturais do modelo estudado 81

5 Modelo numérico-computacional desenvolvido no $A B A Q U S \AA \quad 86$

5.1. Características do modelo numérico-computacional 86

5.2. Teste de malha $\quad 89$

5.3. Definição do passo de tempo 91

5.4. Carregamentos envolvidos 91

5.4.1. Carregamento estático 92

5.4.2. Carregamento dinâmico 92

5.5. Analise dinâmica por Superposição Modal 93

6 Estudos paramétricos $\quad 95$

6.1. Teste 1: modelo com base indeslocável 97

6.2. Teste 2: modelo com $k_{m}$ estático e variável com a profundidade $\quad 99$ 
6.2.1. Ensaio E-11 99

6.2.2. Ensaio E-16 100

6.2.3. Ensaio E-03 101

6.2.4. Análise dos resultados 102

6.3. Teste 3: modelo com $k_{m}$ cíclico e variável com a profundidade 105

6.3.1. Ensaio E-16 106

6.3.1.1. Ciclo de ida 106

6.3.1.2. Ciclo de volta 109

6.3.2. Ensaio E-03 111

6.3.2.1. Ciclo de ida 111

6.3.2.2. Ciclo de volta 113

6.3.3. Análise dos resultados $\quad 114$

6.4. Teste 4: modelo com $k_{m}$ cíclico e constante com a profundidade 119

6.4.1. Ensaio E-03 119

6.4.1.1. Ciclo de ida 119

6.4.1.2. Ciclo de volta 121

6.4.2. Análise dos resultados 122

6.5. Comparação entre modelos numéricos simplificados e em

$\begin{array}{ll}\text { Elementos Finitos } & 125\end{array}$

7 Considerações finais $\quad 128$

$\begin{array}{ll}\text { 7.1. Conclusões } & 128\end{array}$

7.2. Recomendações para trabalhos futuros $\quad 130$

8 Referencias bibliográficas 131 


\section{Lista de Figuras}

Figura 2-1 - Representação vetorial do movimento harmônico

Figura 2-2 - Vetores Posição, Velocidade e Aceleração no plano fase e no sistema de eixos coordenados

Figura 2-3 - Modelo simplificado Massa-Mola em diversas configurações

Figura 2-4 - Espectro de respostas de um sistema com 1 grau de liberdade

Figura 2-5 - Relação entre Transmissibilidade e $\beta$

Figura 2-6 - Fluxograma de análise de problemas de fundações de máquinas

Figura 2-7 - Fundação em bloco de concreto apoiado diretamente em solo

Figura 2-8 - Exemplos de sistema estrutural aporticado de suporte de equipamentos 38

Figura 2-9 - Arranjo típico de um compressor alternativo de um cilindro (BHATIA, 2008)

Figura 2-10 - Forças dinâmicas no sistema mecânico em um dado instante de tempo 41

Figura 3-1 - Planta no nível das fundações (elevação 99.8m)

Figura 3-2 - Planta na elevação 105.215m (Motor Elétrico) e 104.15m (Compressor) 46

Figura 3-3 - Corte A-A

Figura 3-4 - Corte B-B

Figura 3-5 - Fotos da estrutura de concreto armado real (modelo físico) 48

Figura 3-6 - Acoplamento entre compressor e motor elétrico 50

Figura 3-7 - Chassi do compressor $\quad 50$

Figura 3-8 - Cilindros de compressão e tubulações $\quad 50$

Figura 3-9 - Elementos do sistema mecânico

Figura 3-10 - Linhas limites de vibração para Danos Estruturais, Grau de Severidade de Vibração da Máquina e Percepção Humana $\quad 52$

Figura 3-11 - Motor elétrico sobre uma das lajes de suporte 53

Figura 3-12 - Planta de locação de sondagens do tipo SPT consideradas como referência para caracterização geotécnica do subsolo local 54

Figura 3-13 - Perfil geotécnico típico do subsolo local 55

Figura 3-14 - Estaca isolada carregada transversalmente 55

Figura 3-15 - Coeficiente de reação horizontal uniforme 56 
Figura 3-16 - Coeficiente de reação horizontal variável

Figura 3-17 - Coeficiente de mola - Modelo de Winkler

Figura 3-18 - Aparato de montagem do ensaio de carregamento horizontal

Figura 3-19 - Resultado ensaio carregamento cíclico horizontal - Estaca-teste E-16 62

Figura 3-20 - Resultado ensaio carregamento cíclico horizontal - Estaca-teste E-3 62

Figura 3-21 - Croqui com os pontos de medição de vibração

Figura 3-22 - Amplitude das Velocidades de Vibração (mm/s) - Pontos localizados nos pilares

Figura 4-1 - Pórtico transversal típico e modelos Massa-Mola horizontal e vertical 71

Figura 4-2 - Modelo Massa-Mola para movimento na direção horizontal 75

Figura 4-3 - Modelo Massa-Mola para movimento na direção Vertical 78

Figura 4-4 - Modelo simplificado de interação solo-estrutura $\quad 80$

Figura 5-1 - (a) Modelo 3D do sistema Estrutura-Fundação-Solo-Equipamento feito no software $A B A Q U S \AA$ (b) Modelo renderizado

Figura 5-2 - Aspecto geral da malha de elementos finitos gerada para o modelo

Figura 6-1 - Legenda para a apresentação dos resultados

Figura 6-2 - Planta e cortes da estrutura de suporte do compressor

Figura 6-3 - Velocidade Efetiva de Vibração $(\mathrm{mm} / \mathrm{s})$

Figura 6-4 - Erros percentuais - Velocidade efetiva Medida x Velocidade efetiva calculada

Figura 6-5 - Velocidade Efetiva de Vibração $(\mathrm{mm} / \mathrm{s})-n_{h}=64945.9630 \mathrm{kN} / \mathrm{m}^{3} \quad 99$

Figura 6-6 - Erros percentuais $-n_{h}=64945.9630 \mathrm{kN} / \mathrm{m}^{3} \quad 99$

Figura 6-7 - Velocidade Efetiva de Vibração $(\mathrm{mm} / \mathrm{s})-n_{h}=5087.9877 \mathrm{kN} / \mathrm{m}^{3} \quad 100$

Figura 6-8 - Erros percentuais $-n_{h}=5087.9877 \mathrm{kN} / \mathrm{m}^{3} \quad 100$

Figura 6-9 - Velocidade Efetiva de Vibração $(\mathrm{mm} / \mathrm{s})-n_{h}=1624.9799 \mathrm{kN} / \mathrm{m}^{3} \quad 101$

Figura 6-10 - Erros percentuais $-n_{h}=1624.9799 \mathrm{kN} / \mathrm{m}^{3} \quad 101$

Figura 6-11 - Velocidade Efetiva de Vibração (mm/s) - Ciclo Ida Menor 106

Figura 6-12 - Erros percentuais - Ciclo Ida Menor 107

Figura 6-13 - Velocidade Efetiva de Vibração (mm/s) - Ciclo Ida Maior 108

Figura 6-14 - Erros percentuais - Ciclo Ida Maior 108

Figura 6-15 - Velocidade Efetiva de Vibração (mm/s)-Ciclo Volta Menor 109

Figura 6-16 - Erros percentuais - Ciclo Volta Menor 109

Figura 6-17 - Velocidade Efetiva de Vibração (mm/s)-Ciclo Volta Maior $\quad 110$ 
Figura 6-18 - Erros percentuais - Ciclo Volta Maior 111

Figura 6-19 - Velocidade Efetiva de Vibração (mm/s) - Ciclo Ida Menor 112

Figura 6-20 - Erros percentuais - Ciclo Ida Menor 112

Figura 6-21 - Velocidade Efetiva de Vibração (mm/s) - Ciclo Volta Maior 113

Figura 6-22 - Erros percentuais - Ciclo Volta Maior 114

Figura 6-23 - Velocidade Efetiva de Vibração (mm/s) - Ciclo Ida Menor 120

Figura 6-24 - Erros percentuais - Ciclo Ida Menor 120

Figura 6-25 - Velocidade Efetiva de Vibração (mm/s) - Ciclo Volta Maior 121

Figura 6-26 - Erros percentuais - Ciclo Volta Maior 122

Figura 6-27 - Comparação Modelo Simplificado versus FEM - Modo 1

Figura 6-28 - Comparação Modelo Simplificado versus FEM - Modo $3 \quad 126$

Figura 6-29 - Comparação Modelo Simplificado versus FEM - Modo 4 


\section{Lista de Tabelas}

Tabela 2-1 - Legenda dos elementos constituintes do sistema mecânico de um compressor alternativo

Tabela 3-1 - Amplitude das cargas dinâmicas devidas ao compressor 51

Tabela 3-2 - Cargas estáticas dos componentes do compressor 51

Tabela 3-3 - Peso e massa do motor elétrico 53

Tabela 3-4 - Resultados do ensaio de carregamento horizontal - Estaca-teste E-11 60

Tabela 3-5 - Resultados do ensaio de carregamento horizontal - Estaca-teste E-16 60

Tabela 3-6 - Resultados do ensaio de carregamento horizontal - Estaca-teste E-3 61

Tabela 3-7 - Resumo dos resultados do ensaio de carregamento horizontal 61

Tabela 3-8 - Valores de $n_{h}$ retro analisados $\quad 64$

Tabela 3-9 - Valores dos coeficientes de mola $k_{m}$ retro analisados - Caso estático $\quad 64$

Tabela 3-10 - Ensaio E-16 - Ciclo de Ida - Valores de $n_{h}$ retroanalisados 65

Tabela 3-11 - Ensaio E-16 - Ciclo de Volta - Valores de $n_{h}$ retroanalisados 65

Tabela 3-12 - Ensaio E-16 - Ciclo de Ida $-k_{m}$ para $n_{h}=157227.3290 \mathrm{kN} / \mathrm{m}^{3}$ e $n_{h}=191974.2753 \mathrm{kN} / \mathrm{m}^{3}$

Tabela 3-13 - Ensaio E-16 - Ciclo de Volta $-k_{m}$ para $n_{h}=69712.6988 \mathrm{kN} / \mathrm{m}^{3}$ e $n_{h}=107239.9283 \mathrm{kN} / \mathrm{m}^{3}$

Tabela 3-14 - Ensaio E-3 - Ciclo de Ida $-k_{m}$ para $n_{h}=34222.4094 \mathrm{kN} / \mathrm{m}^{3}$ e $n_{h}=82482.4884 \mathrm{kN} / \mathrm{m}^{3}$

Tabela 3-15 - Ensaio E-3 - Ciclo de Volta $-k_{m}$ para $n_{h}=183437.5885 \mathrm{kN} / \mathrm{m}^{3}$ e $n_{h}=326398.0336 \mathrm{kN} / \mathrm{m}^{3}$

Tabela 4-1 - Dados dos pórticos componentes do sistema estrutural 73

Tabela 4-2 - Resultados para as freqüências naturais - Modelo de Rausch 74

Tabela 4-3 - Resultados para as freqüências naturais - Modelo de Barkan 76

Tabela 4-4 - Resultados para as freqüências naturais (Hz)- Modelo de Interação

$\begin{array}{ll}\text { Solo-Estrutura } & 82\end{array}$

Tabela 5-1 - Massas concentradas correspondentes aos equipamentos mecânicos $\quad 87$

Tabela 5-2 - Dados gerais do modelo computacional em $A B A Q U S \circledR \quad 88$

Tabela 5-3 - Tipos e quantidade de elementos finitos utilizados para análise modal $\quad 90$ 
Tabela 5-4 - Tipos e quantidade de elementos finitos utilizados para extração das freqüências naturais e determinação dos modos de vibração do modelo

Tabela 5-5 - Coeficientes das séries de Fourier de seno e cosseno para a força de excitação

Tabela 6-1 - Freqüências naturais calculadas

Tabela 6-2 - Freqüências naturais de vibração $-n_{h}=64945.9630 \mathrm{kN} / \mathrm{m}^{3}$

Tabela 6-3 - Freqüências naturais de vibração $-n_{h}=5087.9877 \mathrm{kN} / \mathrm{m}^{3}$

Tabela 6-4 - Freqüências naturais de vibração $-n_{h}=1624.9799 \mathrm{kN} / \mathrm{m}^{3}$

Tabela 6-5 - Resumo dos erros percentuais

Tabela 6-6 - Freqüências naturais em função dos valores de $n_{h}$

Tabela 6-7 - Ensaio E-16 - Ciclo de Ida $-k_{m}$ para $n_{h}=157227.3290 \mathrm{kN} / \mathrm{m}^{3} \quad 106$

Tabela 6-8 - Freqüências naturais de vibração - Ciclo Ida Menor 107

Tabela 6-9 - Ensaio E-16 - Ciclo de Ida $-k_{m}$ para $n_{h}=191974.2753 \mathrm{kN} / \mathrm{m}^{3} \quad 107$

Tabela 6-10 - Freqüências naturais de vibração - Ciclo Ida Maior 108

Tabela 6-11 - Ensaio E-16 - Ciclo de Volta $-k_{m}$ para $n_{h}=69712.6988 \mathrm{kN} / \mathrm{m}^{3} \quad 109$

Tabela 6-12 - Freqüências naturais de vibração - Ciclo Volta Menor 110

Tabela 6-13 - Ensaio E-16 - Ciclo de Volta $-k_{m}$ para $n_{h}=107239.9282 \mathrm{kN} / \mathrm{m}^{3} \quad 110$

Tabela 6-14 - Freqüências naturais de vibração - Ciclo Volta Maior 111

Tabela 6-15 - Ensaio E-03 - Ciclo de Ida $-k_{m}$ para $n_{h}=34222.4094 \mathrm{kN} / \mathrm{m}^{3} \quad 112$

Tabela 6-16 - Freqüências naturais de vibração - Ciclo Ida Menor 113

Tabela 6-17 - Ensaio E-03 - Ciclo de Volta $-k_{m}$ para $n_{h}=326398.0336 \mathrm{kN} / \mathrm{m}^{3} \quad 113$

Tabela 6-18 - Freqüências naturais de vibração - Ciclo Volta Maior 114

Tabela 6-19 - Resumo dos erros percentuais - Ensaio E-16 115

Tabela 6-20 - Resumo dos erros percentuais - Ensaio E-03 115

Tabela 6-21 - Freqüências naturais em função dos valores de $n_{h}$ - Ensaio E-16 117

Tabela 6-22 - Freqüências naturais em função dos valores de $n_{h}$ - Ensaio E-03 118

Tabela 6-23 - Ensaio E-03 - Ciclo de Ida $-k_{m}=16093.5988 \mathrm{kN} / \mathrm{m} \quad 120$

Tabela 6-24 - Freqüências naturais de vibração - Mola Constante - Ciclo Ida Menor 121

Tabela 6-25 - Ensaio E-03 - Ciclo de volta $-k_{m}=97769.3507 \mathrm{kN} / \mathrm{m} \quad 121$

Tabela 6-26 - Freqüências naturais de vibração Mola Constante Ciclo Volta Maior 122

Tabela 6-27 - Resumo dos erros percentuais para cada teste 122

Tabela 6-28 - Freqüências naturais em função dos valores de $k_{m} \quad 124$ 


\section{Lista de Símbolos}

\section{Coordenadas}

$x$ - coordenada na direção $\mathrm{x}(\mathrm{m})$

$y$ - coordenada na direção y $(\mathrm{m})$

$z$ - coordenada na direção z (m)

\section{Vetores}

$\vec{x}$ - vetor dos deslocamentos nodais $(\mathrm{m})$

$\vec{\Phi}$ - vetor dos modos normais

$\vec{Y}$ - vetor das coordenadas generalizadas

\section{Tensores}

$M \quad$ - matriz de massa

C - matriz de amortecimento

$K$ - matriz de rigidez

\section{Símbolos Romanos}

$\mathrm{T}$ - período de oscilação

$\mathrm{t}$ - tempo (s)

$\mathrm{f}$ - freqüência natural $(\mathrm{Hz})$

$\mathrm{m}$ - massa $(\mathrm{kg})$

$k_{m}$ - coeficiente de mola $(\mathrm{N} / \mathrm{m})$

$k_{v}$ - rigidez resultante dos pilares na direção vertical (N/m)

$k_{h i}$ - rigidez de um pilar na direção horizontal (N/m)

$\mathrm{C}$ - coeficiente de amortecimento viscoso (N.s/m)

$\mathrm{C}_{\mathrm{c}}-$ coeficiente de amortecimento crítico (N.s/m)

$\mathrm{x}$ - deslocamento de um sistema de 1 grau de liberdade (m)

$\mathrm{x}_{\mathrm{est}}$ - máximo deslocamento estático de um sistema de 1 grau de liberdade $(\mathrm{m})$

$\mathrm{F}-$ força $(\mathrm{N})$

$\mathrm{F}_{0}$ - amplitude de força $(\mathrm{N})$

$\mathrm{F}_{\mathrm{t}}$ - força transmitida à fundação $(\mathrm{N})$ 
$\mathrm{F}_{\mathrm{t} 0}$ - amplitude da força transmitida à fundação $(\mathrm{N})$

TR - transmissibilidade

D - fator de amplificação dinâmica

NSPT - índice do teste de penetração padrão

$k_{z}$ - coeficiente de reação horizontal

d - diâmetro da estaca

$n_{h}$ - constante do coeficiente de reação horizontal

E - módulo de elasticidade longitudinal $\left(\mathrm{N} / \mathrm{m}^{2}\right)$

I - momento de inércia

$\mathrm{I}_{\mathrm{p}}$ - momento de inércia de um pilar

$\mathrm{H}$ - altura do pilar

$\mathrm{I}_{\mathrm{b}}$ - momento de inércia de uma viga transversal

e - distancia entre os centros de gravidade e de rigidez (m)

$\mathrm{T}$ - parâmetro do método de Miche

$J_{\Phi}$ - momento de inércia de massa

$A_{P}$ - área da seção transversal do pilar $\left(\mathrm{m}^{2}\right)$

$\mathrm{f}_{\mathrm{ck}}$ - resistência característica a compressão do concreto

$\mathrm{Pa}$ - ponto de instrumentação no nível correspondente ao topo dos pilares

$\mathrm{Pb}$ - ponto de instrumentação no nível das fundações

\section{Símbolos Gregos}

$\omega$ - freqüência natural angular $(\mathrm{rad} / \mathrm{s})$

$\omega_{d}-$ freqüência natural angular amortecida $(\mathrm{rad} / \mathrm{s})$

$\omega_{m}-$ freqüência de excitação do equipamento $(\mathrm{rad} / \mathrm{s})$

$\omega_{n v}$ - freqüência natural referente ao modo de vibração vertical resultante ( $\left.\mathrm{rad} / \mathrm{s}\right)$

$\omega_{n v i}-$ freqüência natural referente ao modo de vibração vertical individual ( $\left.\mathrm{rad} / \mathrm{s}\right)$

$\omega_{n h}$ - freqüência natural referente ao modo de vibração horizontal resultante ( $\left.\mathrm{rad} / \mathrm{s}\right)$

$\omega_{n h i}$ - freqüência natural referente ao modo de vibração horizontal individual ( $\left.\mathrm{rad} / \mathrm{s}\right)$

$\varphi$ - ângulo de fase (rad)

$\pi$ - constante

$\xi$ - taxa de amortecimento

$\beta-$ razão entre freqüências 
$\lambda$ - parâmetro do método de Hetenyi

$\gamma$ - momento de inércia de rigidez

$\delta_{v i}$ - deformação vertical de uma viga transversal

$\tau$ - torque 


\section{1 Introdução}

Durante os primeiros estudos sobre vibrações em estruturas e em fundações de máquinas, métodos simples de cálculo consideravam o efeito dinâmico simplesmente como sendo um carregamento estático amplificado, ou seja, sobre o valor das cargas estáticas aplicava-se um fator chamado Fator Dinâmico, o que levava muitas das vezes a cargas maiores que o carregamento dinâmico real e, conseqüentemente, o dimensionamento se tornava muito conservador.

Com o aumento do porte dos equipamentos como os encontrados em uma planta de refino de petróleo, os quais passaram a operar sob condições ainda mais severas, uma análise mais profunda e científica se tornou necessária e fundamental quando se tratava de carregamentos dinâmicos. Dentre esses equipamentos, destacam-se os compressores alternativos de grande porte, os quais possuem como principal função fornecer energia mecânica aos processos químicos. Os compressores alternativos, devido a exigências de processo químico e arranjo industrial, são comumente instalados em estruturas aporticadas, fato que, associado às características do movimento de suas partes mecânicas, as cargas dinâmicas geradas não raramente provocam vibrações inadmissíveis. Essa condição severa motiva atenção especial durante a fase de projeto.

Além disso, o custo associado às paradas de equipamentos em plantas industriais devido a falhas e mau desempenho mecânico é significantemente maior que o custo associado a um projeto bem desenvolvido, justificando qualquer esforço no sentido de garantir nessa fase o adequado comportamento durante a fase futura de operação.

Portanto, grande evolução técnica e científica foi observada no campo das estruturas e fundações para máquinas de grande porte, com importante contribuição multidisciplinar de pesquisadores e engenheiros das disciplinas de engenharia civil e de engenharia mecânica.

Nesse contexto, desde então foram desenvolvidos métodos analíticos para projeto de estruturas e fundações de máquinas, testes de laboratórios e medições de campo de modo a determinar a influência dos parâmetros do problema na resposta de sistemas. 
Aplicações computacionais para análise do comportamento de sistemas submetidos a cargas dinâmicas se tornaram comuns.

O principal objetivo de um projeto de estruturas de suporte de máquinas, incluindo também suas fundações, é limitar o movimento de seus componentes a amplitudes que não prejudiquem a operação normal dos equipamentos e não causem desconforto às pessoas que trabalham nas vizinhanças. Assim, o aspecto fundamental para o sucesso de um projeto de estruturas para equipamentos vibráteis é a análise cuidadosa da resposta do sistema estudado aos carregamentos dinâmicos previamente ao inicio de operação. Além disso, quando vibrações excessivas de um sistema estrutural existente influenciam negativamente a operação do equipamento suportado, uma outra abordagem analítica se faz necessária de forma a entender as causas do problema e a conduzir para uma remediação apropriada (GAZETAS, 1983).

A interação dinâmica entre o solo e a estrutura nele inserida ainda é um campo onde pesquisadores procuram por respostas para vários problemas. Como exemplo, o solo é modelado como uma mola linear com base na teoria do semi-espaço elástico, o qual por hipótese é considerado como um meio isotrópico linear, o que de fato não é. Além disso, dissipação de poro-pressão no solo submetido a carregamentos dinâmicos, potencial de liquefação e seus efeitos, problemas de domínio infinito, comportamento não-linear e inelástico, amortecimento geométrico, entre outros, são alguns dos principais aspectos sobre os quais pesquisas ainda estão sendo desenvolvidas no intuito de produzir modelos ao mesmo tempo realísticos e simples para uso na prática da engenharia.

$\mathrm{Na}$ análise da resposta dinâmica de fundações, o solo pode ser tratado de varias formas. Esses tratamentos incluem métodos de elementos finitos e de elementos de contorno, soluções analíticas desenvolvidas a partir da solução da equação da onda e de modelos mecânicos simplificados. O método dos elementos finitos permite avaliar configurações complexas do subsolo, mas requer significante esforço computacional. Já as soluções analíticas são geralmente limitadas a condições muito simples e nem sempre são aplicáveis às condições reais, principalmente quando não-linearidades e condições de contorno complexas estão envolvidas (NOGAMI, 1996).

Neste trabalho, busca-se fundamentalmente estudar os parâmetros do solo natural típico da área abrangida pela refinaria REPAR, localizada no município de Araucária, no estado do Paraná, solo esse pertencente à formação geológica denominada Guabirotuba. Esse estudo paramétrico visa a, com o auxilio de modelos simplificados 
massa-mola e modelo em elementos finitos, estabelecer intervalos de valores dos parâmetros do solo local dentro dos quais se identifique o comportamento dinâmico de um sistema formado por uma estrutura aporticada, por compressores alternativos, pela fundação em estacas e finalmente pelo próprio solo. A avaliação numérica do comportamento dinâmico do sistema é balizada por valores de medição na estrutura real de velocidades de vibração efetivas, obtidas por instrumentação. Os parâmetros do solo avaliados são o coeficiente de mola $k_{m}$ e a constante do coeficiente de reação horizontal $n_{h}$,

Tais parâmetros citados são obtidos por retroanálise de resultados de ensaio de campo, utilizando-se dois modelos amplamente utilizados nos escritórios de projeto: modelo proposto por Miche (1932) e modelo proposto por Hetenyi (1946). O primeiro considera que os parâmetros do solo variam com a profundidade, e o segundo os considera constante com a profundidade. Alem desses modelos, existem outros também bastante utilizados, podendo ser citados Matlock e Reese (1960) e Poulos (1980).

Busca-se avaliar também a influência de parâmetros do solo obtidos através de ensaios de carregamento estático (ABNT NBR 12131, 2006) e obtidos através de ensaios de carregamento estático cíclico em estacas, este último se propondo a simular o efeito dinâmico sobre o solo.

Finalmente, faz-se comparações entre os resultados fornecidos pelos modelos simplificados e pelo modelo em elementos finitos em termos das freqüências naturais de vibração.

\section{1.}

\section{Objetivos gerais}

Os objetivos gerais desse trabalho são:

- Melhoria do processo de projeto tendo em vista obter melhor desempenho das máquinas;

- Oferecer informações de fácil aplicação em problemas práticos de fundações de máquinas que normalmente encontram grande dificuldade e incertezas nos escritórios de projeto;

- Promover a idéia da análise multidisciplinar do problema de interação entre estruturas e equipamentos;

- Validar o processo de modelagem, discretização e condições de contorno empregado para obter a solução através do método de elementos finitos; 
- Aumentar o conhecimento das características do solo local;

\section{2.}

\section{Roteiro}

Inicialmente, no capítulo 2 são apresentados os principais conceitos relacionados à dinâmica das máquinas.

No capítulo 3 são apresentadas e descritas todas as características físicas do problema de interação estrutura-solo-equipamento estudado. São apresentados também os resultados do ensaio de carregamento horizontal realizado em campo em estacasteste, os valores das propriedades físicas do solo obtidos com base em retroanálises dos resultados do ensaio de carregamento horizontal, além dos resultados das medições de campo (instrumentação) de velocidade de vibração em pontos específicos da estrutura.

No capítulo 4 são apresentadas análises de vibração livre do caso estudado a partir de três métodos consagrados na literatura aplicados às estruturas aporticadas: Rausch (1959), Barkan (1962) e Chowdhury (1984).

No capítulo 5 é apresentado o modelo numérico-computacional de elementos finitos em 3 dimensões do sistema estrutura-solo-equipamento estudado. O modelo foi desenvolvido com base nos elementos disponíveis no programa de análise por elementos finitos $A B A Q U S^{\circledR}$.

O capítulo 6 descreve os estudos paramétricos realizados a partir do modelo de elementos finitos do sistema interativo estrutura-solo-equipamento-fundação, e dos modelos simplificados massa-mola, além de analisar a influência dos parâmetros identificados no comportamento dinâmico desse sistema.

Ao capítulo 7 são reservadas as considerações finais a respeito do presente trabalho. 


\section{2 \\ Conceitos relacionados à dinâmica das máquinas}

Para a elaboração de um projeto de suporte de equipamentos vibratórios é necessário o conhecimento dos conceitos clássicos de dinâmica, além do entendimento do fenômeno de interação entre os elementos do sistema, quais sejam a estrutura, as fundações, os equipamentos e o meio no qual estão inseridos, ou seja, o solo.

\section{1.}

\section{Propriedades do movimento harmônico}

A maioria dos problemas relacionados com a interação dinâmica entre estruturas, fundações, máquinas e solo considera carregamentos atuantes segundo uma função periódica. A mais simples forma de movimento periódico é o Movimento Harmônico, o qual é representado por funções seno ou cosseno (PRAKASH, 1981). Em sua forma geral, podemos considerar o movimento harmônico representado pela seguinte equação:

$$
x=X \operatorname{sen}(\omega t+\varphi)
$$

onde $\omega$ é a freqüência angular em radianos por unidade de tempo e $\varphi$ é o ângulo de fase em radianos. A variável $x$ representa a projeção na direção vertical de um vetor de comprimento $X$ que gira em torno de um ponto central segundo um circulo de raio também de comprimento $X$, com velocidade angular constante $\omega$. A Figura 2-1 mostra graficamente o movimento harmônico.

Uma vez que a função se repete a cada giro de $2 \pi$ radianos, um ciclo completo ocorre decorrido um intervalo de tempo igual a

$$
T=\frac{2 \pi}{\omega}
$$

onde $T$ é o período do movimento. A freqüência é dada pelo inverso do período, ou seja,

$$
f=\frac{1}{T}=\frac{\omega}{2 \pi}
$$




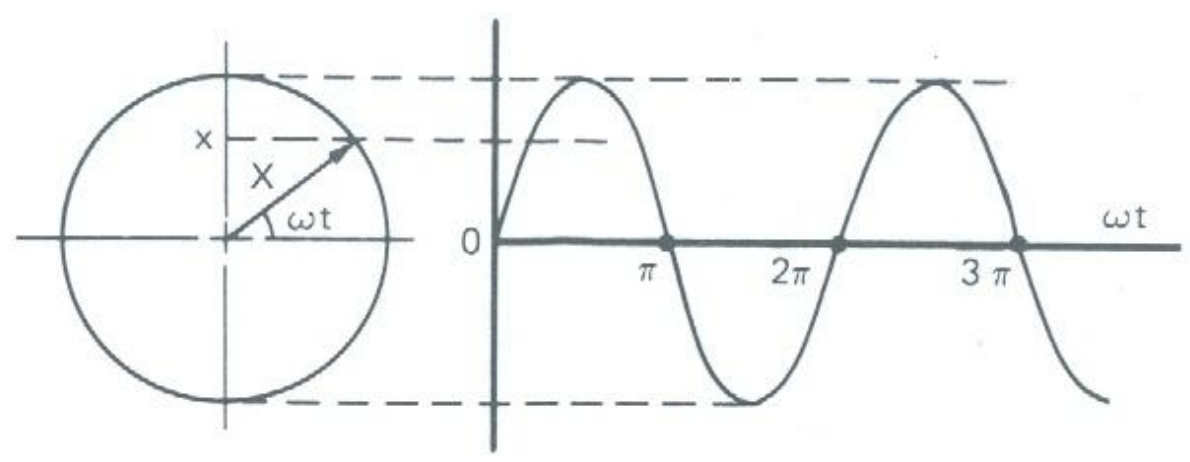

Figura 2-1 - Representação vetorial do movimento harmônico

A determinação da velocidade e da aceleração do movimento é feita diretamente pela diferenciação da função $x$ com relação à variável tempo $t$.

$$
\begin{gathered}
\frac{d x}{d t}=\omega X \cos (\omega t+\varphi)=\omega X \operatorname{sen}\left(\omega t+\varphi+\frac{\pi}{2}\right) \\
\frac{d^{2} x}{d t^{2}}=-\omega^{2} X \operatorname{sen}(\omega t+\varphi)=\omega^{2} X \operatorname{sen}(\omega t+\varphi+\pi)
\end{gathered}
$$

As duas equações anteriores mostram que tanto a velocidade como a aceleração são funções harmônicas e podem ser representadas por vetores de módulo $\omega X$ e $\omega^{2} X$, respectivamente, girando à mesma velocidade do vetor $X$, porém defasados pelos ângulos $\pi / 2$ e $\pi$, respectivamente.

A Figura 2-2 mostra as projeções verticais dos vetores e suas magnitudes em cada instante de tempo para $\omega>1$.
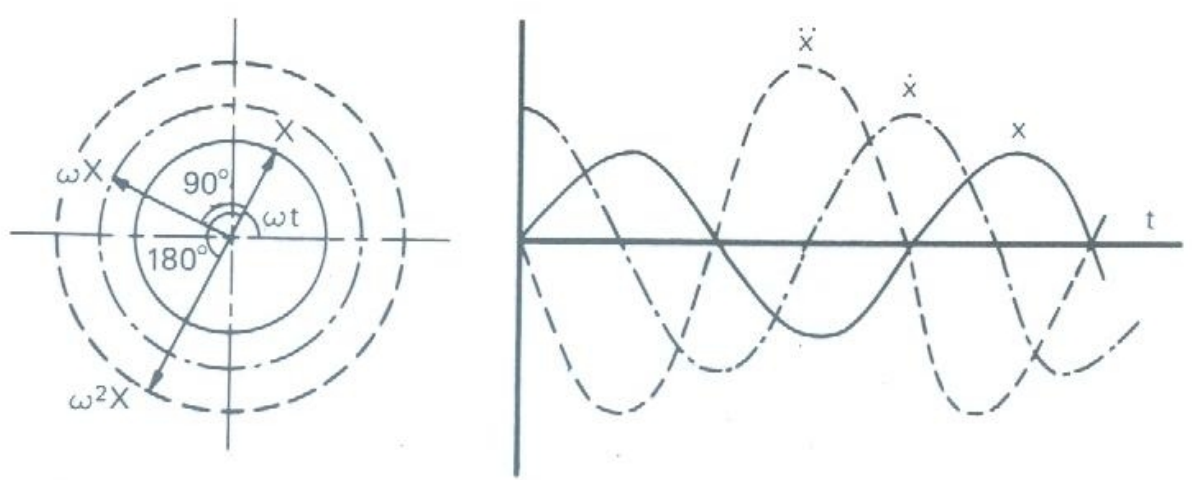

Figura 2-2 - Vetores Posição, Velocidade e Aceleração no plano fase e no sistema de eixos coordenados 


\section{2.}

\section{Modelo Massa-Mola-Amortecedor}

O modelo massa-mola-amortecedor é o sistema mais simples possível utilizado para descrever um problema de vibração, o qual consiste em uma mola e um amortecedor com uma de suas extremidades presa a um ponto fixo e a outra presa a uma massa que pode assumir configurações em torno de sua posição de equilíbrio em cada instante de tempo. Trata-se, pois, de um sistema com um grau de liberdade. Os conceitos fundamentais da Dinâmica das Estruturas apresentados neste item têm como referência o livro de Clough e Penzien (1975).

\subsection{1.}

\section{Vibração livre}

Esquematicamente, o modelo massa-mola-amortecedor pode ser representado pela Figura 2-3.

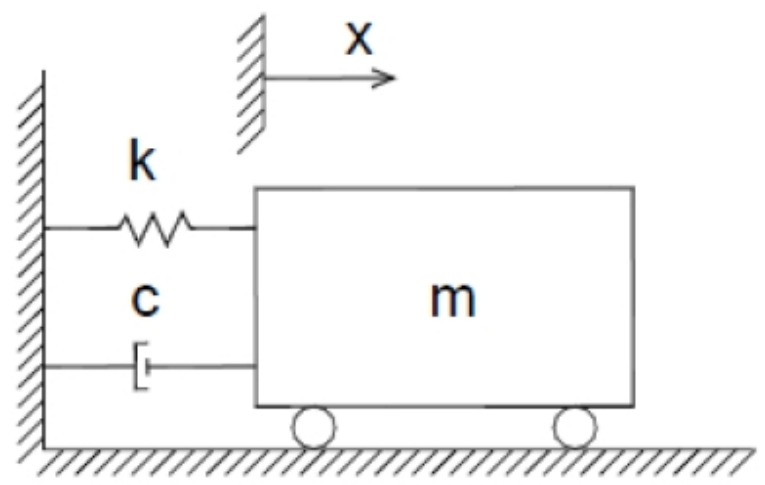

Figura 2-3 - Modelo simplificado Massa-Mola em diversas configurações

A Figura 2-3 mostra a configuração de equilíbrio do sistema em torno da qual a massa $m$ oscila e assume posições definidas pela coordenada $x$, que representa o seu grau de liberdade.

As propriedades físicas do modelo simplificado são basicamente a massa $m$, que consiste no elemento inercial do sistema, a constante de mola $k$, propriedade da mola que reflete sua capacidade de se deformar quando acionada por uma força, e o coeficiente amortecimento $C$.

O amortecimento é uma propriedade que representa a dissipação de energia do sistema, podendo ser de três tipos: de Coulomb, viscoso e por histerese. Por 
conveniência matemática e por apresentar boa representatividade para taxas de amortecimentos pequenas, é adotado no presente trabalho o amortecimento viscoso.

A massa $m$, ao ser conectada a uma mola de constante $k$ e a um amortecedor de coeficiente $C$, assume uma posição chamada posição de equilíbrio, tomada como a origem dos deslocamentos do sistema. Se a mesma massa é deslocada de $x$ para o lado em torno da posição de equilíbrio, então surgem duas forças de magnitude $k^{*} x$ e $C^{*} d x / d t$ tentando restaurar a posição original de equilíbrio. Considerando a hipótese de não haver resistência ao movimento, ou seja, amortecimento nulo, a massa continuaria a oscilar indefinidamente.

A equação do movimento pode ser obtida a partir da condição de resultante nula das forcas que agem sobre a massa. Nesse caso, tomou-se a posição de equilíbrio como a origem dos deslocamentos.

$$
\sum F=m \frac{d^{2} x}{d t^{2}}+C \frac{d x}{d t}+k x=0
$$

Onde $\Sigma F$ é o somatório de todas as forças na direção do movimento.

A solução da equação diferencial (2-6) apresenta a forma geral conforme apresentado a seguir.

$$
x(t)=G e^{s t}
$$

Onde os coeficientes $G$ e $s$ são obtidos a partir das condições iniciais do problema.

A substituição da equação (2-7) na equação (2-6) leva à equação algébrica (2-8) na variável $s$, a qual soluciona o problema.

$$
m s^{2}+C s+k=0
$$

\subsection{2.}

\section{Vibração livre não-amortecida}

$\mathrm{Na}$ hipótese de não existir dissipação de energia do sistema sob a forma de amortecimento viscoso, o coeficiente $C$ se torna nulo e, portanto, a equação assume a solução complexa conjugada (2-9).

$$
s= \pm \omega i
$$

Onde $\omega$ é dado pela equação (2-10). 


$$
\omega=\sqrt{k / m}
$$

Finalmente, a solução geral da equação de movimento não-amortecido pode ser dada pela equação (2-11).

$$
x(t)=G_{1} e^{i \omega t}+G_{2} e^{-i \omega t}
$$

Através da formulação de Euler, a equação (2-11) pode ser escrita através de funções trigonométricas.

$$
x(t)=\text { Asen } \omega t+B \cos \omega t
$$

As constantes $A$ e $B$ podem ser determinadas a partir das condições iniciais de deslocamento $\left(x_{0}\right)$ e velocidade $\left(d x_{0} / d t\right)$ no instante 0 , o que leva a solução completa do problema.

$$
x(t)=\frac{\partial x_{0} / \partial t}{\omega} \operatorname{sen} \omega t+x_{0} \cos \omega t
$$

\subsection{3.}

\section{Vibração livre amortecida}

A solução geral da equação algébrica (2-8) é dada pela equação abaixo, a qual inclui o termo referente ao amortecimento.

$$
s=-\frac{C}{2 m} \pm \sqrt{\left(\frac{C}{2 m}\right)^{2}-\frac{k}{m}}
$$

Dois parâmetros, amortecimento crítico $C_{c}$ e taxa de amortecimento $\xi$, são assim definidos.

$$
\begin{gathered}
C_{c}=2 \sqrt{k m}=2 m \omega=\frac{2 k}{\omega} \\
\xi=\frac{C}{C_{c}}
\end{gathered}
$$

Assim, a equação (2-14) assume a seguinte forma.

$$
s=-\xi \omega \pm \omega \sqrt{\xi^{2}-1}
$$


Quando o valor da taxa de amortecimento é maior que 1, o movimento é dito superamortecido. Quando a taxa de amortecimento é menor que 1, o movimento é dito subamortecido. Já quando a taxa de amortecimento é unitária, o movimento é dito criticamente amortecido.

As estruturas civis tipicamente possuem taxa de amortecimento inferior a 1 e, assim, desenvolvem movimento subamortecido. Nesse caso, a equação (2-9) se reduz a seguinte forma.

$$
s=-\xi \omega \pm i \omega_{d}
$$

Onde

$$
\omega_{d}=\omega \sqrt{1-\xi^{2}}
$$

Vê-se pela equação (2-19) que a freqüência angular $\omega_{d}$ difere minimamente da freqüência natural $\omega$ do sistema quando se trata de estruturas usuais.

A substituição do valor de $s$ na solução geral da equação diferencial de movimento (equação (2-7)) leva à solução do problema de vibração livre amortecida.

$$
x(t)=e^{-\xi \omega t}\left(G_{1} e^{\xi \omega d t}+G_{2} e^{-\xi \omega d t}\right)
$$

Após a transformação dos termos exponenciais em funções harmônicas, bem como a substituição das condições iniciais, a solução completa do problema de vibração livre amortecida pode ser dada pela equação (2-21).

$$
x(t)=e^{-\xi \omega t}\left(\frac{\partial x_{0} / \partial t+\xi x_{0} \omega}{\omega_{d}} \operatorname{sen} \omega_{d} t+x_{0} \cos \omega_{d} t\right)
$$

\subsection{4.}

\section{Vibração forçada}

As cargas dinâmicas de operação das máquinas podem ser representadas por excitações harmônicas, harmônicas com múltiplas freqüências, randômicas e também por pulsos.

De forma geral, as excitações mais comuns são aquelas descritas por funções harmônicas, tais como $F=F_{0} \operatorname{sen}\left(\omega_{m} t+\varphi\right)$ ou $F=F_{0} \cos \left(\omega_{m} t+\varphi\right)$, onde $\omega_{m}$ é a freqüência e $\varphi$ é o ângulo de fase da excitação. 


\subsubsection{1.}

\section{Sistema não-amortecido}

A equação (2-22) representa a equação diferencial de movimento não-amortecido para um sistema com 1 grau de liberdade submetido à vibração forçada.

$$
m \frac{d^{2} x}{d t^{2}}+k x=F_{0} \operatorname{sen}\left(\omega_{m} t\right)
$$

Onde $\omega_{m}$ é a freqüência de excitação da máquina.

Sendo $\beta$ definido por $\beta=\omega_{m} / \omega_{n}$, onde $\omega_{n}$ é a freqüência natural do sistema em vibração livre não-amortecido, e considerando as condições iniciais $x_{0}=0$ e $d x_{0} / d t=0$, a solução da equação de movimento é dada por (2-23).

$$
x(t)=\frac{F_{0}}{k\left(1-\beta^{2}\right)}\left(\operatorname{sen} \omega_{m} t-\beta \operatorname{sen} \omega_{n} t\right)
$$

A resposta dinâmica pode ser escrita de forma adimensional, dividindo-se a equação (2-23) por $x_{\text {est }}=F_{0} / k$, que fisicamente representa a amplitude máxima de deslocamento do sistema massa-mola. $R(t)$ é definido como fator dinâmico.

$$
R(t)=\frac{x(t)}{x_{e s t}}=\frac{1}{1-\beta^{2}}\left(\operatorname{sen} \omega_{m} t-\beta \operatorname{sen} \omega_{n} t\right)
$$

Define-se por Fator de Amplificação Dinâmica $D$ da resposta permanente de um sistema não-amortecido a seguinte relação:

$$
D=\frac{1}{1-\beta^{2}}
$$

\subsubsection{2.}

\section{Sistema amortecido}

A equação (2-26) representa a equação diferencial de movimento amortecido para um sistema com 1 grau de liberdade submetido à vibração forçada.

$$
m \frac{d^{2} x}{d t^{2}}+C \frac{d x}{d t}+k x=F_{0} \operatorname{sen}\left(\omega_{m} t\right)
$$


Os parâmetros envolvidos na equação anterior são os mesmos da equação (2-22), incluindo-se neste caso os termos relacionados ao amortecimento viscoso.

A solução da equação (2-26) é dada pela equação abaixo.

$$
\begin{aligned}
& x(t)=e^{-\xi \omega t}\left(\text { Asen } \omega_{d} t+B \cos \omega_{d} t\right)+ \\
& \frac{F_{0}}{k\left[\left(1-\beta^{2}\right)^{2}+(2 \xi \beta)^{2}\right]}\left[\left(1-\beta^{2}\right) \operatorname{sen} \omega_{m} t-2 \xi \beta \cos \omega_{n} t\right]
\end{aligned}
$$

Observa-se que a equação possui duas parcelas. A primeira se refere à resposta transiente amortecida, que tende a zero quando o tempo tende a infinito. A segunda se refere à resposta permanente, com freqüência numericamente idêntica à da excitação, mas apresentando defasagem.

Define-se por Fator de Amplificação Dinâmica $D$ da resposta permanente de um sistema amortecido a seguinte relação.

$$
D=\frac{1}{\sqrt{\left(1-\beta^{2}\right)^{2}+(2 \xi \beta)^{2}}}
$$

O gráfico $D \mathrm{x} \beta$ representa o espectro de respostas de um sistema de 1 grau de liberdade submetido a uma força harmônica de excitação. A figura mostra o fator de amplificação dinâmica $D$ em função de $\beta$ (relação entre freqüência de excitação e freqüência natural) para vários valores da taxa de amortecimento $\xi$.

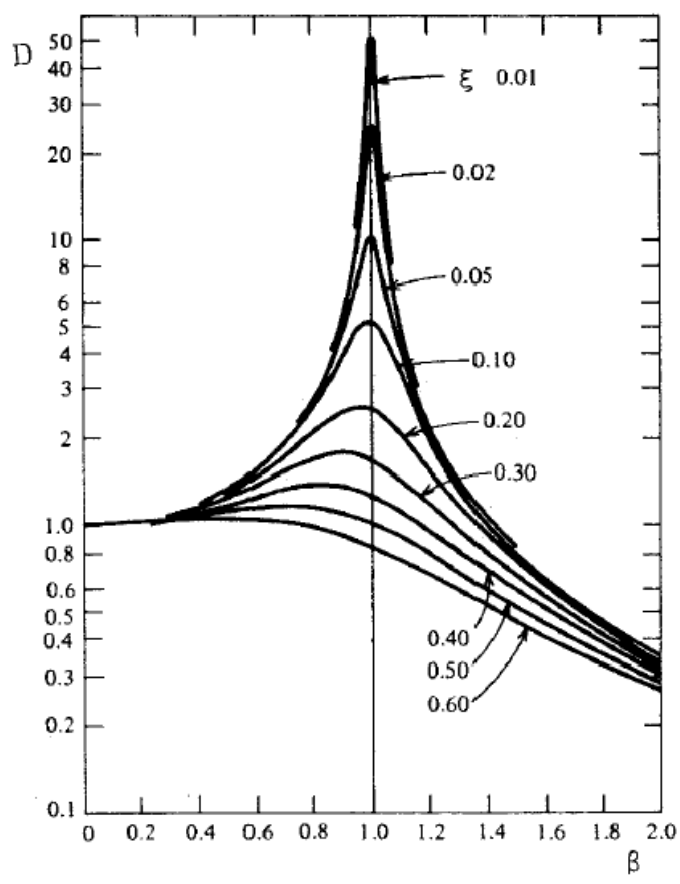

Figura 2-4 - Espectro de respostas de um sistema com 1 grau de liberdade 
Destaca-se o comportamento do fator de amplificação dinâmica quando a relação entre freqüências $\beta$ é igual à unidade, quando então o sistema atinge a condição de ressonância.

\subsubsection{3.}

\section{Isolamento de vibrações}

O movimento das partes móveis de um equipamento mecânico comumente provoca vibrações que são transmitidas às suas fundações. Em muitos casos, o efeito causado pelas vibrações é danoso tanto à estrutura de suporte como ao próprio equipamento. Nesse caso, faz-se necessário utilizar algum artifício que minimize tais efeitos danosos aos elementos do conjunto estrutura-equipamento. $\mathrm{O}$ processo pelo qual os efeitos da vibração são minimizados chama-se isolamento de vibrações.

Um isolador de vibrações é formado por uma associação de molas e amortecedores através dos quais as cargas são transmitidas aos elementos estruturais e de fundações. A força transmitida à fundação de uma máquina é dada pela equação (2-29).

$$
F_{1}(t)=k x+C \frac{d x}{d t}
$$

Substituindo na equação (2-29) a segunda parcela da equação (2-27), correspondente à resposta permanente do sistema, chega-se à expressão de $F_{t}$.

$$
F_{t}(t)=F_{0} D \operatorname{sen}\left(\omega_{m} t-\theta\right)+2 \xi \beta F_{0} D \cos \left(\omega_{m} t-\theta\right)
$$

A amplitude da força $F_{t}$ é dada pela equação (2-31) a seguir.

$$
F_{10}=F_{0} D \sqrt{1+(2 \xi \beta)^{2}}
$$

A medida do isolamento de vibrações $T R$ é dada pela razão entre a amplitude da força transmitida à fundação e a amplitude da força de excitação devida à máquina. Tal medida é denominada Transmissibilidade e é dada pela equação (2-32).

$$
T R=\frac{F_{t 0}}{F_{0}}=D \sqrt{1+(2 \xi \beta)^{2}}
$$

A relação entre $T R$ e $\beta$ pode ser vista graficamente através das curvas mostradas na figura abaixo, para vários valores da taxa de amortecimento $\xi$. 


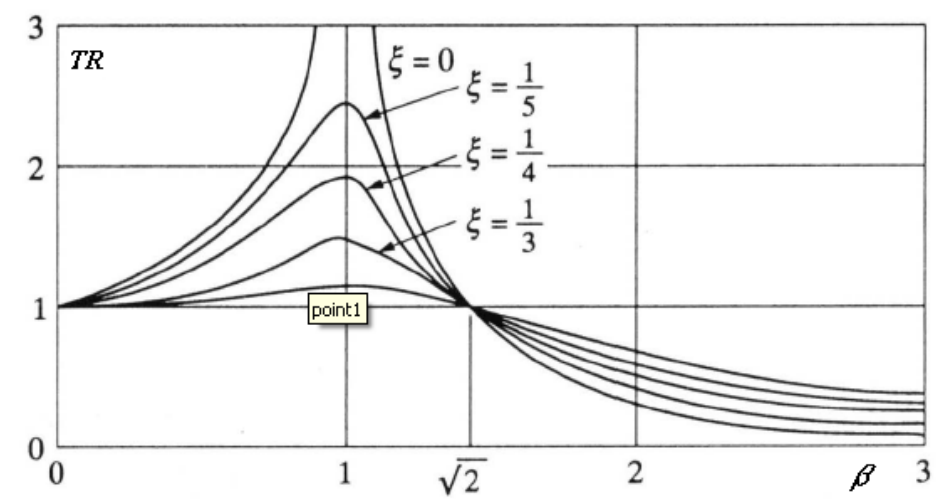

Figura 2-5 - Relação entre Transmissibilidade e $\beta$

\section{3.}

\section{Método da superposição modal}

O método da superposição modal tem como premissa representar a resposta dinâmica de sistemas lineares com vários graus de liberdade através da composição das contribuições de cada um dos modos de vibração individuais ao comportamento global desses sistemas. Cada modo de vibração constitui uma forma de deslocamento independente, com as amplitudes representando as coordenadas generalizadas. Os deslocamentos nodais $\vec{x}$ são dados pela equação (2-33).

$$
\vec{x}=\vec{\Phi} \vec{Y}
$$

Onde $\vec{\Phi}$ é o vetor dos modos normais e $\vec{Y}$ é vetor das coordenadas generalizadas.

A equação (2-41) representa a equação de movimento na forma matricial, escrita em termos das coordenadas generalizadas.

$$
[M] \vec{y}+[C] \vec{Y}+[K] \vec{Y}=\overrightarrow{F(t)}
$$

As matrizes $\boldsymbol{M}, \boldsymbol{C}$ e $\boldsymbol{K}$ são diagonais, de forma que o sistema resultante é composto por equações independentes. Para um dado modo de vibração $i$, tem-se uma equação diferencial da seguinte forma.

$$
\ddot{Y}_{i}+2 \xi_{i} \omega_{i} \dot{Y}_{i}+\omega_{i}{ }^{2} Y_{i}=\frac{F_{i}}{M_{i}}
$$


Onde $\xi_{i}$ é a taxa de amortecimento, $\omega_{i}$ é a freqüência natural, $F_{i}$ é a força generalizada e $M_{i}$ é a massa generalizada. Todas essas grandezas estão associadas ao modo de vibração $i$.

A resposta dinâmica do sistema é obtida com a solução de cada uma das equações nas coordenadas generalizadas, seguida da superposição desses resultados.

No caso de vibração forçada cuja excitação é uma função harmônica, a equação (2-34) se torna:

$$
\left[M \overrightarrow{\vec{Y}}+[C] \overrightarrow{\dot{Y}}+[K] \vec{Y}=\overrightarrow{\Phi^{T}} \vec{F}_{0} \operatorname{sen}\left(\omega_{m} t\right)\right.
$$

Analogamente à equação (2-27), a resposta permanente pode ser então escrita conforme equação (2-37).

$$
Y_{i}(t)=\frac{F_{0 i}}{k_{i}\left[\left(1-\beta_{i}^{2}\right)^{2}+\left(2 \xi_{i} \beta_{i}\right)^{2}\right]}\left[\left(1-\beta_{i}^{2}\right) \operatorname{sen} \omega_{m} t-2 \xi_{i} \beta_{i} \cos \omega_{n} t\right]
$$

A resposta nas coordenadas originais é finalmente obtida a partir da superposição das respostas correspondentes a cada coordenada generalizada.

$$
x(t)=\sum_{i=1}^{s} \phi_{i} Y_{i}(t)=\sum_{i=1}^{s}\left(\vec{A}_{i} \operatorname{sen} \omega_{m} t+\vec{B}_{i} \cos \omega_{n} t\right)=\vec{A} \operatorname{sen} \omega_{m} t+\vec{B} \cos \omega_{n} t
$$

Onde

$$
\begin{aligned}
& \vec{A}=\sum_{i=1}^{s} \phi_{i} \frac{F_{0 i}}{k_{i}} \frac{1-\beta_{i}^{2}}{\left(\left(1-\beta_{i}^{2}\right)^{2}+\left(2 \xi_{i} \beta_{i}\right)^{2}\right)} \\
& \vec{B}=\sum_{i=1}^{s} \phi_{i} \frac{F_{0 i}}{k_{i}} \frac{\left(-2 \xi_{i} \beta_{i}\right)}{\left(\left(1-\beta_{i}^{2}\right)^{2}+\left(2 \xi_{i} \beta_{i}\right)^{2}\right)}
\end{aligned}
$$

Além do método da superposição modal, a análise dinâmica de um sistema com $n$ graus de liberdade pode ser realizada no domínio do tempo, através de métodos de integração direta da equação do movimento e, no domínio da freqüência, pelo uso de séries de Fourier representando o carregamento. Nesse último caso, determina-se a amplificação do sistema para cada uma das freqüências da série e utiliza-se a transformação inversa para escrever a resposta ao longo do tempo. 


\section{4 .}

\section{Interação entre máquinas e estruturas}

O desempenho, a segurança e a estabilidade das máquinas, além de seu dimensionamento, dependem também da sua interação com o ambiente com o qual está em contato. Assim, as estruturas, as fundações e o solo têm papel importante em seu comportamento e, portanto, devem ser considerados partes integrantes do projeto global de qualquer equipamento dinâmico.

É fato que o custo associado à estrutura e às fundações de máquinas é fração do custo do equipamento, contudo é fato também que o dimensionamento inadequado dos elementos estruturais do sistema de suporte desses mesmos equipamentos pode levar ao mau funcionamento e falhas cujos prejuízos excedem significantemente os custos necessários a um correto projeto de engenharia civil.

\subsection{1.}

\section{Procedimento do projeto de fundações de máquinas}

De forma geral, um problema de fundações de máquinas corresponde a uma máquina suportada por uma estrutura, e esta por sua vez apoiada em solo, e todos os elementos submetidos direta ou indiretamente a carregamentos dinâmicos.

A Figura 2-6 mostra um típico fluxo de análise de um sistema de fundações de máquinas e exemplifica a interação entre cada um de seus componentes.

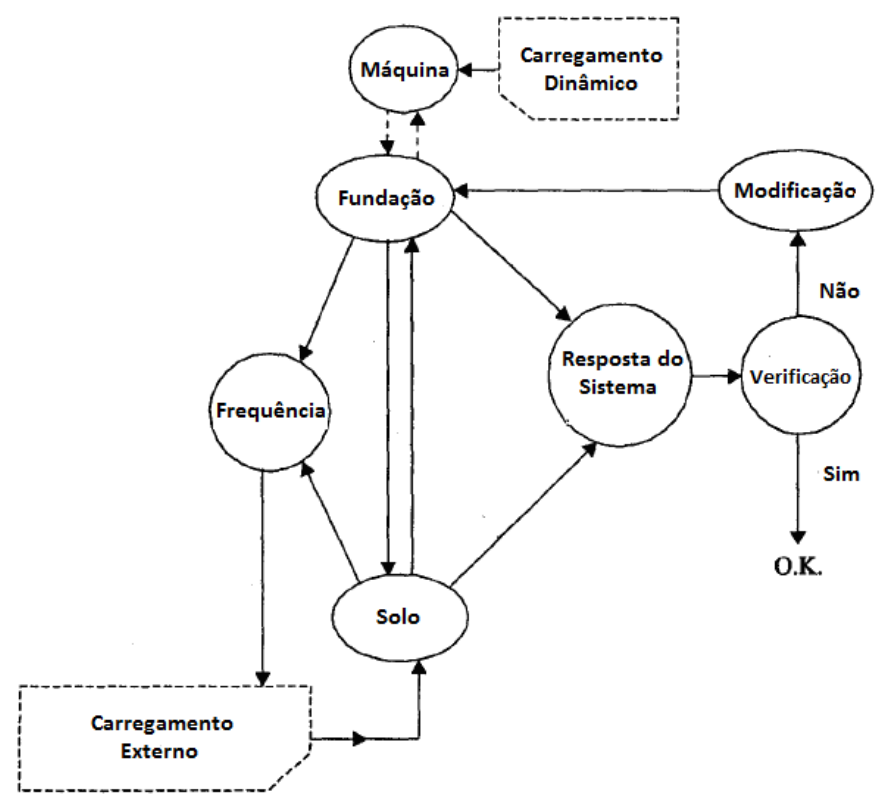

Figura 2-6 - Fluxograma de análise de problemas de fundações de máquinas 
Considerando o fluxograma apresentado, duas premissas básicas se apresentam quando se trata de qualquer projeto de fundações de máquinas.

A primeira diz que as cargas dinâmicas devidas às máquinas são transmitidas pela superestrutura e fundações ao solo de tal forma que efeitos danosos sejam eliminados e que as amplitudes de vibração das máquinas e dos elementos estruturais permaneçam dentro de limites pré-estabelecidos.

A segunda premissa diz que a superestrutura e sua fundação devem ser seguras suficientes para suportar as cargas estáticas e dinâmicas geradas pela máquina.

De forma a satisfazer essas duas premissas, o projeto de fundações de máquinas requer uma avaliação apropriada das propriedades e parâmetros de vibração do sistema estrutural que garanta com um grau de confiança aceitável a não ocorrência de condição de ressonância durante a operação do equipamento (ARYA ET AL, 1979).

\subsection{2.}

\section{Componentes de um problema de fundações de máquinas}

Um problema típico de fundações de máquinas envolve três componentes fundamentais, quais sejam a máquina, a superestrutura e sua fundação, e o solo.

\subsubsection{1. Máquina}

As máquinas, de acordo com o tipo de movimento de suas partes móveis, podem ser classificadas como rotativas, alternativas ou de impacto.

As máquinas rotativas são formadas basicamente por um rotor cujas partes móveis giram em torno de um eixo comum. As máquinas alternativas são formadas por um ou mais pistões cujos movimentos lineares são devidos ao movimento circular de uma manivela a eles conectada. Finalmente, as máquinas de impacto são formadas basicamente por uma massa em queda livre de uma altura fixa sobre uma base, criando cargas de pequena duração no conjunto.

As máquinas também são classificadas de acordo com sua velocidade angular de operação em:

- Máquinas de muito baixa velocidade (até $100 \mathrm{rpm}$ );

- Máquinas de baixa velocidade (de 100 a $1500 \mathrm{rpm}$ );

- Máquinas de média velocidade (de 1500 a 3000 rpm);

- Máquinas de alta velocidade (acima de $3000 \mathrm{rpm}$ ). 


\subsubsection{2.}

\section{Superestrutura e fundação}

Basicamente dois tipos de estruturas são utilizados em plantas industriais, quais sejam bloco maciço de concreto armado e estruturas aporticadas.

Os blocos normalmente são apoiados diretamente no solo. Nesse caso, a máquina e o bloco são tratados como corpos rígidos e o solo como elemento sem massa, tendo apenas rigidez. Um típico sistema estrutural formado por bloco de concreto armado está apresentado na Figura 2-7.

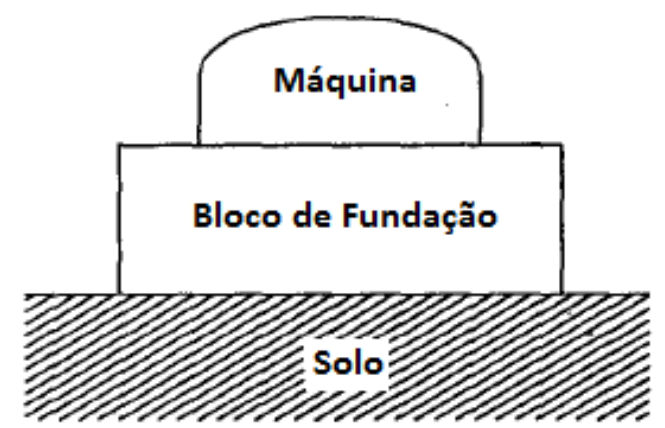

\section{Figura 2-7 - Fundação em bloco de concreto apoiado diretamente em solo}

As estruturas aporticadas são formadas por uma base sobre a qual são instalados os equipamentos e pilares de grande seção transversal. As fundações podem ser diretamente apoiadas sobre o solo (radier) ou sobre estacas. Nesse caso, a máquina é tratada como um corpo rígido, os pilares como um elemento elástico e o solo como elemento elástico sem massa. A Figura 2-8 mostra esquematicamente um sistema aporticado para suporte dos equipamentos.
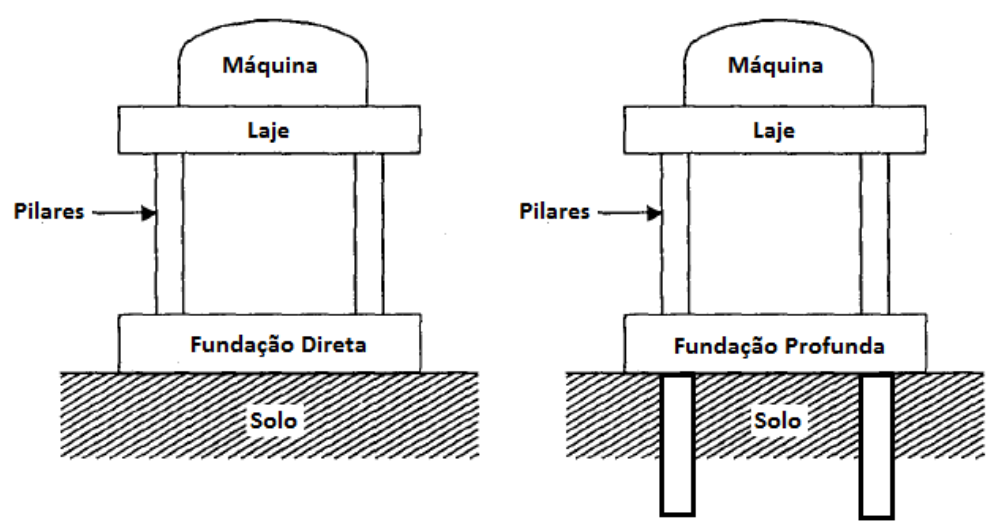

Figura 2-8 - Exemplos de sistema estrutural aporticado de suporte de equipamentos 


\subsubsection{3.}

Solo

O solo corresponde ao último componente do sistema. Diferentemente dos outros componentes, principalmente devido a sua composição, o solo traz consigo incertezas referentes às suas propriedades dinâmicas. Essas propriedades podem variar muito de local para local e, considerando carregamentos dinâmicos, influencia significantemente a resposta dinâmica do sistema como um todo.

Os principais parâmetros que representam o solo são: Módulo de elaticidade longitudinal, módulo de elasticidade transversal, coeficiente de Poisson, massa específica, amortecimento, coeficiente de compressão uniforme, coeficiente de compressão não-uniforme, coeficiente de cisalhamento uniforme e coeficiente de cisalhamento não-uniforme (BHATIA, 2008).

Os principais aspectos relacionados ao solo que influenciam a sua interação com a estrutura são: mecanismos de transferência de energia, participação da sua massa na vibração das fundações, aplicabilidade da lei de Hook, redução da tensão admissível e parâmetros dinâmicos do solo (BHATIA, 2008).

\section{5. Sistema dinâmico Estrutura-Solo-Equipamento}

Um problema que consiste na interação dinâmica entre um compressor alternativo, sua estrutura de suporte em concreto armado e o solo de fundação são tratados nesta seção. Como será demonstrado, o movimento dos pistões no interior dos cilíndros do compressor gera a ação de forças e momentos transientes sobre a estrutura e, conseqüentemente, sobre suas fundações.

\subsection{1.}

\section{Carregamento dinâmico devido a compressor alternativo}

Tipicamente, o mecanismo oscilante básico mostrado na Figura 2-9 consiste de um pistão movendo-se dentro de um cilindro guia, uma barra de conexão de comprimento conhecido fixada em suas extremidades ao pistão e ao elemento giratório (manivela ou virabrequim), o qual rotaciona em torno do seu eixo (eixo da manivela) com freqüência angular $\omega$. O movimento do pistão pode ser horizontal ou vertical dependendo do projeto do equipamento. 


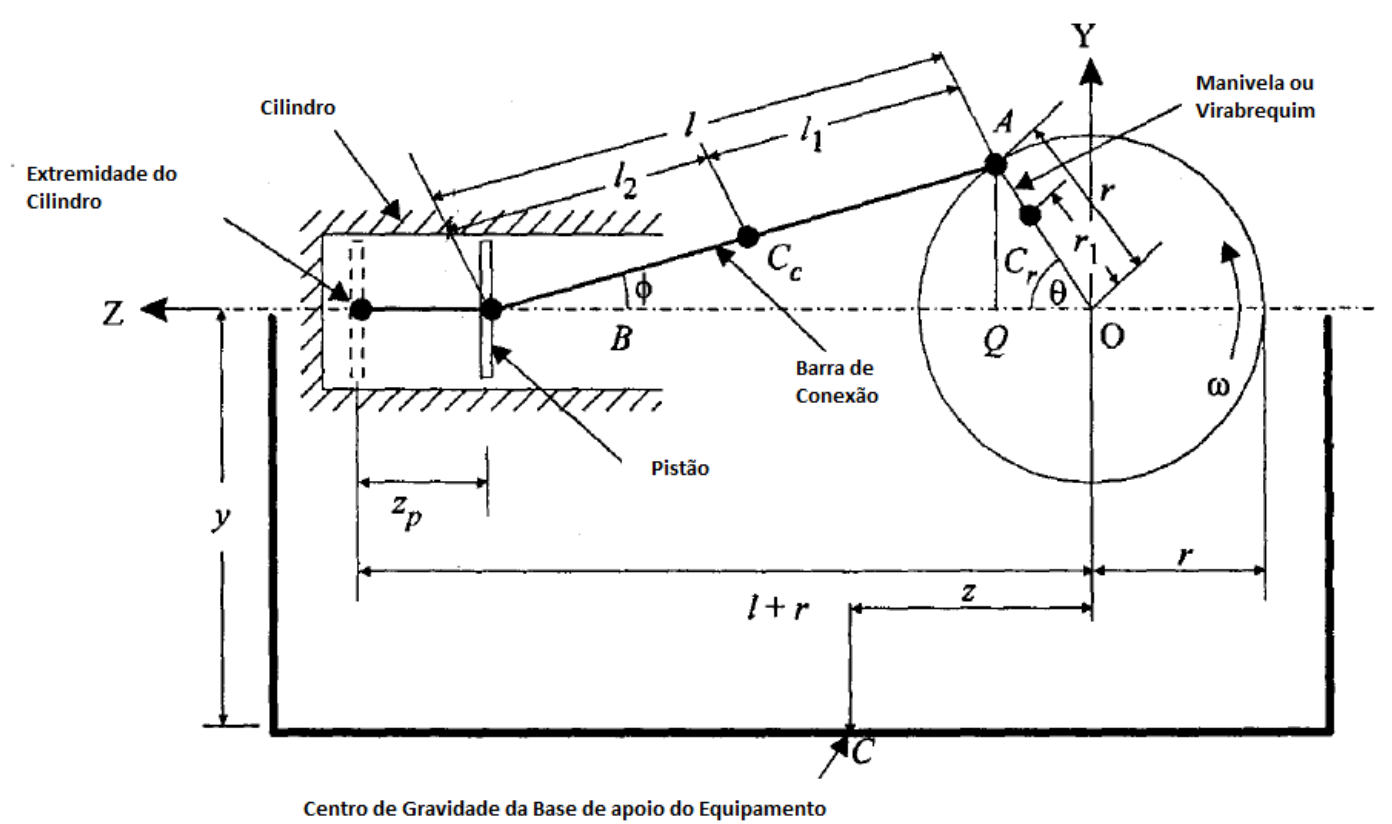

Figura 2-9 - Arranjo típico de um compressor alternativo de um cilindro

(BHATIA, 2008)

Os elementos constituintes do sistema mecânico do compressor alternativo mostrado na Figura 2-9 estão descritos na Tabela 2-1.

Tabela 2-1 - Legenda dos elementos constituintes do sistema mecânico de um compressor alternativo

\begin{tabular}{|l|c|}
\hline Massa da manivela & $m_{r}$ \\
\hline Comprimento da manivela & $r$ \\
\hline Centro de gravidade da manivela & $C_{r}$ \\
\hline Centro de gravidade da barra de conexão & $C_{c}$ \\
\hline Eixo de rotação & 0 \\
\hline Distancia entre $\mathrm{C}_{\mathrm{r}}$ e O & $r_{1}$ \\
\hline Velocidade de rotação & $\omega$ \\
\hline Ponto de conexão à manivela & $A$ \\
\hline Ponto de conexão ao pistão & $B$ \\
\hline Massa da barra de conexão & $m_{c}$ \\
\hline Comprimento da barra de conexão & $I_{1}$ \\
\hline Distância entre $\mathrm{C}_{\mathrm{c}}$ e ponto A & $I_{1}$ \\
\hline Distância entre $\mathrm{C}_{\mathrm{c}}$ e ponto B & $I_{2}$ \\
\hline Massa do pistão & $m_{p}$ \\
\hline
\end{tabular}

As forças que surgem devido ao movimento dos componentes do compressor estão indicadas em sistema de coordenadas Y-Z conforme Figura 2-10. 


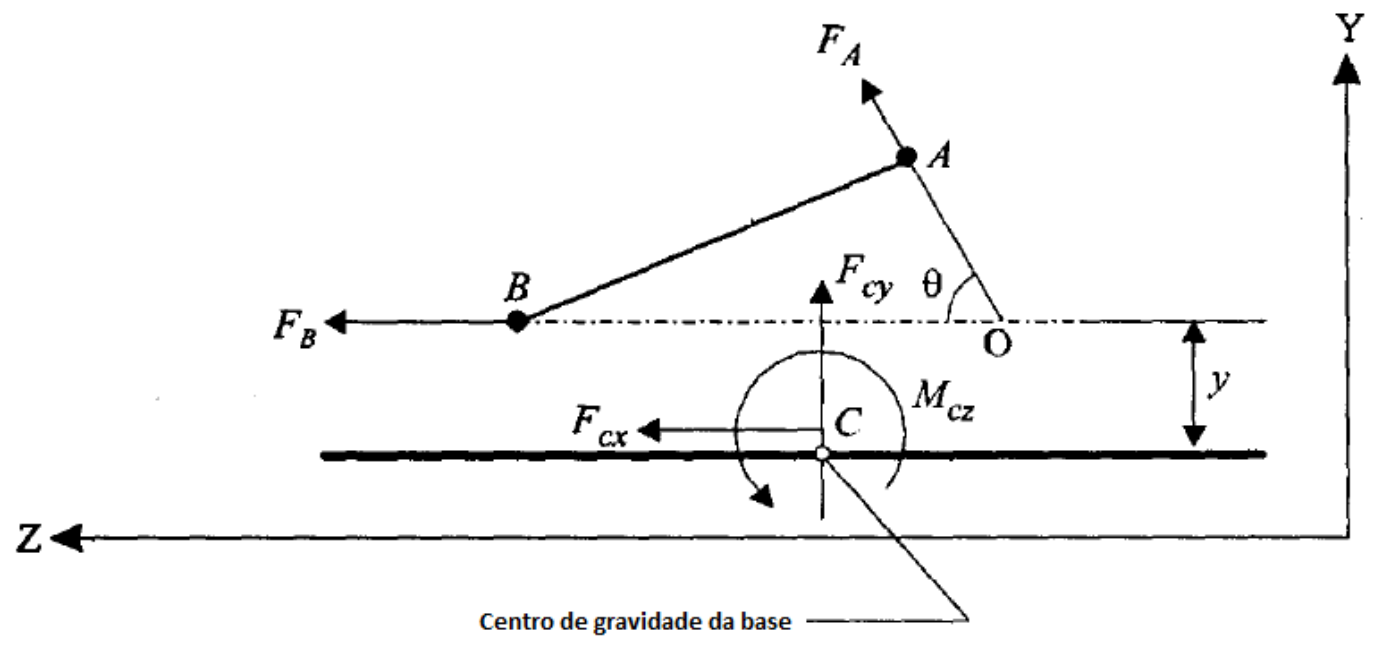

Figura 2-10 - Forças dinâmicas no sistema mecânico em um dado instante de tempo

De acordo com a Figura 2-9, em um dado instante de tempo $t$, a extremidade do pistão assume a posição $z_{p}$, a barra de conexão faz um ângulo $\varphi$ com o eixo O-Z e a barra da manivela faz um ângulo $\theta$ com o mesmo eixo.

Considera-se que a massa da barra de conexão está proporcionalmente dividida entre os pontos A e B, e a massa da manivela está dividida proporcionalmente entre os pontos A e O conforme equações (2-40) e (2-41), respectivamente.

$$
\begin{gathered}
m_{A}=m_{r}\left(\frac{r_{1}}{r}\right)+m_{c}\left(\frac{l_{2}}{l}\right) \\
m_{B}=m_{r}\left(\frac{l_{1}}{l}\right)+m_{p}
\end{gathered}
$$

As forças dinâmicas geradas nos pontos A e B podem ser escritas conforme equações abaixo.

$$
\begin{aligned}
& F_{A}=m_{A} r \omega^{2} \\
& F_{B}=m_{B} \ddot{z}_{p}
\end{aligned}
$$

A posição do pistão $z_{p}$ pode ser deduzida geometricamente a partir da Figura 2-9.

$$
z_{p}=l+r-(r \cos \theta+l \cos \varphi)=r(1-\cos \theta)+l(1-\cos \varphi)
$$


Ainda da Figura 2-9, pode-se deduzir que:

$$
A Q=r \operatorname{sen} \theta=l \operatorname{sen} \varphi
$$

Desenvolvendo a equação (2-45), chega-se a expressão a seguir.

$$
\cos \varphi=\left(1-\frac{r^{2}}{l^{2}} \operatorname{sen}^{2} \theta\right)^{1 / 2}
$$

A partir da expansão da equação (2-46) em serie, ignorando-se os termos de maior ordem, chega-se aos seguintes resultados.

$$
\begin{gathered}
\cos \varphi=1-\frac{1}{2} \frac{r^{2}}{l^{2}} \operatorname{sen}^{2} \theta \text { ou } \\
1-\cos \varphi=\frac{1}{2} \frac{r^{2}}{l^{2}} \operatorname{sen}^{2} \theta=\frac{1}{2} \frac{r^{2}}{l^{2}} \frac{1-\cos 2 \theta}{2}=\frac{1}{4} \frac{r^{2}}{l^{2}}(1-\cos 2 \theta)
\end{gathered}
$$

A substituição da equação (2-47) na equação (2-44), considerando o ângulo $\theta$ variável no tempo como sendo $\theta=\omega t$, chega-se a expressão da posição do pistão em cada instante segundo o sistema de coordenadas utilizado.

$$
z_{p}=r\left(1+\frac{r}{4 l}\right)-r\left(\cos \omega t+\frac{r}{4 l} \cos 2 \omega t\right)
$$

A velocidade e a aceleração do ponto correspondente ao pistão podem ser diretamente obtidas por diferenciação da equação acima.

$$
\begin{aligned}
& \ddot{z}_{p}=r \omega\left(\operatorname{sen} \omega t+\frac{r}{2 l} \operatorname{sen} 2 \omega t\right) \\
& \ddot{z}_{p}=r \omega^{2}\left(\cos \omega t+\frac{r}{l} \cos 2 \omega t\right)
\end{aligned}
$$

Ao substituir a equação (2-50) na equação (2-43), chega-se à expressão da força gerada no ponto B (pistão).

$$
F_{B}=m_{B} r \omega^{2}(\cos \omega t)+m_{B} r \omega^{2}\left(\frac{r}{l} \cos 2 \omega t\right)
$$


Da equação anterior, vê-se que a força gerada pelo pistão possui duas componentes, uma primária com velocidade angular idêntica à do compressor, e outra secundária com velocidade angular duas vezes maior que aquela do compressor.

A dedução das expressões de força em sistemas mecânicos de compressores alternativos de múltiplos cilindros pode ser feita de forma análoga.

\section{6. \\ Interação solo-estrutura}

O entendimento completo de um problema de carregamento dinâmico sobre uma estrutura e sua fundação devido a um equipamento mecânico ou mesmo devido a sismos somente pode ser alcançado quando o sistema como um todo é analisado em conjunto.

Ao ignorar o efeito do solo, por exemplo, tratando-o como indeformável, a resposta da estrutura pode variar de forma significativa.

Baseado em um numero de analises executadas, pode ser verificado que o tratamento da estrutura de forma isolada de sua fundação pode resultar tanto em um dimensionamento conservativo como em um dimensionamento perigosamente ousado (CHOWDHURY E DASGUPTA, 2009).

A consideração do solo como um meio elástico deformável provoca o acoplamento de sua rigidez com a rigidez da estrutura, alterando o comportamento global do conjunto. Além disso, se as fundações de uma estrutura são apoiadas diretamente no solo, se elas são apoiadas em estacas, se elas estão embutidas no solo, se as camadas de solo são estratificadas, todos esses aspectos, entre outros, são capazes de influenciar o comportamento geral de um sistema.

Assim, tendo em mente a importância do conhecimento da interação entre os componentes de um sistema físico, esforço em pesquisa tem sido aplicado de modo a estudar a interação dinâmica entre solo e estrutura sob um mesmo domínio.

Uma primeira questão que surge diz respeito sobre qual o efeito do período (ou freqüência) na resposta do sistema tratado como um conjunto comparativamente ao caso em que o solo é ignorado (caso da base fixa).

Nesse contexto, duas classes de problemas típicos de interação dinâmica soloestrutura se apresentam: sistemas sujeitos a sismos e sistemas sujeitos a vibração de máquinas.

É fato que o solo afeta essas duas classes de problemas de maneiras diferentes. Para máquinas suportadas por estruturas aporticadas, por exemplo, os elementos 
estruturais são projetados rígidos o suficiente de modo a não gerar tensões induzidas significativas (estrutura sobre-sintonizadas). Contudo, a estrutura pode atuar de forma sub-sintonizada ou até mesmo próxima da zona de ressonância quando o solo é considerado no problema.

Para o caso de sismos, os efeitos são diferentes. Por exemplo, uma estrutura apoiada no solo pode ser representada por um corpo imerso em um espaço elástico infinito e que, quando da ocorrência de dissipação de energia por ondas através do solo, sua massa começa a vibrar em uma dada freqüência (de campo livre). Portanto, se as freqüências naturais da estrutura se aproximam da freqüência fundamental do solo de fundação, esses componentes do sistema solo-estrutura estarão em ressonância e sujeitos a efeitos catastróficos (CHOWDHURY E DASGUPTA, 2009).

A influência do solo no comportamento dinâmico de um sistema está diretamente associada à sua rigidez e as duas propriedades fundamentais do solo das quais depende a rigidez são o módulo de elasticidade ao cisalhamento $(G)$ e o coeficiente de Poisson $(v)$. O conhecimento dessas propriedades é de grande importância na analise da interação entre o solo e os demais componentes do sistema, pois seus valores são inerentemente dependentes de muitas variáveis e de empirismo, e não raros de difícil determinação. 


\section{3 \\ Modelo físico}

Nesse capítulo são apresentadas todas as características físicas do problema de interação estrutura-solo-equipamento estudado, quais sejam geometria e material do sistema estrutura-fundação, propriedades físicas do solo e dados operacionais dos equipamentos mecânicos. São apresentados também os resultados do ensaio de carregamento horizontal realizado em campo em estacas-teste, os valores da propriedade física (coeficiente de mola) do solo obtidos com base em retroanálises dos resultados do ensaio de carregamento horizontal, além dos resultados das medições de campo (instrumentação) de velocidade de vibração em pontos específicos da estrutura.

\section{1. \\ Descrição da estrutura}

O suporte do sistema formado pelo compressor, motor elétrico, grelha metálica de fixação do compressor à base (chamada de skid) e as tubulações acopladas corresponde a uma estrutura de concreto armado aporticada, com fundações em estacas e blocos de coroamento contraventados por cintamento.

É estudada uma estrutura suportando um compressor alternativo assim denominado C-2632, bem como seus equipamentos acessórios.

As características geométricas gerais da estrutura analisada constam do projeto estrutural e estão representadas da Figura 3-1 a Figura 3-4.

Toda geometria do sistema estrutural foi estabelecida a partir de informações do arranjo básico da unidade industrial e das informações do fabricante dos equipamentos.

Requisitos de arranjo básico de engenharia de processo e de tubulação implicaram na instalação do compressor em plataforma elevada a 4,50 m acima do nível do piso. 


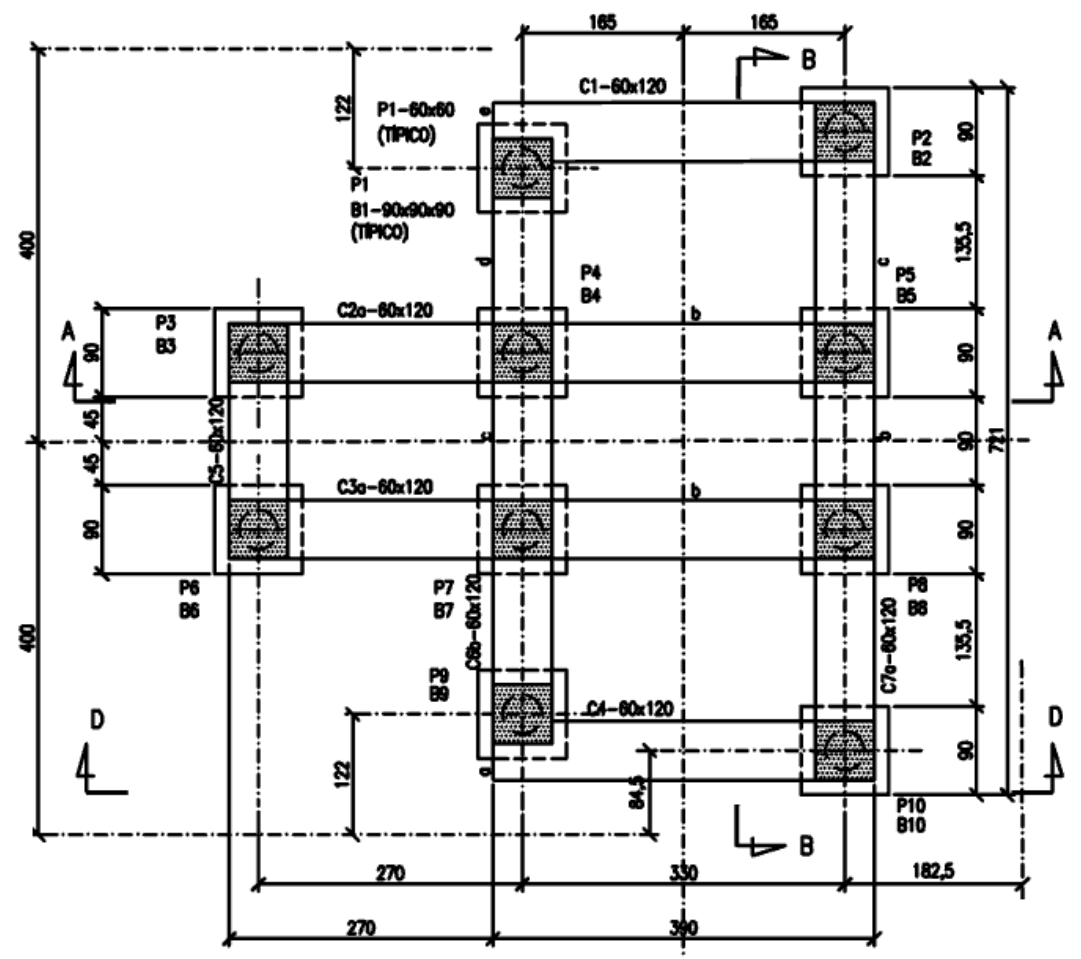

Figura 3-1 - Planta no nível das fundações (elevação 99.8m)

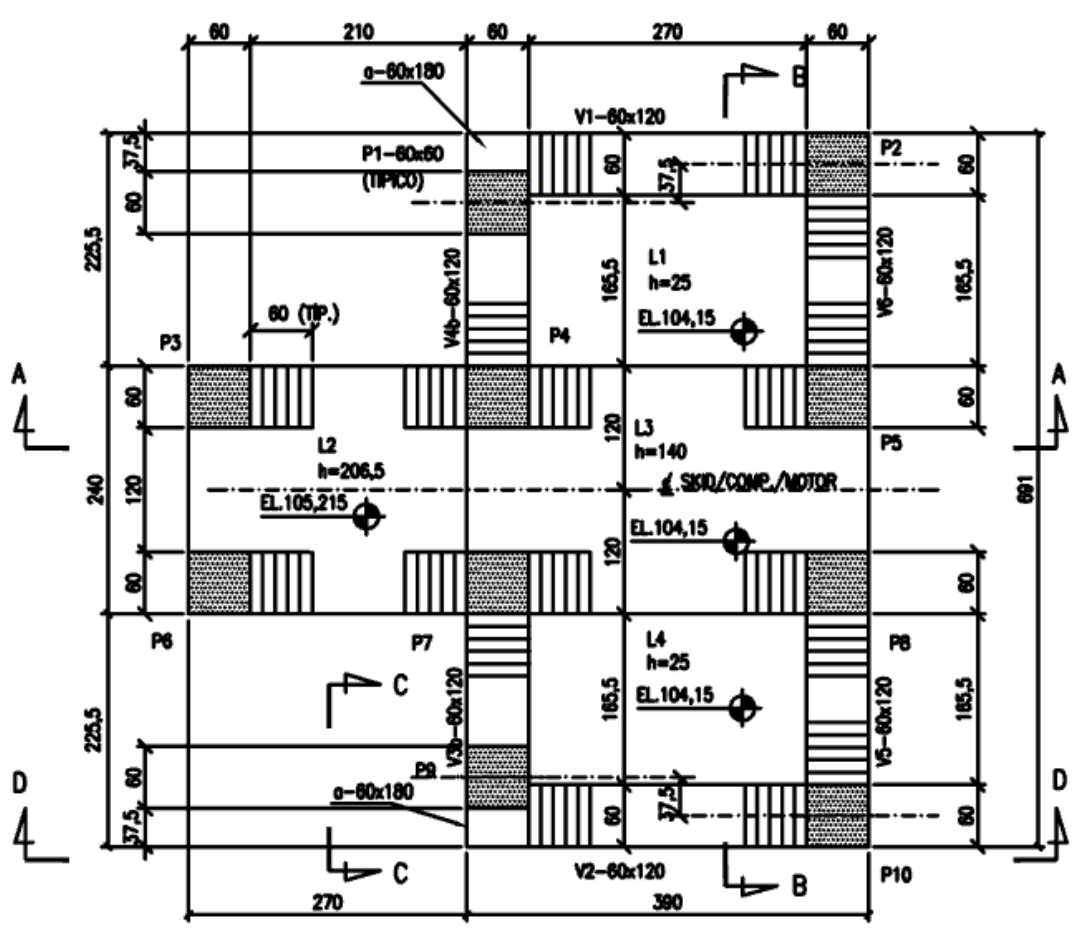

Figura 3-2 - Planta na elevação 105.215m (Motor Elétrico) e 104.15m (Compressor) 


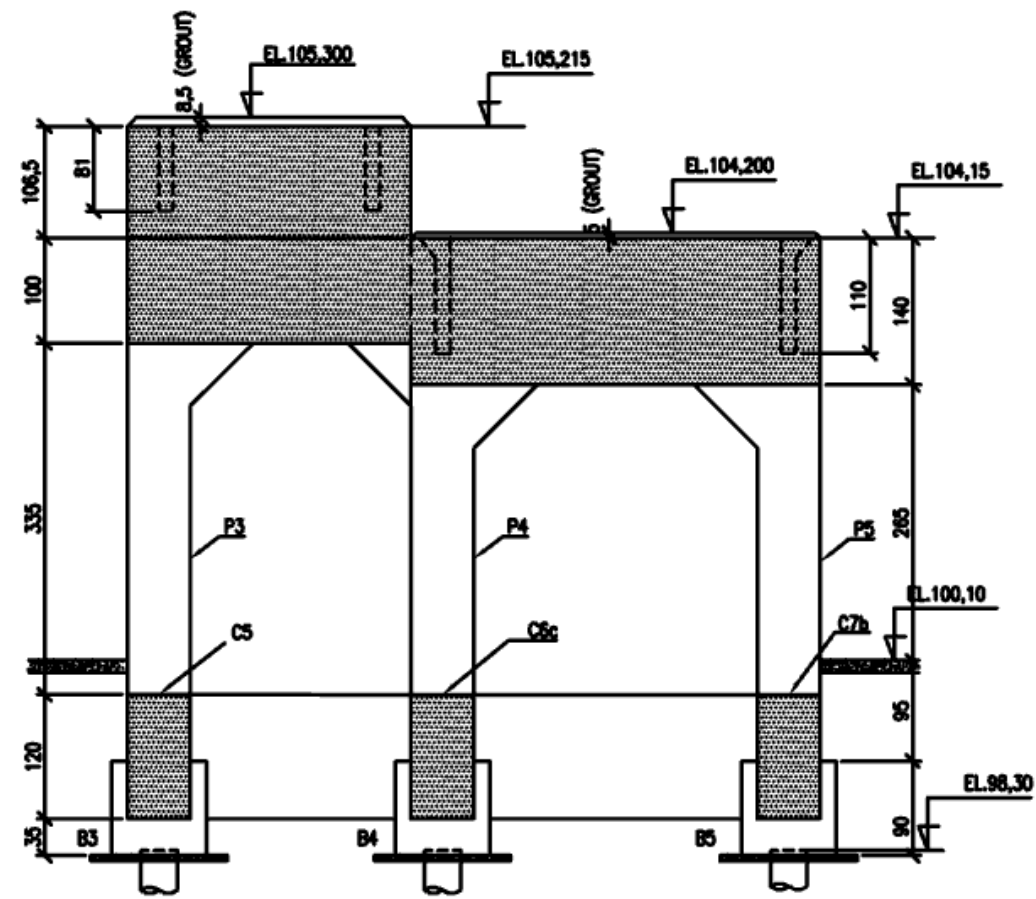

Figura 3-3 - Corte A-A

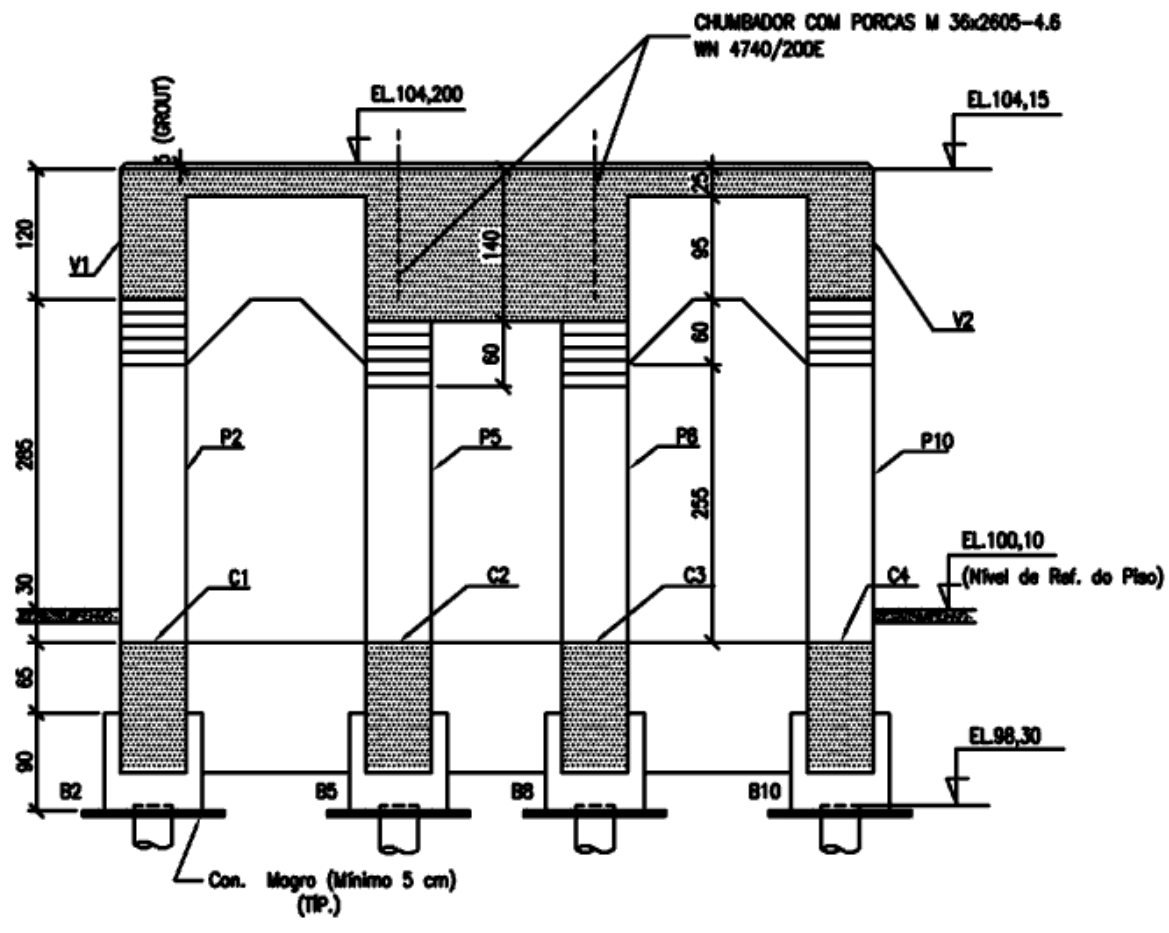

Figura 3-4 - Corte B-B

A Figura 3-5 mostra a estrutura real estudada, destacando-se o caráter massivo dos pilares e da laje de apoio dos equipamentos. 

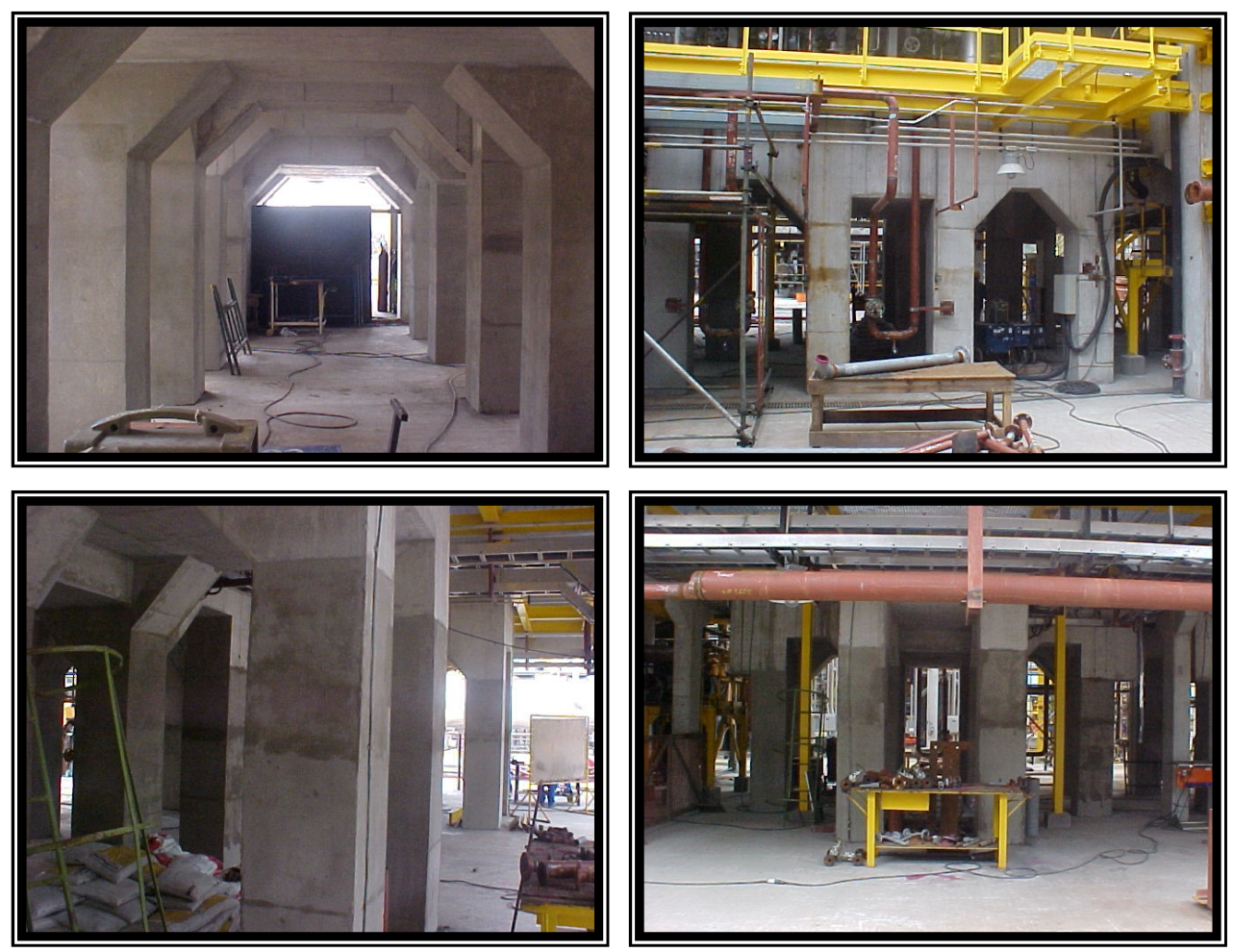

Figura 3-5 - Fotos da estrutura de concreto armado real (modelo físico)

A construção da estrutura e sua fundação, bem como a montagem dos equipamentos sobre a mesma ocorreram sem quaisquer anormalidades ou nãoconformidades, de acordo com as informações e registros do Consórcio construtor.

Entretanto, ao se iniciarem os testes para comissionamento e início da operação dos equipamentos, observaram-se vibrações aparentemente excessivas nas estruturas de suporte. Foram constatadas ainda induções de vibrações nas estruturas próximas (estruturas de suporte de outros compressores e do próprio prédio de abrigo dos equipamentos).

Foram, então, realizadas instrumentação e medições de velocidade de vibração em vários pontos da estrutura, resultando na confirmação de que o seu comportamento não se adequava aos requisitos e limitações requeridos pelo fabricante dos equipamentos.

Os resultados das medições de velocidade de vibração estão reproduzidos no item 3.4 .

\section{2 .}

Descrição do equipamento

Em plantas industriais de refino de petróleo, como ocorre na Unidade de Hidrossulfurização, compressores de gás são elementos obrigatórios. Muitas das vezes, por exigências de engenharia de processo químico, flexibilidade de tubulações e de 
geometria, a instalação de equipamentos não pode ser feita diretamente no piso da unidade, o que no caso de compressores de grande porte cria certa preocupação em relação a vibrações excessivas.

$\mathrm{O}$ conjunto de equipamentos que forma o sistema mecânico suportado pela estrutura em estudo é composto basicamente por compressor de gás, motor elétrico e acessórios em geral.

Apesar da existência de tubulações acopladas ao compressor de gás, sua contribuição física como elemento de inércia e de rigidez foi desprezada uma vez que sua massa em relação ao conjunto é muito pequena e a interface na qual há o acoplamento tubulação-compressor é flexível.

\subsection{1.}

\section{Compressor de gás}

Os produtos do petróleo refinado contêm inicialmente certa quantidade de enxofre que necessita ser removida para atendimento das especificações de uso como produto acabado. Esse processo de retirada de substâncias indesejadas é realizado basicamente em Unidades de Hidrodessulfurização de refinarias e conta com os compressores como agentes físicos fornecedores de energia ao processo químico.

Tipicamente, os compressores misturam hidrogênio com um dado hidrocarboneto (gás liquido, petróleo, diesel), pressurizando-o e o conduzindo até os reatores preenchidos com produtos catalizadores.

No presente estudo, o compressor analisado é do tipo alternativo de cilindros horizontais, fabricado pela empresa alemã Neuman \& Esser, operando à freqüência de $590 \mathrm{rpm}$. As imagens seguintes mostram alguns de seus componentes.

A Figura 3-6 mostra o acoplamento entre o eixo da manivela do compressor e o eixo do motor elétrico. A Figura 3-7 mostra o chassi do compressor. A Figura 3-8 destaca os cilindros de compressão de gás e as tubulações. Finalmente, a Figura 3-9 fornece uma visão geral do conjunto de equipamentos do sistema mecânico no nível da laje de suporte. 


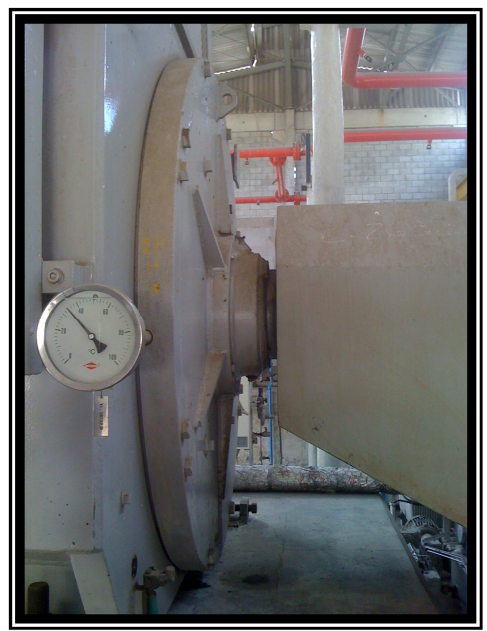

Figura 3-6 - Acoplamento entre compressor e motor elétrico

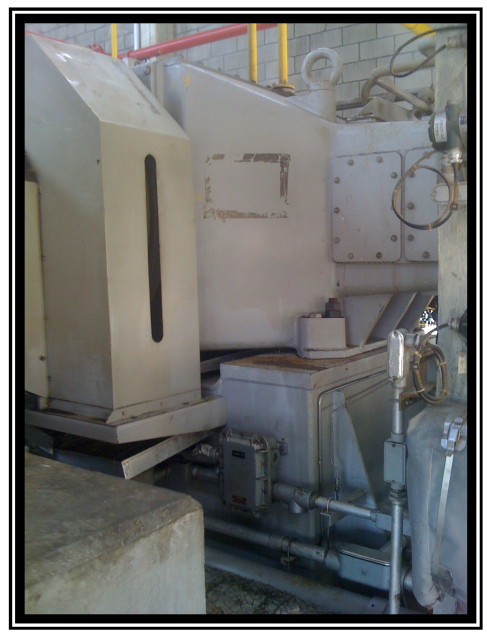

Figura 3-7 - Chassi do compressor

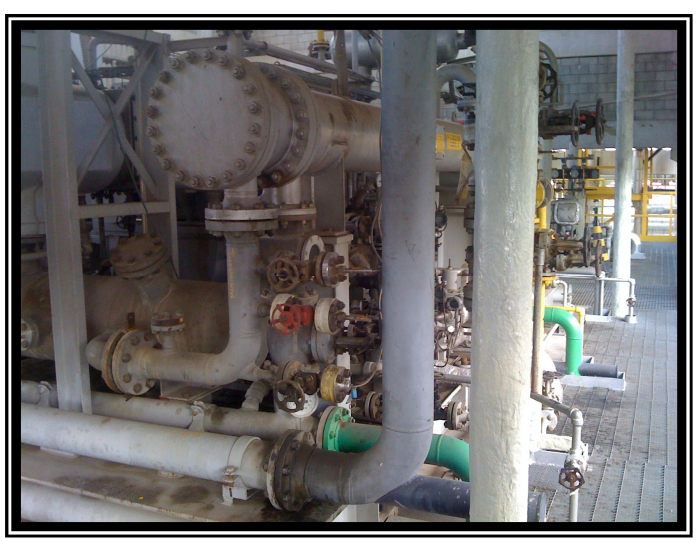

Figura 3-8 - Cilindros de compressão e tubulações 


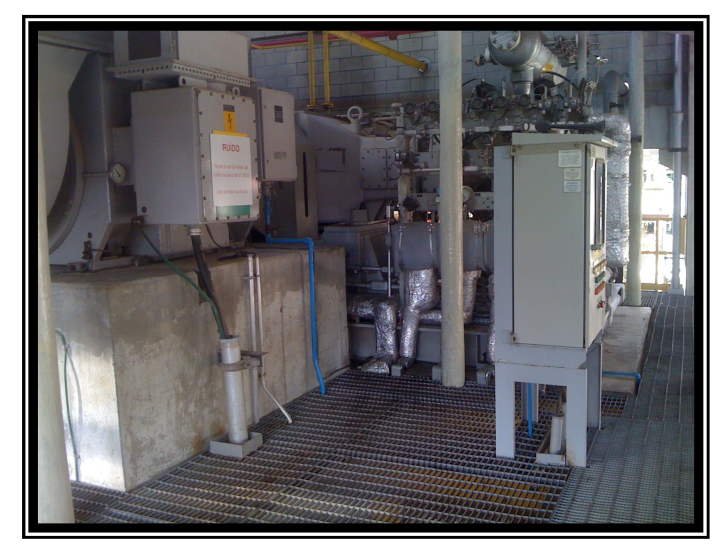

Figura 3-9 - Elementos do sistema mecânico

As cargas oscilatórias típicas geradas por equipamentos vibráteis têm como causa fundamental a dinâmica do movimento de cada um dos seus componentes mecânicos. Além das cargas inerentes à dinâmica do movimento, existem aquelas que são geradas basicamente pelo desbalanceamento das massas oscilantes, as quais são indesejáveis e comprometem o desempenho do equipamento. Uma vez que o presente estudo trata de um compressor novo, as cargas dinâmicas consideradas são apenas aquelas informadas pelo fabricante do equipamento, não sendo introduzida nenhuma carga dinâmica adicional devido ao desbalanceamento ou a outra causa qualquer.

As amplitudes das cargas dinâmicas transmitidas pelo compressor estão apresentadas na Tabela 3-1 a seguir.

Tabela 3-1 - Amplitude das cargas dinâmicas devidas ao compressor

\begin{tabular}{|c|c|c|}
\hline Direção & Forças Dinâmicas (N) & Torques Dinâmicos (N.m) \\
\hline Horizontal & 20788 & 35287 \\
\hline Vertical & 0 & 9542 \\
\hline
\end{tabular}

Os pesos ou cargas estáticas de cada um dos componentes do compressor estão apresentados na Tabela 3-2.

Tabela 3-2 - Cargas estáticas dos componentes do compressor

\begin{tabular}{|l|c|}
\hline \multicolumn{1}{|c|}{ Componentes } & Peso (N) \\
\hline Compressor & 100000 \\
\hline Suporte Cilíndrico 1 & 18000 \\
\hline Suporte Cilíndrico 2 & 19000 \\
\hline SKID & 71625 \\
\hline
\end{tabular}

Como uma forma de evitar falhas nas tubulações causadas por fadiga, falhas nas válvulas, redução da eficiência de compressão e erros na medição de escoamento do fluido de processo, os fabricantes de compressores limitam as velocidades de vibração do sistema mecânico e conseqüentemente do sistema estrutural de suporte 
correspondente. O gráfico apresentado na Figura 3-10 foi extraído da norma ISO 2372 (1974) e mostra, para cada freqüência de operação, os limites de vibração associados a aspectos qualitativos tais como danos estruturais, severidade de vibração da máquina e percepção humana.

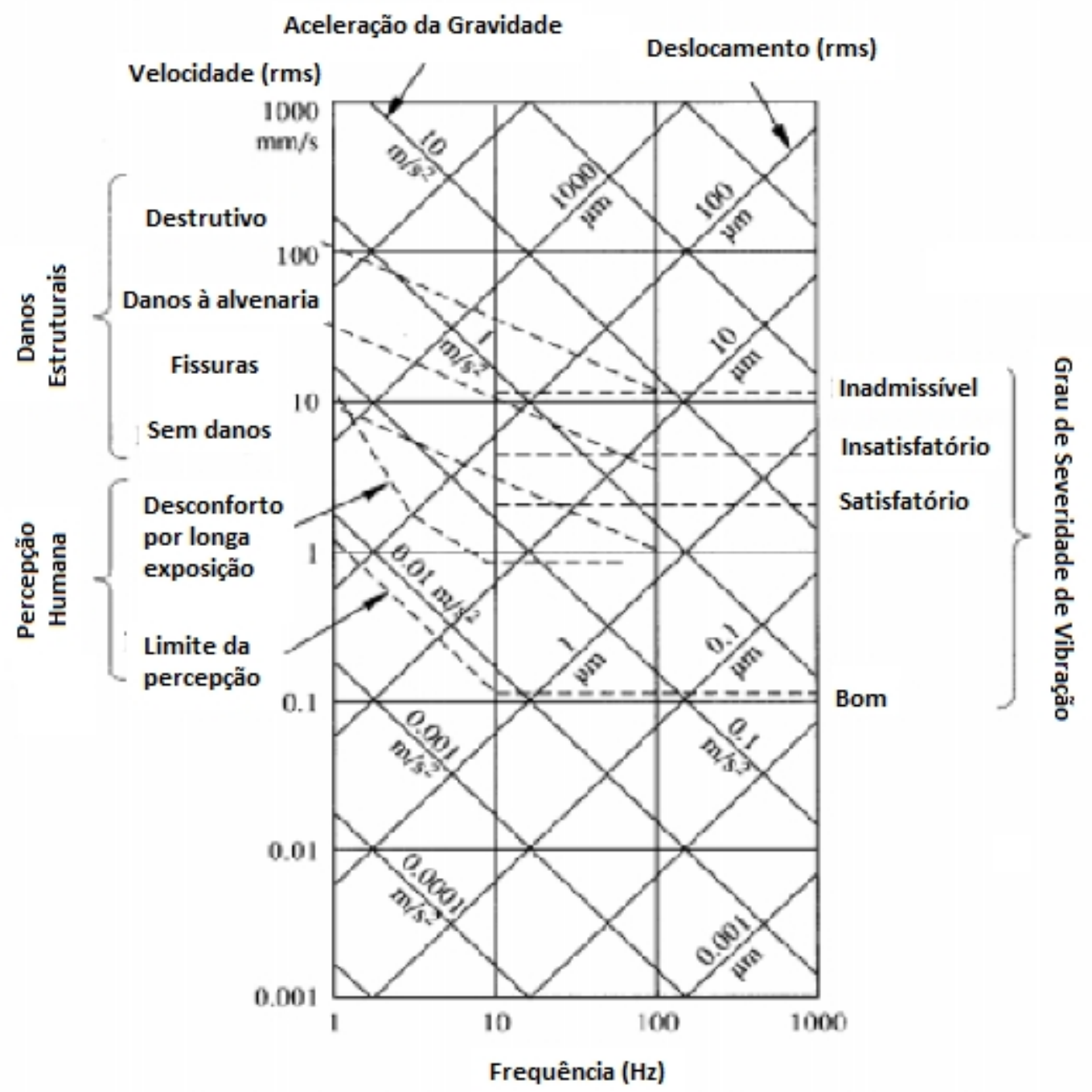

Figura 3-10 - Linhas limites de vibração para Danos Estruturais, Grau de Severidade de Vibração da Máquina e Percepção Humana

No caso estudado, as velocidades efetivas de vibração aceitáveis no nível do topo da estrutura de apoio dos equipamentos (assentamento dos skids) foram limitadas a 2,00 $\mathrm{mm} / \mathrm{s}$. 


\subsection{2.}

\section{Motor elétrico}

O motor elétrico tem como única e exclusiva função transmitir movimento rotacional ao virabrequim e, conseqüentemente, movimentos alternantes aos pistões do compressor acoplado.

Devido ao arranjo dos equipamentos, de modo a permitir perfeito acoplamento entre os componentes mecânicos, o motor elétrico está instalado na elevação 105,215m. A figura mostra o motor elétrico instalado.

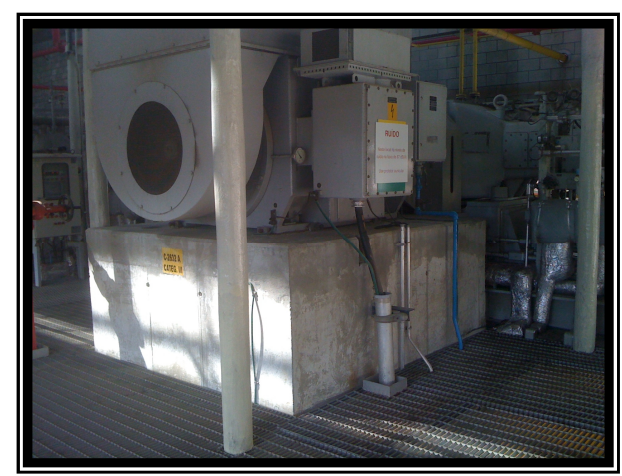

Figura 3-11 - Motor elétrico sobre uma das lajes de suporte

A magnitude das forças dinâmicas geradas pelo motor elétrico é pequena e, conseqüentemente, a sua contribuição na resposta dinâmica do sistema é desprezível (ARYA ET AL, 1979). Portanto, no modelo desenvolvido, o motor elétrico participa apenas com sua massa.

O peso e a massa correspondentes ao motor estão destacados na Tabela 3-3 abaixo.

\section{Tabela 3-3 - Peso e massa do motor elétrico}

\begin{tabular}{|l|c|c|}
\hline Componentes & Peso (N) & Massa (kg) \\
\hline Motor Elétrico & 70000 & 7000 \\
\hline
\end{tabular}

\section{3.}

\section{Descrição do solo local}

A formação geológica-geotécnica típica da região onde estão instalados os equipamentos do estudo é formada por duas fases bem destacadas. A primeira e mais superficial é conhecida como Formação Tinguis. A segunda e mais profunda é conhecida como Formação Guabirotuba, consistindo geralmente do maciço no qual os elementos de fundações estão inseridos. 
Destacadamente, a Formação Guabirotuba é uma unidade geológica presente de forma continua ou isolada em grande parte da região metropolitana de Curitiba, portanto muitas obras de porte são executadas em seus solos (NASCIMENTO E PUPPI, 1999).

Entre suas peculiaridades, podem ser citadas a cor cinza esverdeada, a presença típica de argilas siltosas ou siltes argilosos muitas vezes com areia, resistência elevada (limitando em alguns casos o prosseguimento de sondagens), rigidez elevada, baixa compressibilidade e expressivo pré-adensamento, suscetível à expansão em função de variação de umidade natural e desconfinamento. Essas características se apresentam de forma homogênea nas áreas de ocorrência.

A figura abaixo ilustra parte da planta de arranjo da unidade industrial onde os compressores do estudo estão localizados, destacando-se a locação de algumas sondagens à percussão SPT representativas da região.

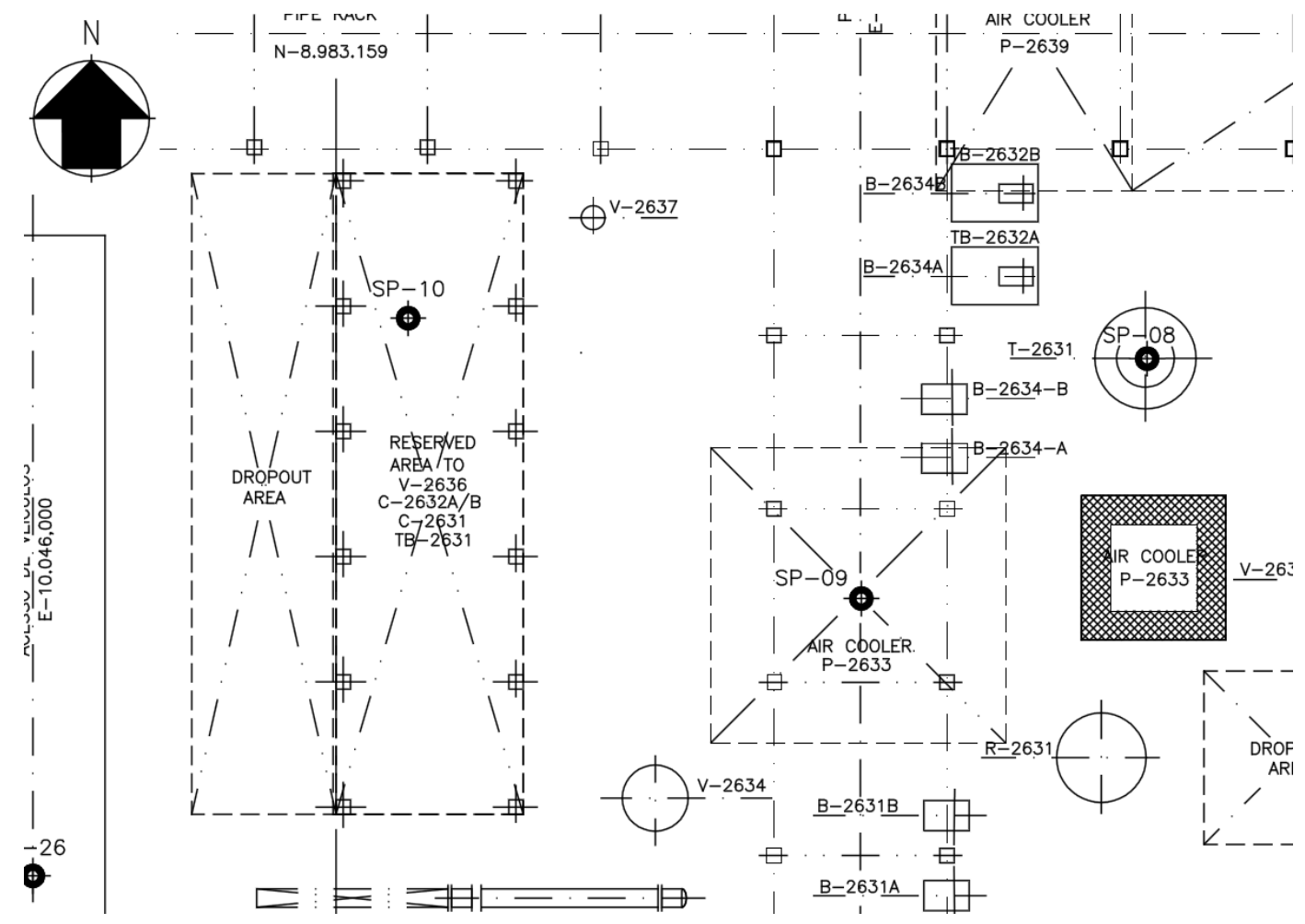

Figura 3-12 - Planta de locação de sondagens do tipo SPT consideradas como referência para caracterização geotécnica do subsolo local

Na Figura 3-13 a seguir está ilustrado um perfil geotécnico típico formado pelos resultados das sondagens SP-10 e SP-08, ambas marcadas na planta de locação acima, demonstrando através dos valores elevados do índice NSPT a alta resistência dos solos da formação Guabirotuba. A sondagem SP-10 está localizada exatamente dentro dos 
limites da estrutura de abrigo dos compressores. Ainda sobre essa figura, as linhas horizontais estão espaçadas de 1 metro ao longo da profundidade do furo de sondagem.

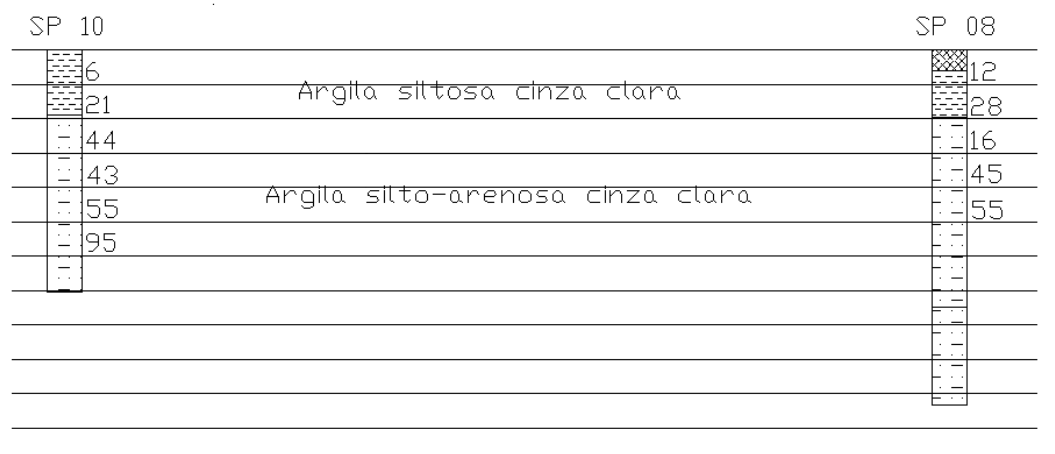

Figura 3-13 - Perfil geotécnico típico do subsolo local

Nascimento e Puppi (1999) citam a pouca parametrização geotécnica dos solos típicos dessa formação geológica, lacuna a partir da qual o presente trabalho encontra oportunidade também em contribuir com o meio acadêmico e de projetos acerca de valores de parâmetros de dinâmica para os solos locais.

\subsection{1.}

\section{Conceitos relacionados a estacas carregadas horizontalmente}

Para a avaliação de uma estaca carregada horizontal ou transversalmente, é comumente utilizado o método do coeficiente de reação horizontal, que pressupõe que o solo seja admitido como um meio contínuo.

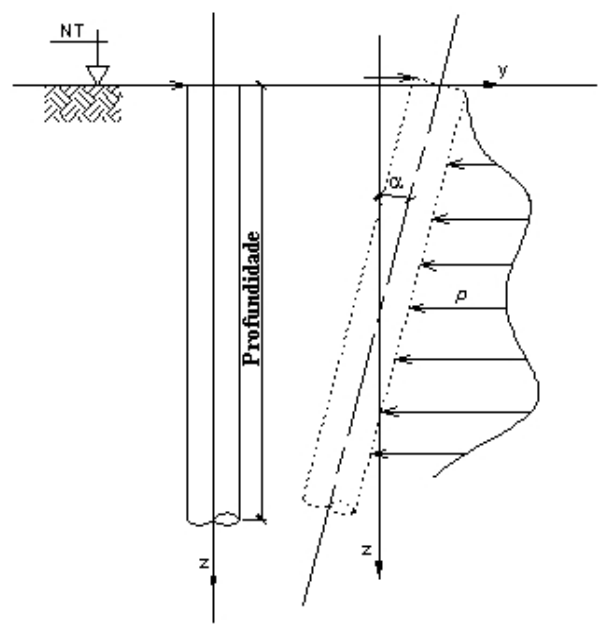

Figura 3-14 - Estaca isolada carregada transversalmente

O coeficiente de reação do solo $k_{z}$ é definido como a razão entre a pressão unitária atuante $p$ e o respectivo deslocamento horizontal $y$ sofrido pelo solo, em uma dada profundidade $z$. Sua unidade é dada em força por unidade de volume. 


$$
k_{Z}=\frac{p}{y}
$$

O coeficiente de reação horizontal não depende apenas do solo, mas também do diâmetro da estaca $d$ e de seu comprimento ou profundidade $z$, conforme tratado por Terzagui (1955).

Em relação à profundidade da estaca, o coeficiente de reação horizontal do solo pode se comportar de duas maneiras: constante ou linearmente crescente.

O primeiro caso ocorre tipicamente em argilas rijas ou areias compactas de tal forma que a relação apresentada na equação (3-1) é uma constante, para um dado diâmetro.

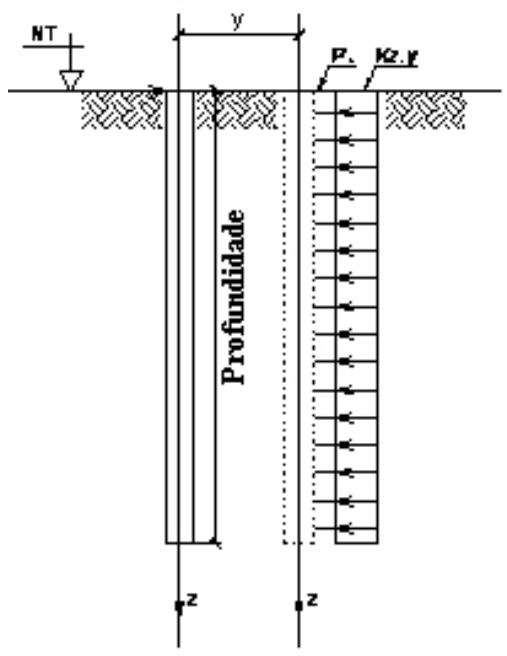

Figura 3-15 - Coeficiente de reação horizontal uniforme

Já o segundo caso é comum em argilas normalmente adensadas ou em areias pouco compactas. Como mostra a equação (3-2), as variáveis se relacionam através do parâmetro $n_{h}$, denominado por Terzagui (1955) como Constante do Coeficiente de Reação Horizontal, que pode ser tabelado em função do tipo, compacidade e consistência do solo. 


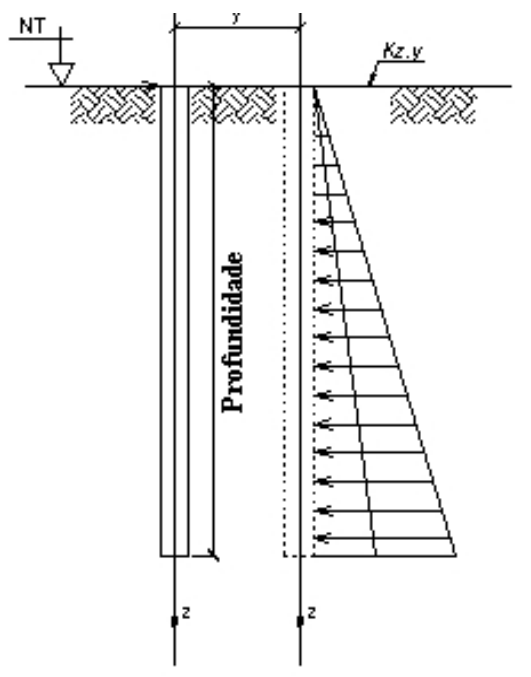

Figura 3-16 - Coeficiente de reação horizontal variável

$$
k_{Z}=n_{h} \frac{z}{d}
$$

Outra abordagem sobre o tratamento de estacas carregadas horizontalmente é o método do coeficiente de mola de Winkler, o qual propõe uma idealização do solo como um meio discreto formado por uma série de molas independentes e de comportamento linear elástico. As molas assim idealizadas podem ter o seu coeficiente $k_{m}$ calculado pela razão entre a força horizontal $F$ resistida por ela e o correspondente deslocamento $y$ sofrido no ponto de contato com a estaca. Sua unidade é dada em força por unidade de comprimento.

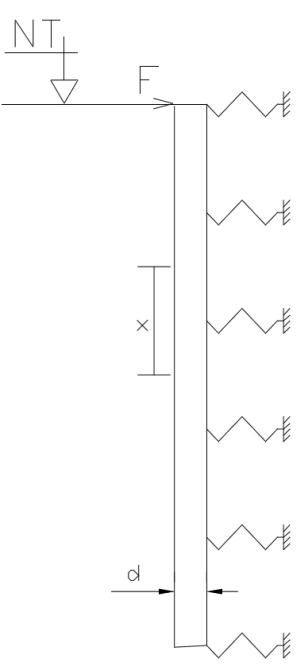

Figura 3-17 - Coeficiente de mola - Modelo de Winkler

$$
k_{m}=\frac{F}{y}
$$


No caso em que há proporcionalidade ente $F$ e $y$, o coeficiente de reação horizontal do solo $k_{z}$ e o coeficiente de mola $k_{m}$ se relacionam conforme equação (3-4) através da consideração de sua área de influência.

$$
k_{m}=k_{2} d \cdot x
$$

Onde $d$ é o diâmetro da estaca e $x$ a semi-distância entre molas adjacentes.

Tanto o método do coeficiente de reação horizontal do solo como o método do coeficiente de mola leva em conta carregamentos estáticos em sua determinação.

\subsection{2.}

\section{Ensaio de carregamento horizontal}

A participação do solo como elemento constituinte de um modelo idealizado de interação estática e dinâmica entre estruturas, fundações e máquinas é materializada a partir da consideração de suas propriedades constitutivas. No âmbito da dinâmica, dentre as propriedades físicas constitutivas básicas do solo que diretamente influenciam o comportamento global de um sistema pode-se citar o módulo de elasticidade longitudinal ou módulo de Young $(E)$, módulo de elasticidade ao cisalhamento $(G)$, coeficiente de Poisson $(v)$ e propriedades de amortecimento.

Tanto os métodos analíticos como os métodos numéricos de interação soloestrutura levam em conta em sua formulação os parâmetros citados. No presente estudo, o solo foi considerado como um componente discreto, de comportamento linear, sem massa, atuando independentemente em duas direções horizontais ortogonais como uma mola de coeficiente $k_{m}$. Cada mola é aplicada em um ponto (nó) das fundações (estacas).

No presente estudo, analisa-se um sistema em que o componente mecânico produz essencialmente esforços cíclicos segundo uma direção horizontal, de modo que o solo também é preferencialmente solicitado nessa mesma direção. Considerando o exposto e tendo em vista definir o modelo constitutivo do solo, foi executado em campo ensaio de carregamento estático horizontal em três estacas de mesmo diâmetro $(40,0 \mathrm{~cm})$ e em uma região próxima àquela onde estão instalados os compressores do problema analisado, com subsolos enquadrados na mesma formação geológica. $O$ aparato utilizado no ensaio está ilustrado na Figura 3-18. 


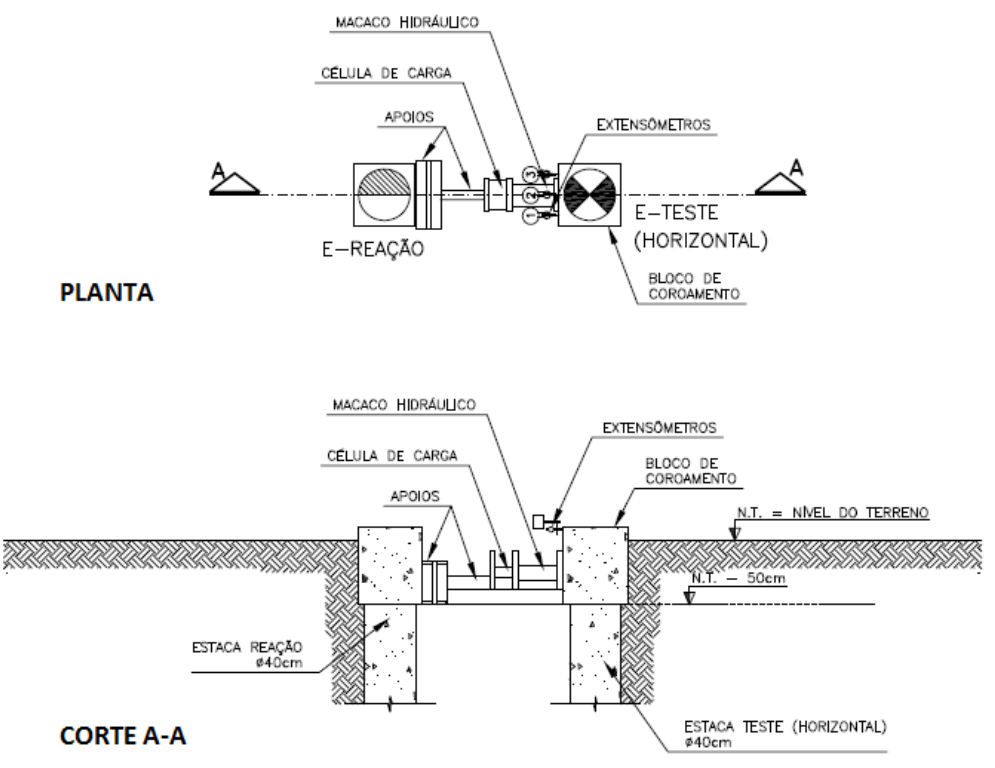

Figura 3-18 - Aparato de montagem do ensaio de carregamento horizontal

O ensaio de carregamento estático é regido pela norma brasileira ABNT NBR 12131 (2006) e por normas internacionais como, por exemplo, a norma ASTM D3966 (2007). Nesse tipo de ensaio, são aplicadas cargas estáticas crescentes no topo de uma estaca, em vários estágios, e medidos os deslocamentos correspondentes através de quatro extensômetros (curso mínimo de $25,00 \mathrm{~mm}$ e resolução de $0,01 \mathrm{~mm}$ ). De forma geral, as cargas aplicadas podem ser axiais (compressão ou tração) e laterais às estacas. O dispositivo de aplicação de carga é constituído por um ou mais cilindros hidráulicos alimentados por bombas, atuando contra um sistema de reação estável.

Para simular o efeito de um carregamento dinâmico no solo, o ensaio de carregamento estático em duas das estacas testadas foi adaptado. Após o término do teste, promoveu-se acréscimos e decréscimos cíclicos do nível de carregamento na estaca em torno da carga correspondente ao último estagio do ensaio (+/- $10 \%$ do valor da carga do último nível de carregamento). Nesse caso, a velocidade do carregamento seguiu o procedimento de prova de carga rápida previsto na norma ABNT NBR 12131 (2006).

Os resultados dos ensaios de carregamento horizontal para cada uma das estacasteste foram extraídos do relatório de execução e estão apresentados na Tabela 3-4, Tabela 3-5 e Tabela 3-6 a seguir. 
Tabela 3-4 - Resultados do ensaio de carregamento horizontal - Estaca-teste E-11

\begin{tabular}{cccc}
\hline Estágio & $\begin{array}{c}\text { Tempo de } \\
\text { Duração } \\
(\min )\end{array}$ & $\begin{array}{c}\text { Carga } \\
\text { Aplicada } \\
(\mathrm{kN})\end{array}$ & $\begin{array}{c}\text { PCH-02 E-11 } \\
\text { Desloc. Final } \\
\text { Médio (mm) }\end{array}$ \\
\hline $1^{\circ}$ & 30 & 15 & 0,16 \\
$2^{\circ}$ & 30 & 25 & 0,32 \\
$3^{\circ}$ & 30 & 35 & 0,53 \\
$4^{\circ}$ & 30 & 45 & 0,79 \\
$5^{\circ}$ & 30 & 54 & 1,05 \\
$6^{\circ}$ & 30 & 64 & 1,41 \\
$7^{\circ}$ & 60 & 74 & 2,02 \\
$8^{\circ}$ & 30 & 84 & 2,71 \\
$9^{\circ}$ & 30 & 94 & 3,92 \\
$10^{\circ}$ & 1009 & 104 & 5,48 \\
$11^{\circ}$ & 15 & 78 & 5,19 \\
$12^{\circ}$ & 15 & 52 & 4,65 \\
$13^{\circ}$ & 15 & 26 & 3,78 \\
$14^{\circ}$ & 30 & 0 & 2,28 \\
\hline
\end{tabular}

Tabela 3-5 - Resultados do ensaio de carregamento horizontal - Estaca-teste E-16

\begin{tabular}{cccc}
\hline Estágio & $\begin{array}{c}\text { Tempo de } \\
\text { Duração } \\
(\mathrm{min})\end{array}$ & $\begin{array}{c}\text { Carga } \\
\text { Aplicada } \\
(\mathrm{kN})\end{array}$ & $\begin{array}{c}\text { PCH-03 E-16 } \\
\text { Desloc. Final } \\
\text { Médio }(\mathrm{mm})\end{array}$ \\
\hline $1^{\circ}$ & 30 & 15 & 0,76 \\
$2^{\circ}$ & 30 & 25 & 1,64 \\
$3^{\circ}$ & 30 & 35 & 2,78 \\
$4^{\circ}$ & 30 & 45 & 4,57 \\
$5^{\circ}$ & 60 & 54 & 7,71 \\
$6^{\circ}$ & 60 & 64 & 10,86 \\
$7^{\circ}$ & 60 & 74 & 14,03 \\
$8^{\circ}$ & 891 & $84^{(4)}$ & 20,40 \\
$9^{\circ}$ & 15 & 64 & 20,12 \\
$10^{\circ}$ & 30 & 43 & 18,66 \\
$11^{\circ}$ & 15 & 21 & 16,12 \\
$12^{\circ}$ & 60 & 0 & 9,71 \\
\hline
\end{tabular}


Tabela 3-6 - Resultados do ensaio de carregamento horizontal - Estaca-teste E-3

\begin{tabular}{cccc}
\hline Estágio & $\begin{array}{c}\text { Tempo de } \\
\text { Duração } \\
(\min )\end{array}$ & $\begin{array}{c}\text { Carga } \\
\text { Aplicada } \\
(\mathrm{kN})\end{array}$ & $\begin{array}{c}\text { PCH-04 E-3 } \\
\text { Desloc. Final } \\
\text { Médio }(\mathrm{mm})\end{array}$ \\
\hline $1^{\circ}$ & 30 & 12 & 0,37 \\
$2^{\circ}$ & 30 & 24 & 1,97 \\
$3^{\circ}$ & 30 & 36 & 4,19 \\
$4^{\circ}$ & 30 & 48 & 8,78 \\
$5^{\circ}$ & 180 & 59 & 22,36 \\
$6^{\circ}$ & 930 & 65 & 31,31 \\
$7^{\circ}$ & 15 & 49 & 30,53 \\
$8^{\circ}$ & 15 & 32 & 29,87 \\
$9^{\circ}$ & 15 & 16 & 28,40 \\
$10^{\circ}$ & 30 & 0 & 22,50 \\
\hline
\end{tabular}

A Tabela 3-7 resume os resultados, destacando a carga máxima atingida no ensaio e o respectivo deslocamento horizontal do topo da estaca. Os resultados deste ensaio servirão para o calculo do coeficiente de mola do solo dito estático.

Tabela 3-7 - Resumo dos resultados do ensaio de carregamento horizontal

\begin{tabular}{|l|c|c|c|}
\hline Estaca-Teste & $\mathrm{E}-11$ & $\mathrm{E}-16$ & $\mathrm{E}-3$ \\
\hline Sondagem de referência & $\mathrm{SP}-23$ & $\mathrm{SP}-13$ & $\mathrm{SP}-10 \mathrm{~A}$ \\
\hline Carga (kN) & 104 & 84 & 65 \\
\hline Deslocamento (mm) & 5.48 & 20.4 & 31.31 \\
\hline
\end{tabular}

Para as estacas-teste E-16 e E-3, realizou-se também o ensaio de carregamento cíclico, cujas curvas Carga Aplicada versus Deslocamento para cada um dos ciclos estão apresentados a seguir.
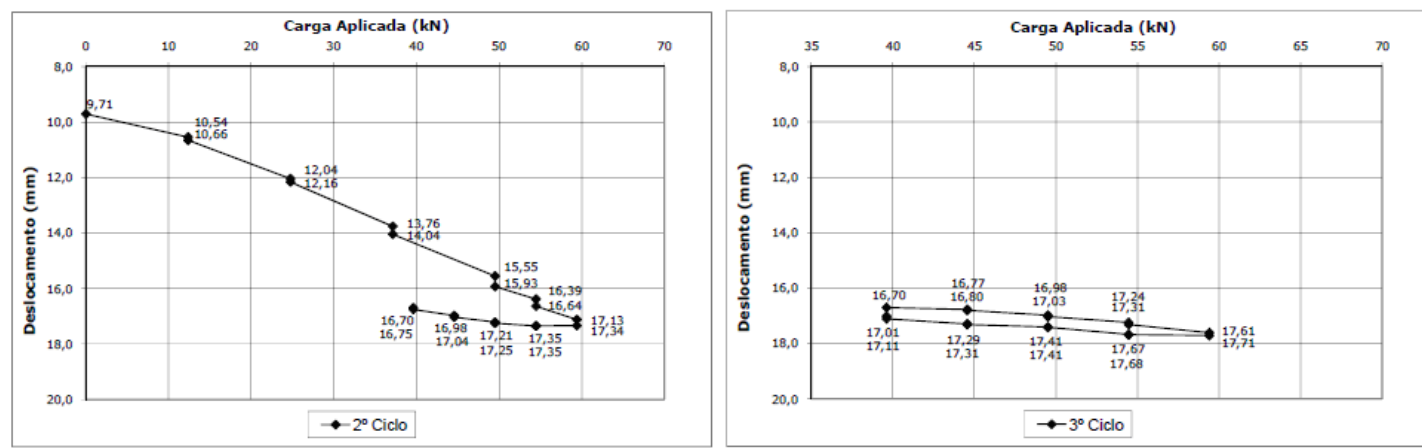

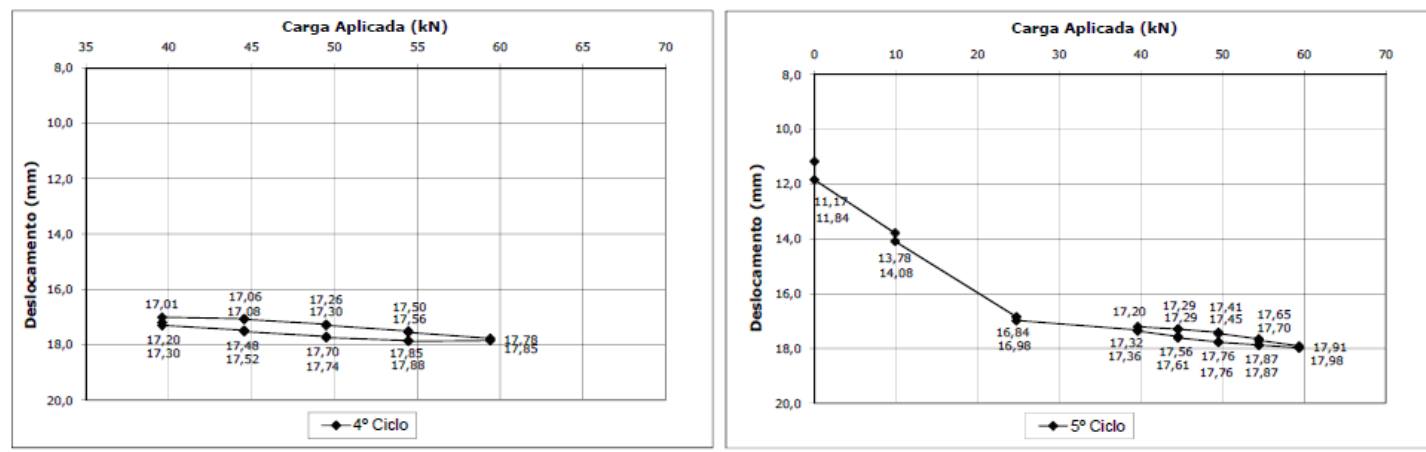

Figura 3-19 - Resultado ensaio carregamento cíclico horizontal - Estaca-teste E-16
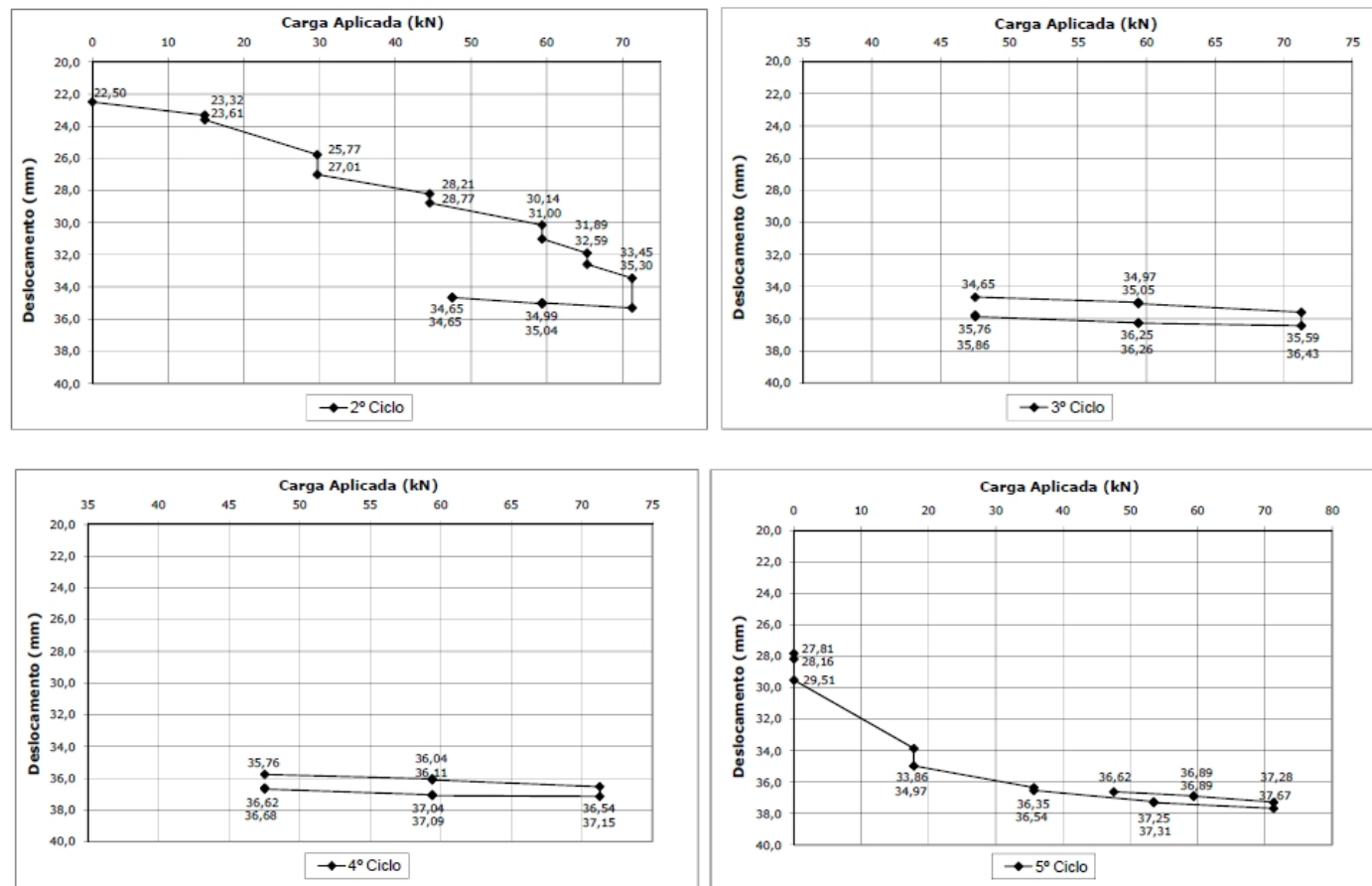

Figura 3-20 - Resultado ensaio carregamento cíclico horizontal - Estaca-teste E-3

Os resultados destes ensaios cíclicos servirão para o calculo do coeficiente de mola do solo dito dinâmico (ou cíclico).

Novak (1974) propõe valores de coeficiente de mola independentes da freqüência a qual o solo está submetido. Essa condição é uma idealização da realidade, de modo que o presente trabalho tem como um dos objetivos também fornecer intervalos típicos de valores dos parâmetros do solo em questão quando carregamentos cíclicos são considerados, e mostrar como um sistema interativo estrutura-solo se comporta sob essas condições. 


\subsection{3.}

\section{Retroanálise do resultado do ensaio de carregamento horizontal}

Como descrito detalhadamente no item 3.3.2, o ensaio de carregamento horizontal foi feito em duas etapas. A primeira etapa consistiu no incremento de cargas até uma carga máxima pré-definida, medindo-se o correspondente deslocamento. Após essa fase, iniciou-se a segunda etapa com o procedimento de carregamentos cíclicos.

O coeficiente de mola do solo calculado por retroanálise com os resultados da primeira etapa relaciona as grandezas deslocamento e força quando esta última é aplicada independente do tempo.

O coeficiente de mola do solo calculado por retroanálise com os resultados da segunda etapa relaciona as grandezas deslocamento e força quando esta última é aplicada em ciclos, de forma a simular efeitos de vibração. A avaliação do coeficiente de mola foi feito em cada ciclo.

No procedimento de retroanálise utilizou-se dois métodos que tratam da analise de estacas submetidas a carregamentos horizontais. São eles o Método de Miche (1930) e o Método de Hetenyi (1946), ambos amplamente empregados em projeto de fundações de máquinas para representação do modelo constitutivo do solo em função da profundidade.

\subsubsection{1. \\ Método de Miche}

Miche (1930) analisou o problema de estacas imersas em um meio elástico com coeficiente de reação horizontal crescendo linearmente com a profundidade, submetidas a uma força horizontal em seu topo.

De acordo com o método, o deslocamento horizontal $y$ do topo da estaca devido a uma força $F$ é dado pela formula abaixo.

$$
y=\frac{2,4 T^{3} F}{E I}
$$

Onde $E$ é o módulo de elasticidade do material da estaca, $I$ é o momento de inércia da seção da estaca e $T$ é um parâmetro com dimensão de comprimento dado pela equação (3-6). 


$$
T=\sqrt[5]{\frac{E I}{n_{h}}}
$$

Substituindo a equação (3-6) em (3-5) e resolvendo para $n_{h}$, chega-se a equação $(3-7)$.

$$
n_{h}=\sqrt[3]{\left(\frac{2,4 F}{y}\right)^{5}(E I)^{2}}
$$

Desta equação são conhecidos os parâmetros $E$ e $I$, que dependem do material da estaca e de sua geometria, e os valores de $F$ e $y$, que são obtidos do ensaio de carregamento horizontal descrito anteriormente.

Com os resultados indicados na Tabela 3-7, pode-se então calcular o valor de $n_{h} \mathrm{e}$ consequentemente os valores do coeficiente de mola horizontal ao longo da profundidade da estaca, para o caso dito estático. De maneira análoga, com os resultados indicados na Figura 3-19 e na Figura 3-20, calcula-se os valores do coeficiente de mola horizontal para o caso dito dinâmico.

Os valores de $n_{h}$ e $k_{m}$ calculados para o caso dito estático estão apresentados na Tabela 3-8 e na Tabela 3-9.

Tabela 3-8 - Valores de $n_{h}$ retro analisados

\begin{tabular}{|c|c|c|c|}
\hline Estaca & E-11 & E-16 & E-3 \\
\hline $\mathbf{H}(\mathbf{k N})$ & 104 & 84 & 65 \\
\hline $\mathbf{y} \mathbf{0}(\mathbf{m})$ & 0.00548 & 0.02040 & 0.03131 \\
\hline $\mathbf{T}$ & 0.83744430 & 1.39366101 & 1.75104280 \\
\hline $\mathbf{n}_{\mathbf{h}}\left(\mathbf{k N} / \mathbf{m}^{\mathbf{3}}\right)$ & 64945.9631 & 5087.9878 & 1624.9800 \\
\hline
\end{tabular}

\begin{tabular}{|c|c|c|c|}
\hline Estaca & $E-11$ & E-16 & $E-3$ \\
\hline \multirow{3}{*}{$Z(m)$} & \multicolumn{3}{|c|}{$n_{h}$} \\
\hline & 64945.9631 & 5087.9878 & 1624.9800 \\
\hline & \multicolumn{3}{|c|}{$k_{m}(\mathrm{kN} / \mathrm{m})$} \\
\hline 1 & 64945.9631 & 5087.9878 & 1624.9800 \\
\hline 2 & 129891.9261 & 10175.9755 & 3249.9599 \\
\hline 3 & 194837.8892 & 15263.9633 & 4874.9399 \\
\hline$\overline{4}$ & 259783.8522 & 20351.9510 & 6499.9198 \\
\hline 5 & 324729.8153 & 25439.9388 & 8124.8998 \\
\hline 6 & 389675.7783 & 30527.9265 & 9749.8797 \\
\hline 7 & 454621.7414 & 35615.9143 & 11374.8597 \\
\hline 8 & 519567.7045 & 40703.9020 & 12999.8396 \\
\hline 9 & 584513.6675 & 45791.8898 & 14624.8196 \\
\hline 10 & 649459.6306 & 50879.8776 & 16249.7996 \\
\hline$k_{m}$ médic & 357202.7968 & 27983.9327 & 8937.3898 \\
\hline
\end{tabular}

Tabela 3-9 - Valores dos coeficientes de mola $k_{m}$ retro analisados - Caso estático 
Os valores de $n_{h}$ e $k_{m}$ para o caso dito dinâmico são calculados para cada um dos ciclos com os dados das provas de carga E-03 e E-16.

Nesse contexto, os ciclos estão divididos em dois tipos, o primeiro denominado ciclo de ida e o segundo denominado ciclo de volta, de modo que cada tipo representa o deslocamento em uma direção.

A Tabela 3-10 mostra os valores de $n_{h}$ obtidos por retroanálise para o ciclo de ida.

Tabela 3-10 - Ensaio E-16 - Ciclo de Ida - Valores de $n_{h}$ retroanalisados

Ciclo 1 - Ida

Ciclo 2 - Ida

Ciclo 3 - Ida

\begin{tabular}{|c|c|c|c||c|c|}
\hline Ensaio & E-16 & Ensaio & E-16 & Ensaio & E-16 \\
\hline $\mathbf{H}(\mathbf{k N})$ & 20 & $\mathbf{H}(\mathbf{k N})$ & 20 & $\mathbf{H}(\mathbf{k N})$ & 20 \\
\hline $\mathbf{y} \mathbf{0}(\mathbf{m})$ & 0.00059 & $\mathbf{y} \mathbf{~ ( m )}$ & 0.0006 & $\mathbf{y 0}(\mathbf{m})$ & 0.00055 \\
\hline $\mathbf{T}(\mathbf{m})$ & 0.690209389 & $\mathbf{T}(\mathbf{m})$ & 0.694087052 & $\mathbf{T}(\mathbf{m})$ & 0.674245033 \\
\hline $\mathbf{n}_{\mathbf{h}}\left(\mathbf{k N} / \mathbf{m}^{3}\right)$ & 170776.2606 & $\mathbf{n}_{\mathbf{h}}\left(\mathbf{k N} / \mathbf{m}^{3}\right)$ & 166058.8790 & $\mathbf{n}_{\mathbf{h}}\left(\mathbf{k N} / \mathbf{m}^{3}\right)$ & 191974.2753 \\
\hline $\mathbf{n}_{\mathbf{h}} / \mathbf{D}$ & 426940.6515 & $\mathbf{n}_{\mathbf{h}} / \mathbf{D}$ & 415147.1976 & $\mathbf{n}_{\mathbf{h}} / \mathbf{D}$ & 479935.6882 \\
\hline
\end{tabular}

Ciclo 4 - Ida

\begin{tabular}{|c|c|}
\hline Ensaio & E-16 \\
\hline $\mathbf{H}(\mathbf{k N})$ & 20 \\
\hline $\mathbf{y} \mathbf{0}(\mathbf{m})$ & 0.00062 \\
\hline $\mathbf{T}(\mathbf{m})$ & 0.701714993 \\
\hline $\mathbf{n}_{\mathbf{h}}\left(\mathbf{k N} / \mathbf{m}^{3}\right)$ & 157227.3290 \\
\hline $\mathbf{n}_{\mathbf{h}} / \mathbf{D}$ & 393068.3226 \\
\hline
\end{tabular}

A Tabela 3-11 mostra os valores de $n_{h}$ obtidos por retroanálise para o ciclo de volta.

Tabela 3-11 - Ensaio E-16 - Ciclo de Volta - Valores de $n_{h}$ retroanalisados

Ciclo 1 - Volta
\begin{tabular}{|c|c|}
\hline Ensaio & E-16 \\
\hline $\mathbf{H}(\mathbf{k N})$ & 20 \\
\hline $\mathbf{y} 0(\mathbf{m})$ & 0.00101 \\
\hline $\mathbf{T}(\mathbf{m})$ & 0.82566521 \\
\hline $\mathbf{n}_{\mathrm{h}}\left(\mathbf{k N} / \mathbf{m}^{3}\right)$ & 69712.6988 \\
\hline $\mathbf{n}_{\mathbf{h}} / \mathbf{D}$ & 174281.747 \\
\hline
\end{tabular}

Ciclo 2 - Volta

\begin{tabular}{|c|c|}
\hline Ensaio & E-16 \\
\hline $\mathbf{H}(\mathbf{k N})$ & 20 \\
\hline $\mathbf{0} \mathbf{( m )}$ & 0.00084 \\
\hline $\mathbf{T}(\mathbf{m})$ & 0.77646751 \\
\hline $\mathbf{n}_{\mathbf{h}}\left(\mathbf{k N} / \mathbf{m}^{\mathbf{3}}\right)$ & 94779.7101 \\
\hline $\mathbf{n}_{\mathbf{h}} \mathbf{D}$ & 236949.275 \\
\hline
\end{tabular}

Ciclo 3 - Volta

\begin{tabular}{|c|c|}
\hline Ensaio & $E-16$ \\
\hline $\mathbf{H}(\mathbf{k N})$ & 20 \\
\hline $\mathbf{y} \mathbf{( m )}$ & 0.00078 \\
\hline $\mathbf{T}(\mathbf{m})$ & 0.757521668 \\
\hline$n_{h}\left(\mathbf{k N} / \mathbf{m}^{3}\right)$ & 107239.9283 \\
\hline $\mathbf{n}_{h} / \mathbf{D}$ & 268099.8206 \\
\hline
\end{tabular}

Depreende-se dos resultados acima que a magnitude do parâmetro $n_{h}$ varia em cada ciclo e, além disso, também varia em função da direção em que o carregamento é aplicado. Assim, infere-se que a propriedade física do solo, no caso a constante de mola $k_{m}$, não é estritamente apenas uma propriedade constitutiva do material.

Essa constatação demonstra a importância de uma consideração cuidadosa do solo como elemento de um sistema interativo solo-estrutura de modo a gerar modelos de análise robustos e consistentes com a realidade.

Para efeito do presente estudo, serão considerados os valores retroanalisados da constante de mola $k_{m}$ obtidos a partir do menor e do maior valor de $n_{h}$ no ciclo de ida 
(Tabela 3-12 e Tabela 3-14), e também do menor e do maior valor de $n_{h}$ no ciclo de volta (Tabela 3-13 e Tabela 3-15).

Tabela 3-12 - Ensaio E-16 - Ciclo de Ida $-k_{m}$ para $n_{h}=157227.3290 \mathrm{kN} / \mathrm{m}^{3} \mathrm{e}$

$$
n_{h}=191974.2753 \mathrm{kN} / \mathrm{m}^{3}
$$

Ciclo Ida - Menor Valor

Ciclo Ida - Maior Valor

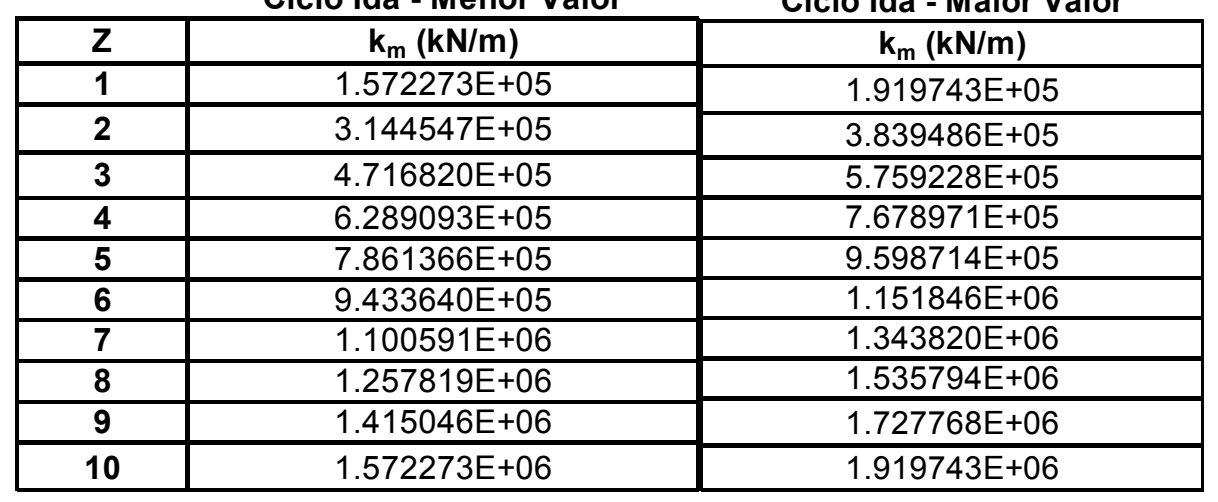

Tabela 3-13 - Ensaio E-16 - Ciclo de Volta $-k_{m}$ para $n_{h}=69712.6988 \mathrm{kN} / \mathrm{m}^{3} \mathrm{e}$

$$
n_{h}=107239.9283 \mathrm{kN} / \mathrm{m}^{3}
$$

Ciclo Volta - Menor Valor

Ciclo Volta - Maior Valor

\begin{tabular}{|c|c|c|}
\hline $\mathbf{Z}$ & $\mathbf{k}_{\mathbf{m}}(\mathbf{k N} / \mathbf{m})$ & $\left.\mathbf{k}_{\mathbf{m}} \mathbf{( k N} / \mathbf{m}\right)$ \\
\hline $\mathbf{1}$ & $6.971270 \mathrm{E}+04$ & $1.072399 \mathrm{E}+05$ \\
\hline $\mathbf{2}$ & $1.394254 \mathrm{E}+05$ & $2.144799 \mathrm{E}+05$ \\
\hline $\mathbf{3}$ & $2.091381 \mathrm{E}+05$ & $3.217198 \mathrm{E}+05$ \\
\hline $\mathbf{4}$ & $2.788508 \mathrm{E}+05$ & $4.289597 \mathrm{E}+05$ \\
\hline $\mathbf{5}$ & $3.485635 \mathrm{E}+05$ & $5.361996 \mathrm{E}+05$ \\
\hline $\mathbf{6}$ & $4.182762 \mathrm{E}+05$ & $6.434396 \mathrm{E}+05$ \\
\hline $\mathbf{7}$ & $4.879889 \mathrm{E}+05$ & $7.506795 \mathrm{E}+05$ \\
\hline $\mathbf{8}$ & $5.577016 \mathrm{E}+05$ & $8.579194 \mathrm{E}+05$ \\
\hline $\mathbf{9}$ & $6.274143 \mathrm{E}+05$ & $9.651594 \mathrm{E}+05$ \\
\hline $\mathbf{1 0}$ & $6.971270 \mathrm{E}+05$ & $1.072399 \mathrm{E}+06$ \\
\hline
\end{tabular}

Tabela 3-14 - Ensaio E-3 - Ciclo de Ida $-k_{m}$ para $n_{h}=34222.4094 \mathrm{kN} / \mathrm{m}^{3}$ e $n_{h}=82482.4884 \mathrm{kN} / \mathrm{m}^{3}$

Ciclo Ida - Menor Valor

Ciclo Ida - Maior Valor

\begin{tabular}{|c|c|c|}
\hline $\mathbf{Z}$ & $\mathbf{k}_{\mathbf{m}}(\mathbf{k N} / \mathbf{m})$ & $\mathbf{k}_{\mathbf{m}} \mathbf{( k N / \mathbf { m } )}$ \\
\hline $\mathbf{1}$ & $3.422241 \mathrm{E}+04$ & $8.248249 \mathrm{E}+04$ \\
\hline $\mathbf{2}$ & $6.844482 \mathrm{E}+04$ & $1.649650 \mathrm{E}+05$ \\
\hline $\mathbf{3}$ & $1.026672 \mathrm{E}+05$ & $2.474475 \mathrm{E}+05$ \\
\hline $\mathbf{4}$ & $1.368896 \mathrm{E}+05$ & $3.299300 \mathrm{E}+05$ \\
\hline $\mathbf{5}$ & $1.711120 \mathrm{E}+05$ & $4.124124 \mathrm{E}+05$ \\
\hline $\mathbf{6}$ & $2.053345 \mathrm{E}+05$ & $4.948949 \mathrm{E}+05$ \\
\hline $\mathbf{7}$ & $2.395569 \mathrm{E}+05$ & $5.773774 \mathrm{E}+05$ \\
\hline $\mathbf{8}$ & $2.737793 \mathrm{E}+05$ & $6.598599 \mathrm{E}+05$ \\
\hline $\mathbf{9}$ & $3.080017 \mathrm{E}+05$ & $7.423424 \mathrm{E}+05$ \\
\hline $\mathbf{1 0}$ & $3.422241 \mathrm{E}+05$ & $8.248249 \mathrm{E}+05$ \\
\hline
\end{tabular}


Tabela 3-15 - Ensaio E-3 - Ciclo de Volta $-k_{m}$ para $n_{h}=183437.5885 \mathrm{kN} / \mathrm{m}^{3} \mathrm{e}$ $n_{h}=326398.0336 \mathrm{kN} / \mathrm{m}^{3}$

Ciclo Volta - Menor Valor Ciclo Volta - Maior Valor

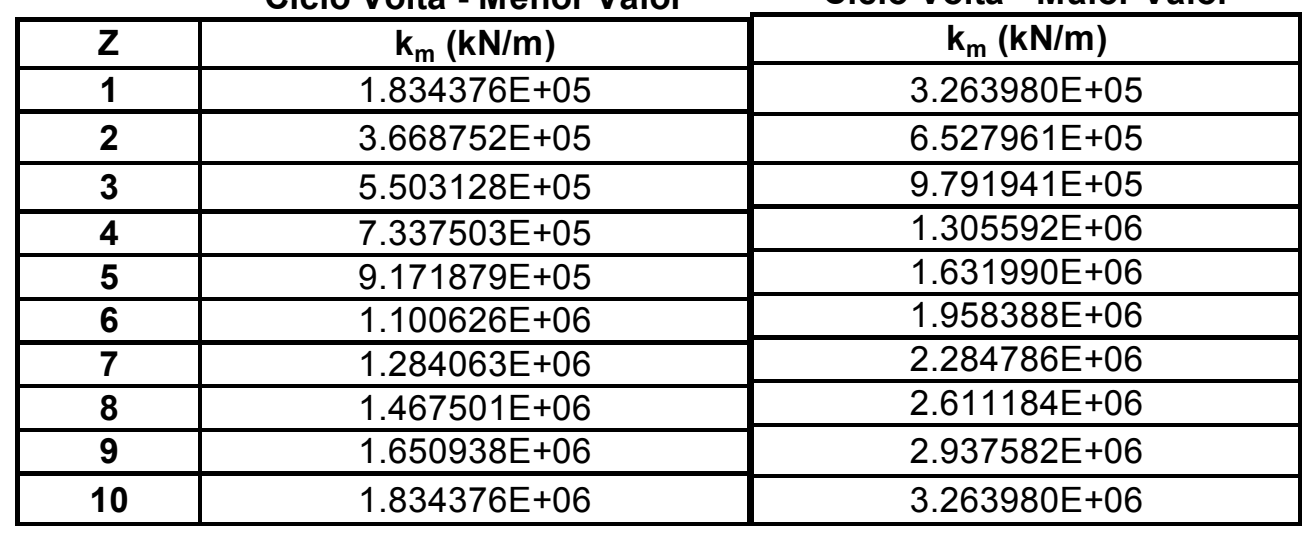

\subsubsection{2.}

\section{Método de Heteny}

Hetenyi (1946) analisou o problema de uma viga sobre apoio elástico, com coeficiente de reação horizontal constante com a profundidade, submetidas a uma força horizontal e a um momento fletor em seu topo.

De acordo com o método, o deslocamento horizontal $y$ do topo da estaca devido a uma força $F$ é dado pela formula abaixo.

$$
y=\frac{2 F \lambda}{k_{z} d}
$$

Onde $k_{z}$ é o coeficiente de reação horizontal, $d$ é o diâmetro da estaca e $\lambda$ é um parâmetro da formulação dado pela equação (3-9).

$$
\lambda=\sqrt[4]{\frac{k_{z} d}{E I}}
$$

Substituindo a equação (3-9) em (3-8) e resolvendo para $k_{z} d$, chega-se à equação $(3-7)$.

$$
k_{2} d=\sqrt[3]{\frac{4 F^{4}}{E I y^{4}}}
$$

Desta equação são conhecidos os parâmetros $E$ e $I$, que dependem do material da estaca e de sua geometria, e os valores de $F$ e $y$, que são obtidos do ensaio de carregamento horizontal descrito anteriormente. 
Com os resultados indicados na Tabela 3-7, pode-se então calcular o valor de $k_{z} \mathrm{e}$ consequentemente os valores do coeficiente de mola horizontal $k_{m}$ ao longo da profundidade da estaca.

Os valores desses parâmetros e a forma como foram utilizados nos testes estão apresentados em detalhe no item 6.4, o qual trata do modelo em que se avalia a resposta do sistema quando $k_{m}$ é constante com a profundidade.

\section{4 . \\ Instrumentação}

A percepção de movimentos indesejáveis no sistema quando do início dos testes de comissionamento dos equipamentos exigiu que se lançasse mão da instrumentação de modo a confirmar as suspeitas de mau funcionamento do conjunto e a magnitude das vibrações.

O consórcio responsável pelo projeto e execução da unidade industrial contratou uma empresa especializada em manutenção industrial para a realização dos serviços de fornecimento e instalação de instrumentos e a coleta dos dados de vibração em pontos da estrutura de suporte do compressor.

A metodologia seguida por essa empresa consistiu em três etapas. Na primeira etapa foram analisados todos os dados referentes aos equipamentos, tais como características físicas, funcionamento, componentes e, principalmente, a freqüência de operação do compressor.

$\mathrm{Na}$ segunda etapa, foram escolhidos os pontos potencialmente críticos para a instalação dos instrumentos de coleta de dados, nos quais as medições envolveriam as três direções no sistema de coordenadas cartesianas. Um dos instrumentos, o acelerômetro fixo, foi posicionado em um ponto da estrutura no nível de assentamento do motor elétrico, enquanto o outro acelerômetro era movimentado e posicionado por todos os 56 pontos de medição pré-selecionados da estrutura. Portanto, todas as medições foram feitas tendo como referência o ponto fixo.

Abaixo pode ser visto o croqui do sistema Estrutura-Equipamento com o ponto fixo (Pto 1) e os pontos de localização dos instrumentos. O bloco preto representa o motor elétrico, o bloco azul representa o compressor, o bloco cinza-escuro representa o skid metálico e a estrutura de suporte é representada pela cor cinza-claro. Deve-se ressaltar que a numeração utilizada no croqui mencionado é independente de qualquer outra numeração utilizada no modelo computacional a ser descrito no capitulo 5. 
$\mathrm{Na}$ terceira e última etapa, que consiste basicamente em uma fase de pósprocessamento, os dados coletados em campo, especificamente velocidades, são então exportados para um software capaz de representá-los visualmente através da animação do conjunto Estrutura-Equipamento em pleno funcionamento. Além do comportamento do sistema no domínio do tempo, nessa fase podem ser construídos espectros de vibração $(r m s)$ em pontos específicos do conjunto, ou seja, é possível simular qual o valor médio da amplitude de deslocamento - ou de outra variável dinâmica - para diversos valores de freqüência que não somente a de operação do compressor.
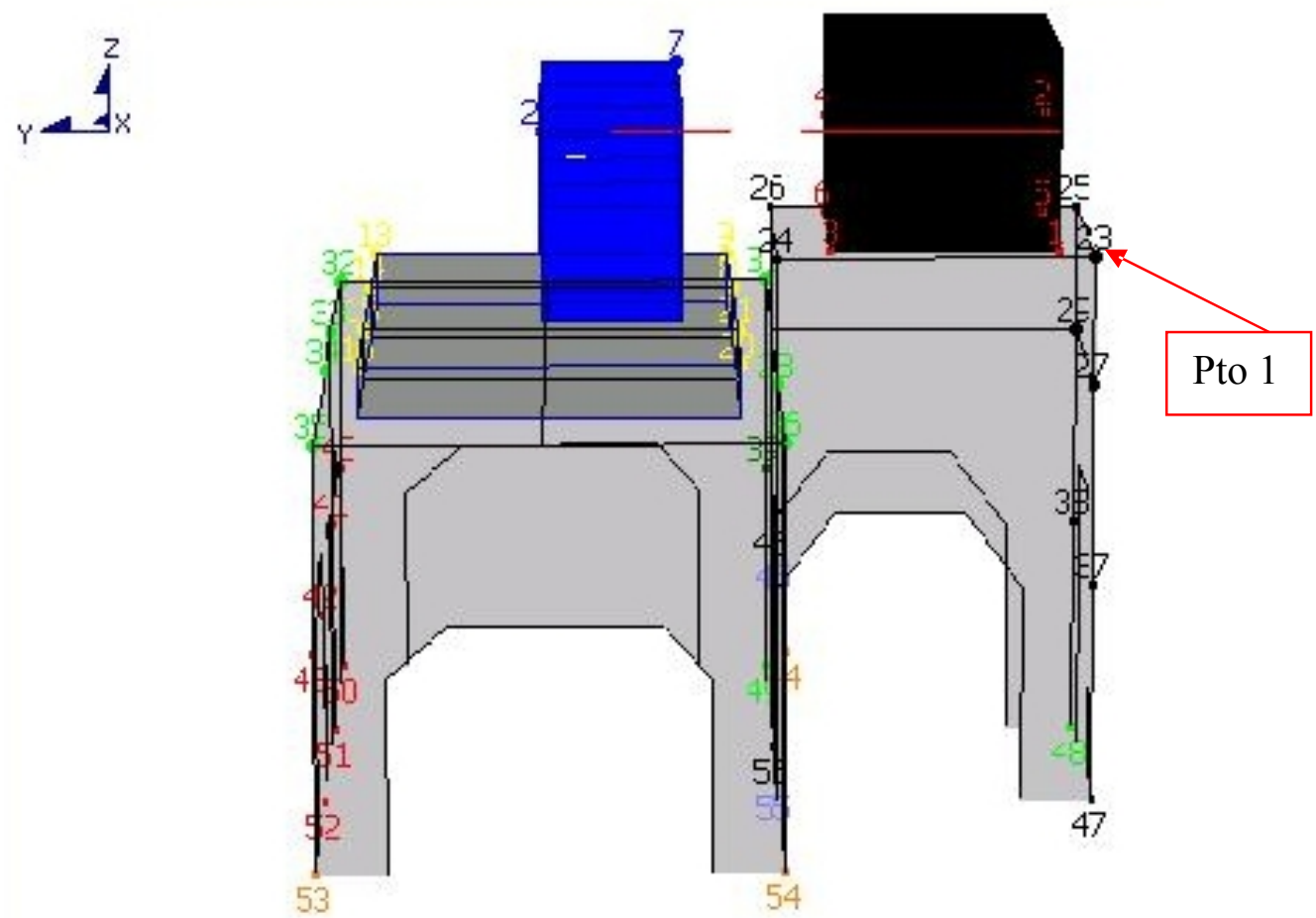

Figura 3-21 - Croqui com os pontos de medição de vibração

Os equipamentos utilizados para o processo de aquisição de dados de campo foram um Coletor e Analisador de Espectros modelo CSI 2120A de dois canais, acelerômetros, cabos e programa computacional RBMware de análise de dados de vibração.

Conforme menciona a norma brasileira ABNT NBR 10082 (1987), a velocidade de vibração é um parâmetro significativo para caracterização da severidade da vibração da máquina.

A Figura 3-22 apresenta as amplitudes das velocidades de vibração $r m s$ (em $\mathrm{mm} / \mathrm{s}$ ) na estrutura de apoio do compressor. Os pontos de coleta de dados foram locados em todos os pilares da estrutura, mais precisamente em dois pontos específicos: o 
primeiro ponto a $0,10 \mathrm{~m}$ do nível do terreno $($ Ponto baixo $=\mathrm{Pb})$ e o segundo a $2,00 \mathrm{~m}$ do nível do terreno $($ Ponto alto $=\mathrm{Pa}$ ). Os retângulos contendo os valores de amplitude de velocidade de vibração representam os pilares da estrutura.

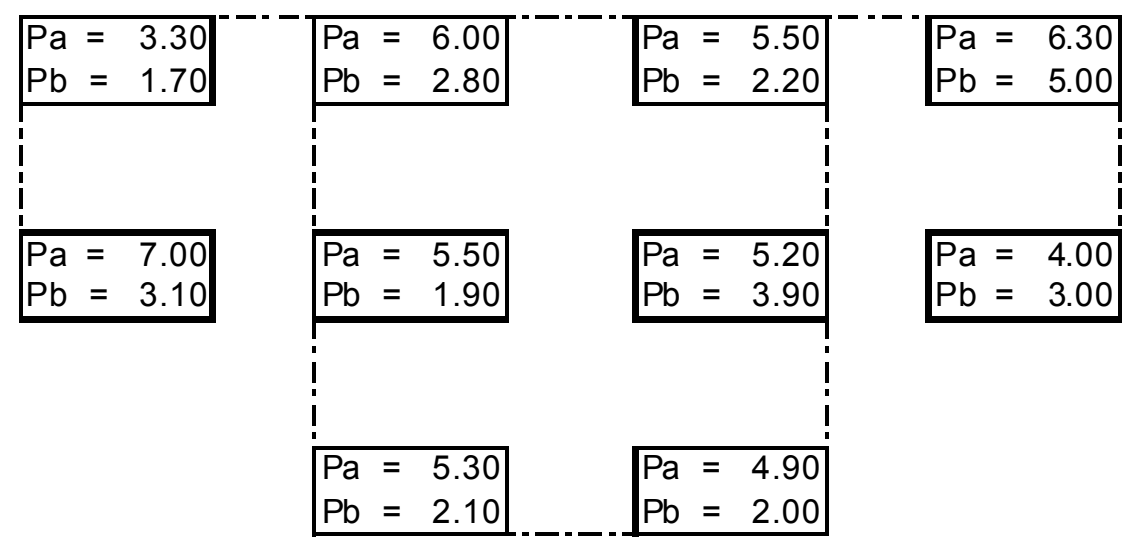

Figura 3-22 - Amplitude das Velocidades de Vibração (mm/s) - Pontos localizados nos pilares

Para a realização de testes e estudos a partir de um modelo matemático de um sistema dinâmico, primeiramente tal modelo deve ter sua confiabilidade garantida. A avaliação da confiabilidade pode ser feita através de comparações de algum parâmetro especifico típico do sistema analisado (protótipo ou modelo físico) com o mesmo parâmetro do modelo matemático-computacional desenvolvido, consistindo em um processo de calibração. No caso de estudos de dinâmica de estruturas, é comum a calibração do modelo através da comparação entre, por exemplo, as freqüências naturais do sistema obtidas de um ensaio de campo conhecido como teste modal e as correspondentes freqüências naturais obtidas do modelo matemático. Seguindo essa metodologia, WU (2004) e STEINWENDER ET AL (1987) realizaram testes modais em uma estrutura de ponte rolante e em suportes de tubulação, respectivamente.

No presente trabalho, o modelo teve a velocidade efetiva $(r m s)$ como parâmetro de calibração. 


\section{4 Modelos simplificados massa-mola}

Neste capítulo serão apresentadas análises de vibração livre do caso estudado a partir de três métodos consagrados na literatura aplicados às estruturas aporticadas. Os dois primeiros métodos, de Rausch (1959) e de Barkan (1962), não levam em consideração a influência do solo na resposta dinâmica do sistema. O terceiro método, proposto por Chowdhury (1984), inclui na analise de vibrações a interação soloestrutura e seus efeitos sobre o sistema.

\section{1.}

\section{Método de Rausch}

Rausch (1959) propôs um modelo matemático para determinação da freqüência natural do sistema no qual as massas de cada um dos pórticos transversais que compõem a estrutura, bem como as massas das vigas longitudinais que se ligam a esses pórticos transversais e a massa do conjunto mecânico são consideradas concentradas sobre os pilares que as sustentam, tendo assim apenas 2 graus de liberdade desacoplados (translação vertical e horizontal). $O$ modelo assume também que as fundações são rígidas suficientes de modo que não há deslocamentos da infra-estrutura e, portanto, sem interação solo-estrutura. Além disso, o método não tem como objetivo calcular as amplitudes de vibração, se prestando apenas a verificação de condições de ressonância.
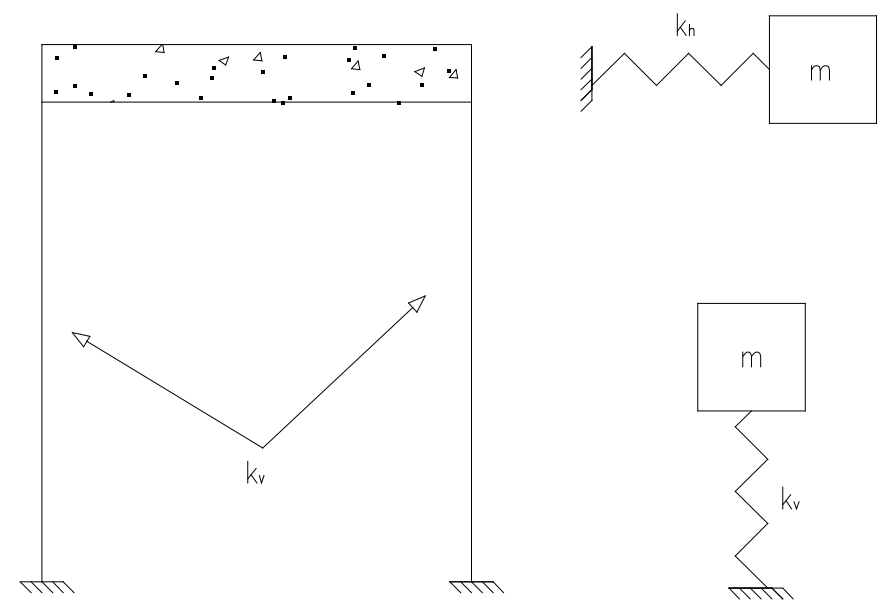

Figura 4-1 - Pórtico transversal típico e modelos Massa-Mola horizontal e vertical 


\subsection{1.}

\section{Freqüências naturais referentes aos modos na direção vertical}

$\mathrm{Na}$ direção vertical, a freqüência natural do sistema $\omega_{n v}$ é definida como sendo a média das freqüências naturais individuais de todos os $N$ pórticos que formam o sistema estrutural.

$$
\omega_{n v}=\frac{1}{N} \sum_{i=1}^{N} \omega_{n v i}
$$

$\mathrm{Na}$ direção vertical, a freqüência natural de um pórtico é dada pela equação abaixo.

$$
\omega_{n v i}=\sqrt{\frac{k_{v}}{m}}=\sqrt{\frac{k_{v} g}{W}}
$$

onde $k_{v}$ é a rigidez vertical de um pórtico, $g$ é a aceleração da gravidade, $m$ e $W$ são a massa e o peso agindo na direção vertical, respectivamente.

A deformação $\delta_{v}$ de uma mola com rigidez $k_{v}$ suportando um peso $W$ é dada pela equação (4-3). Nesse caso, a deformação $\delta_{v}$ corresponde à deformação total da viga transversal de cada pórtico, calculada no ponto médio de seu vão.

$$
\delta_{v}=\frac{W}{k_{v}}
$$

Portanto, a freqüência natural em Hertz correspondente ao modo de vibração na direção vertical de um pórtico pode ser dada pela equação (4-4).

$$
\omega_{n v i}=\frac{1}{2 \pi} \sqrt{\frac{g}{\delta_{v}}}
$$

\subsection{2.}

\section{Freqüências naturais referentes aos modos na direção horizontal}

De forma semelhante à obtenção da freqüência natural do sistema na direção vertical, a determinação da freqüência natural correspondente ao modo horizontal leva em conta um sistema massa-mola de um grau de liberdade em que sua rigidez corresponde ao somatório das rigidezes horizontais de cada um dos pórticos do sistema estrutural e sua massa corresponde à soma das massas da laje de apoio dos equipamentos com a massa dos próprios equipamentos.

A rigidez horizontal de um dado pórtico é calculada considerando que a massa do sistema $m$ (laje e equipamentos), concentrada na extremidade de uma viga em balanço, 
sofre um deslocamento pela ação da gravidade. Assim, o valor da rigidez horizontal desse pórtico $k_{h i}$ é dado pela equação (4-5)

$$
k_{h i}=\frac{12 E I_{p}}{H^{3}}\left(\frac{6 \psi+1}{3 \psi+2}\right)
$$

Onde $\psi$ é dado pela equação (4-6), em que $I_{b}$ e $I_{p}$ são os momentos de inércia da viga transversal e do pilar ou coluna, respectivamente, e $L$ e $H$ são o comprimento da viga transversal e a altura do pilar, respectivamente.

$$
\psi=\frac{I_{b} H}{I_{p} L}
$$

Portanto, a freqüência natural na direção horizontal em $\mathrm{rad} / \mathrm{s}$ do modelo simplificado massa-mola pode ser dada pela equação (4-7).

$$
\omega_{n h}=\sqrt{\frac{\sum_{i=1}^{N} k_{h i}}{m}}=\sqrt{\frac{g}{W} \sum_{i=1}^{N} k_{h i}}
$$

Onde $N$ é o numero de pórticos que formam o sistema estrutural.

\subsection{3. \\ Determinação das freqüências naturais do modelo estudado}

Com auxilio do programa de computação simbólica $M A P L E \AA$, foi escrita uma rotina para o cálculo da freqüência natural vertical e horizontal pelo método de Rausch (1959). A Tabela 4-1 resume os dados de geometria de cada um dos pórticos componentes do sistema estrutural analisado, bem como as massas equivalentes suportadas por eles. A rigidez de cada pórtico, nas duas direções consideradas, também está apresentada na tabela. Os dados de geometria estão expressos em metros, as massas em $\mathrm{kg}$ e as rigidezes em $\mathrm{N} / \mathrm{m}$.

Tabela 4-1 - Dados dos pórticos componentes do sistema estrutural

\begin{tabular}{|c|c|c|c|c|c|c|c|c|}
\hline \multirow{3}{*}{ Pórtico } & \multicolumn{3}{|c|}{ Viga Transversal } & \multicolumn{2}{c|}{ Pilar } & \multicolumn{2}{c|}{ Rigidez } \\
\cline { 2 - 5 } & $\begin{array}{c}\text { Menor } \\
\text { dimensão }\end{array}$ & $\begin{array}{c}\text { Maior } \\
\text { dimensão }\end{array}$ & Comprimento & \multicolumn{2}{|c|}{} & \multirow{2}{*}{ Massa } & & Horizontal \\
\hline $\mathbf{1}$ & 0.6 & 1.2 & 3.3 & 0.6 & 0.6 & 14380.61 & $2.199760000 \mathrm{E}+09$ & $7.360090000 \mathrm{E}+07$ \\
\hline $\mathbf{2}$ & 0.6 & 1.4 & 3.3 & 0.6 & 0.6 & 25929.21 & $2.210770000 \mathrm{E}+09$ & $7.487980000 \mathrm{E}+07$ \\
\hline $\mathbf{3}$ & 0.6 & 1.4 & 3.3 & 0.6 & 0.6 & 25929.21 & $2.210770000 \mathrm{E}+09$ & $7.487980000 \mathrm{E}+07$ \\
\hline $\mathbf{4}$ & 0.6 & 1.2 & 3.3 & 0.6 & 0.6 & 14280.61 & $2.218720000 \mathrm{E}+09$ & $7.360090000 \mathrm{E}+07$ \\
\hline
\end{tabular}


As duas freqüências naturais, correspondentes aos modos de vibração na direção vertical e na direção horizontal, foram então calculadas. A Tabela 4-2 a seguir apresenta os resultados obtidos.

Tabela 4-2 - Resultados para as freqüências naturais - Modelo de Rausch

\begin{tabular}{|c|c|}
\hline Modo de Vibração & Frequência Natural $\mathbf{( H z )}$ \\
\hline Horizontal & 9.67 \\
\hline Vertical & 61.28 \\
\hline
\end{tabular}

\section{2.}

\section{Método de Barkan}

Com base no método de Rausch (1959), Barkan (1962) propôs um modelo matemático para determinação da freqüência natural do sistema considerando um conjunto de duas massas e duas molas.

A primeira das massas do modelo corresponde à soma entre a massa do equipamento e uma fração da massa da viga transversal do pórtico. A segunda massa do modelo corresponde à soma entre a massa da viga longitudinal ligada ao pórtico transversal, uma fração da massa da viga transversal do mesmo pórtico e uma fração da massa do pilar.

Em relação às molas, a primeira delas equivale à rigidez à flexão da viga transversal do pórtico e a segunda equivale à rigidez axial dos pilares.

Além disso, como no método de Rausch (1959), o modelo assume que as fundações são rígidas suficientes de modo que não há deslocamentos da infra-estrutura e, portanto, sem interação solo-estrutura.

No método de Barkan (1962), as freqüências naturais correspondentes aos modos de vibração vertical podem ser apenas obtidas para cada um dos pórticos individualmente, não permitindo o calculo para o sistema estrutural como um todo. Dessa forma, uma vez que um dos interesses aqui é comparar os resultados dos métodos de analise de vibração para o modelo global, nesse capitulo serão apenas obtidas as freqüências naturais correspondentes aos modos de vibração horizontal. 


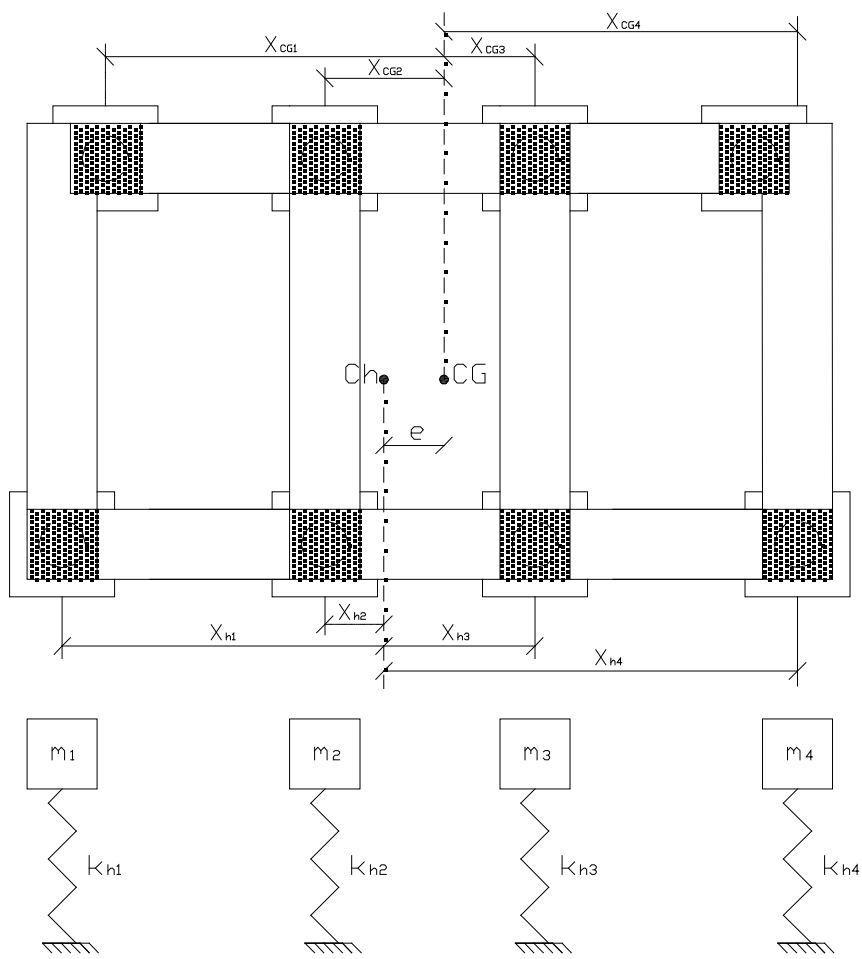

Figura 4-2 - Modelo Massa-Mola para movimento na direção horizontal

\subsection{1. \\ Freqüências naturais referentes aos modos na direção horizontal}

A determinação da freqüência natural na direção horizontal leva em conta um sistema massa-mola com dois graus de liberdade: translação horizontal $(x)$ e rotação no plano $(\varphi)$.

Novamente, a rigidez resultante do sistema corresponde ao somatório das rigidezes horizontais de cada um dos pórticos, e a massa resultante corresponde à soma das massas da laje de apoio dos equipamentos com a massa dos próprios equipamentos.

$$
\begin{gathered}
k h=\sum_{i=1}^{N} k_{h i} \\
m=\sum_{i=1}^{N} m_{i}
\end{gathered}
$$

Os parâmetros $m_{i}$ e $k_{h i}$ são dados pelas equações abaixo.

$$
\begin{gathered}
m_{i}=m_{0 i}+m_{b i}+0.3 m_{p i}+m_{L i} \\
k_{h i}=\frac{12 E I_{p}}{H^{3}}\left(\frac{6 \psi+1}{3 \psi+2}\right)
\end{gathered}
$$


onde $m_{i}$ é a massa total de um dado pórtico, $m_{b i}$ é a massa da viga transversal, $m_{p i}$ é a massa dos pilares, $m_{0 i}$ é a massa do equipamento suportado pela viga transversal e $m_{L}$ é a massa da viga longitudinal ligada ao pórtico. Os parâmetros da expressão da rigidez horizontal são definidos exatamente como no método de Rausch (1959).

Na formulação de Barkan (1962), três novos parâmetros são considerados: $e, J_{\Phi} \mathrm{e}$ $\gamma$. O parâmetro $e$ corresponde a distância, no plano, entre os centros de gravidade e de rigidez do sistema estrutural. $J_{\Phi}$ é o momento de inércia de massa e $\gamma$ é o momento de inércia de rigidez do sistema estrutural.

$$
\begin{gathered}
J_{\Phi}=\sum_{i=1}^{N} m_{i} X_{C G i}^{2} \\
\gamma=\sum_{i=1}^{N} k_{h i} X_{h i}^{2}
\end{gathered}
$$

A equação matricial de movimento do sistema analisado em vibração livre pode ser escrita conforme apresentado a seguir.

$$
\left[\begin{array}{cc}
m & 0 \\
0 & J_{\Phi}
\end{array}\right]\left\{\begin{array}{l}
\ddot{x} \\
\ddot{\varphi}
\end{array}\right\}+\left[\begin{array}{cc}
k_{h} & k_{h} e \\
k_{h} e & k_{h} e^{2}+\gamma
\end{array}\right]\left\{\begin{array}{l}
x \\
\varphi
\end{array}\right\}=0
$$

As duas freqüências naturais acopladas do sistema, na direção horizontal, podem ser obtidas pela extração dos autovalores da equação matricial acima.

\subsubsection{Determinação das freqüências naturais do modelo estudado}

Com auxilio do programa de computação simbólica $M A P L E \AA$, foi escrita uma rotina para o cálculo das freqüências naturais correspondentes aos modos de vibração horizontal. Os dados de geometria, massas equivalentes e rigidezes são idênticos aos apresentados na Tabela 4-1 do item 4.1.3.

As duas freqüências naturais correspondentes aos modos de vibração na direção horizontal, mais precisamente a translação horizontal e a rotação da laje superior em torno de um eixo perpendicular ao seu plano, foram então calculadas. A seguir estão resumidos os resultados obtidos.

Tabela 4-3 - Resultados para as freqüências naturais - Modelo de Barkan

\begin{tabular}{|c|c|}
\hline Modo de Vibração & Frequência Natural (Hz) \\
\hline Translação & 9.67 \\
\hline Rotação & 11.08 \\
\hline
\end{tabular}


Verifica-se pelos resultados anteriores que os valores das freqüências naturais correspondentes ao modo de vibração em que o sistema sofre translação da laje de apoio dos equipamentos resultaram idênticas quando calculadas pelos métodos de Rausch e Barkan.

\section{3.}

\section{Modelo de interação dinâmica estrutura-solo}

As duas metodologias apresentadas anteriormente não levam em conta a participação do solo para efeito da análise dinâmica do sistema estrutura-soloequipamento.

Esses dois métodos foram propostos em uma época em que as máquinas nas plantas industriais eram muito pesadas e robustas, sendo normalmente montadas sobre bases de concreto massivas no nível do solo. É claro que esse tipo de configuração ainda existe, porém é cada vez mais comum a instalação dessas máquinas em estruturas elevadas.

Para o caso de bases massivas apoiadas diretamente no solo ou apoiadas em estacas, devido a sua grande rigidez, tem-se normalmente uma estrutura sobresintonizada e, portanto, menor preocupação com problemas de amplificação dinâmica. Já para o caso de bases apoiadas em pilares, comumente tem-se uma estrutura subsintonizada. É nesse segundo caso em que minimizar a influência do solo na resposta dinâmica do sistema pode levar ao fracasso do projeto.

Assim, um modelo mais racional que considerasse a contribuição do solo na resposta dinâmica de uma estrutura aporticada foi então proposto por Chowdhury (1984).

\subsection{1.}

\section{Freqüências naturais referentes aos modos na direção vertical}

Na direção vertical, o modelo é formado por três massas conectadas entre si por molas cujas rigidezes equivalem à rigidez translacional (constante de mola) do solo na direção vertical $\left(k_{1}\right)$, rigidez axial dos pilares $\left(k_{2}\right)$ do pórtico e a rigidez flexural da viga transversal do mesmo pórtico $\left(k_{3}\right)$. 


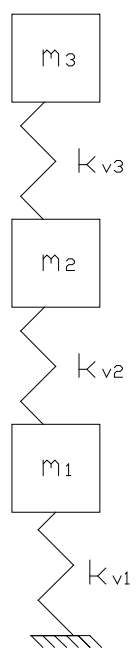

Figura 4-3 - Modelo Massa-Mola para movimento na direção Vertical

As massas $m_{1}, m_{2}$ e $m_{3}$ do modelo são dadas pelas expressões a seguir.

$$
\begin{gathered}
m_{1}=m_{f}+m_{s}+0.30 m_{p} \\
m_{2}=m_{L}+0.25 m_{b}+0.30 m_{p} \\
m_{3}=m_{0}+0.45 m_{b}
\end{gathered}
$$

Onde $m_{f}$ é a massa das fundações no nível do solo, $m_{s}$ é a massa do solo que participa da vibração, $m_{b}$ é a massa da viga transversal do pórtico, $m_{p}$ é a massa dos pilares, $m_{L}$ é a massa da viga longitudinal ligada ao pórtico e $m_{0}$ é a massa do equipamento suportado pela viga transversal.

A rigidez torsional da viga longitudinal ligada ao pórtico transversal é desprezada uma vez que sua magnitude é muito menor que a rigidez flexural da viga transversal e que a rigidez axial do pilar.

De forma semelhante ao método de Rausch (1959), cada pórtico é tratado individualmente e a contribuição de cada um deles é somada ao final do processo de cálculo.

A resultante da rigidez translacional do solo na direção vertical $k_{l}$ é dada pela soma de cada constante de mola do solo considerada no modelo. No caso estudado, considera-se que existe uma mola devido ao solo para cada um dos pilares do sistema estrutural, conforme equação (4-13). 


$$
k_{1}=\sum_{1}^{N} k_{v i}
$$

A rigidez axial resultante dos $N$ pórticos é dada pela equação (4-14).

$$
k_{2}=\sum_{1}^{N} \frac{2 E A_{p}}{H}
$$

A rigidez flexural resultante das vigas transversais dos $N$ pórticos do sistema estrutural é representada pela equação (4-15).

$$
k_{3}=\sum_{i=1}^{N} \frac{1}{\delta_{v i}}
$$

Onde a deformação vertical $\delta_{v i}$ de uma dada viga transversal é dada pela equação (4-16).

$$
\delta_{v i}=\frac{L^{3}}{96 E I_{b}}\left(\frac{1+2 \psi}{2+\psi}\right)
$$

Considerando que as massas se deslocam na direção $z$, a equação matricial de movimento do sistema analisado pode ser escrita conforme apresentado a seguir.

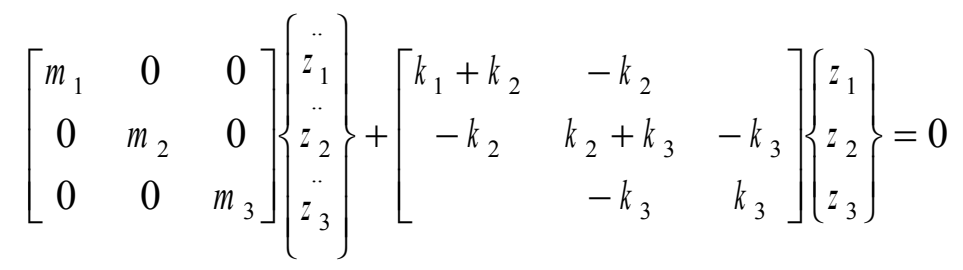

Portanto, três freqüências naturais do sistema na direção vertical podem ser obtidas pela extração dos autovalores da equação matricial acima.

\subsection{2.}

\section{Freqüências naturais referentes aos modos na direção horizontal}

Em comparação com o método de Rausch, que considera um grau de liberdade na direção horizontal, e o método de Barkan, que considera dois graus de liberdade nessa direção, o método proposto por Chowdhury (1984) considera quatro graus de liberdade. Além da translação horizontal $(x)$ e rotação no plano $(\varphi)$ da laje de apoio dos equipamentos, são introduzidas a translação das fundações $(u)$ e um movimento de rotação $(\theta)$ das fundações no plano perpendicular àquele onde ocorre a rotação $\varphi$. A figura apresenta em corte um pórtico típico, destacando-se a laje de apoio, os pilares, a fundação e os graus de liberdade associados. 


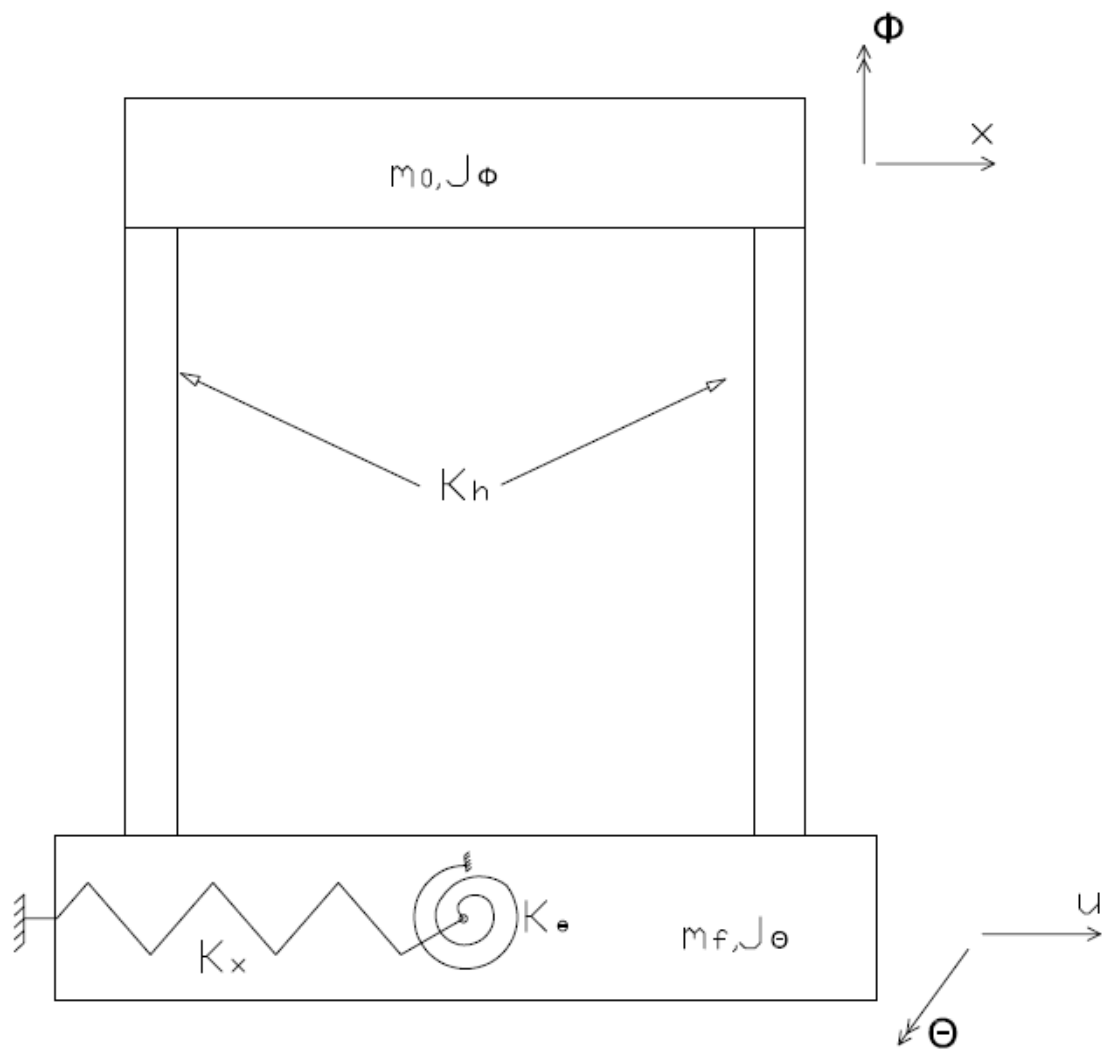

Figura 4-4 - Modelo simplificado de interação solo-estrutura

A equação de movimento desse sistema de quatro graus de liberdade é obtida a partir do principio da conservação da energia formulado por Lagrange, computando-se as energias cinéticas e potenciais do sistema analisado, considerado conservativo, e as coordenadas generalizadas referentes aos graus de liberdade típicos desse sistema. $\mathrm{O}$ funcional de energia correspondente ao sistema analisado é então minimizado, de acordo com o principio de Hamilton, obtendo-se finalmente as equações de EulerLagrange e, conseqüentemente, a equação de movimento do problema.

A dedução da equação do movimento em vibração livre conforme descrito no parágrafo anterior não será feita aqui, de modo que ela está diretamente apresentada a seguir.

$\left[\begin{array}{cccc}m & m e & m & m H \\ m e & J_{\Phi}+m e^{2} & m e & m e H \\ m & m e & m+m & m H \\ m H & m e H & m H & J_{\theta}+m H^{2}\end{array}\right]\left\{\begin{array}{l}\ddot{x} \\ \ddot{\varphi} \\ \ddot{u} \\ \ddot{\theta}\end{array}\right\}+\left[\begin{array}{cccc}k_{h} & 0 & 0 & 0 \\ 0 & k_{h} e^{2}+\gamma & 0 & 0 \\ 0 & 0 & k_{x} & 0 \\ 0 & 0 & 0 & k_{\theta}\end{array}\right]\left\{\begin{array}{l}x \\ \varphi \\ u \\ \theta\end{array}\right\}=0$

Onde $m$ é a massa resultante de todos os componentes suportados pelos pilares, $m_{f}$ é a massa das fundações no nível do solo, e corresponde a distância, no plano, entre os 
centros de gravidade e de rigidez do sistema estrutural, $J_{\Phi}$ é o momento de inércia de massa, $\gamma$ é o momento de inércia de rigidez, $H$ é o comprimento de um pilar, $k_{h}$ é a rigidez resultante do sistema estrutural na direção horizontal, $k_{x}$ é a rigidez resultante translacional do solo na direção horizontal e $k_{\theta}$ é a rigidez rotacional do solo.

Vê-se que pelo fato da matriz de massa ser cheia, as equações do sistema são acopladas.

No caso estudado, devido à presença das estacas e pelo fato dessas estarem embutidas em solo com resistência muito elevada ao longo de sua profundidade, considera-se que as fundações não sofrem rotações segundo o grau de liberdade $\theta$. Portanto, a quarta linha e a quarta coluna das matrizes de massa e de rigidez foram eliminadas.

As três freqüências naturais acopladas do sistema, na direção horizontal, podem ser então obtidas pela extração dos autovalores da equação matricial (4-18).

\subsection{3. Determinação das freqüências naturais do modelo estudado}

Novamente com auxilio do programa de computação simbólica MAPLE®, foi escrita uma rotina para o cálculo das freqüências naturais correspondentes aos modos de vibração do modelo de interação solo-estrutura. Os dados de geometria, massas equivalentes e rigidezes são idênticos aos apresentados na Tabela 4-1 do item 4.1.3.

As três freqüências naturais correspondentes aos modos de vibração do modelo, a saber translação horizontal e rotação da laje superior em torno de um eixo perpendicular ao seu plano, além da translação horizontal das fundações, são então calculadas.

O elemento solo é representado no modelo através de seu coeficiente de mola no nível das fundações. Utilizando-se o modelo proposto por Chowdhury (1984), avalia-se a influencia do parâmetro do solo $k_{m}$ na determinação das freqüências naturais do sistema. Nessa avaliação, são utilizados os coeficientes de mola obtidos por retroanálise no item 3.3.3, referentes ao caso estático e cíclico. No caso em que os coeficientes de mola variam com a profundidade (Modelo de Miche), é considerado apenas o seu valor na superfície do terreno. Os coeficientes de mola obtidos pelo modelo de Hetenyi (1946) também são empregados na análise.

A seguir estão resumidos os resultados obtidos. Os três modos de vibração citados no parágrafo anterior estão associados ao primeiro, terceiro e quarto modos obtidos pelo método de elementos finitos, respectivamente. Essa associação é importante quando se 
compara no capitulo 6 os resultados dos modelos simplificados aos resultados do modelo de elementos finitos.

Tabela 4-4 - Resultados para as freqüências naturais (Hz)- Modelo de Interação Solo-Estrutura

\begin{tabular}{|c|c|c|c|c|}
\hline \multirow{2}{*}{$\begin{array}{l}\text { Modos de } \\
\text { Vibração }\end{array}$} & \multirow{3}{*}{ Característica } & \multicolumn{3}{|c|}{ Caso Estático - Miche } \\
\cline { 3 - 5 } & & Ensaio E-11 & Ensaio E-16 & Ensaio E-03 \\
\cline { 3 - 5 } & & $\mathbf{6 4 9 4 5 9 6 3}$ & $\mathbf{5 0 8 7 9 8 8}$ & $\mathbf{1 6 2 4 9 8 0}$ \\
\hline Modo 1 & Translação Topo & 7,15 & 2,51 & 1,44 \\
\hline Modo 3 & Rotação Topo & 11,14 & 11,06 & 11,05 \\
\hline Modo 4 & Translação Fundação & 17,62 & 14,15 & 13,98 \\
\hline
\end{tabular}

\begin{tabular}{|c|c|c|c|c|c|c|c|c|c|}
\hline \multirow{4}{*}{$\begin{array}{l}\text { Modos de } \\
\text { Vibração }\end{array}$} & \multirow{4}{*}{ Característica } & \multicolumn{6}{|c|}{ Caso Cíclico - Miche } & \multirow{2}{*}{\multicolumn{2}{|c|}{$\begin{array}{c}\text { Caso Cíclico - Hetenyi } \\
\text { Ensaio E-03 }\end{array}$}} \\
\hline & & \multicolumn{4}{|c|}{ Ensaio E-16 } & \multicolumn{2}{|c|}{ Ensaio E-03 } & & \\
\hline & & \multicolumn{8}{|c|}{$\mathrm{km}(\mathrm{N} / \mathrm{m})$} \\
\hline & & 69712699 & 107239928 & 157227329 & 191974275 & 34222409 & 326398034 & 16093599 & 97769351 \\
\hline Modo 1 & Translação Topo & 7,28 & 7,99 & 8,47 & 8,66 & 5,82 & 9,02 & 4,28 & 7,85 \\
\hline Modo 3 & Rotação Topo & 11,14 & 11,17 & 11,19 & 11,20 & 11,11 & 11,23 & 11,08 & 11,16 \\
\hline Modo 4 & Translação Fundação & 17,92 & 20,20 & 23,04 & 24,87 & 15,74 & 31,05 & 14,71 & 19,63 \\
\hline
\end{tabular}

Os resultados apresentados na tabela estão apresentados graficamente abaixo.

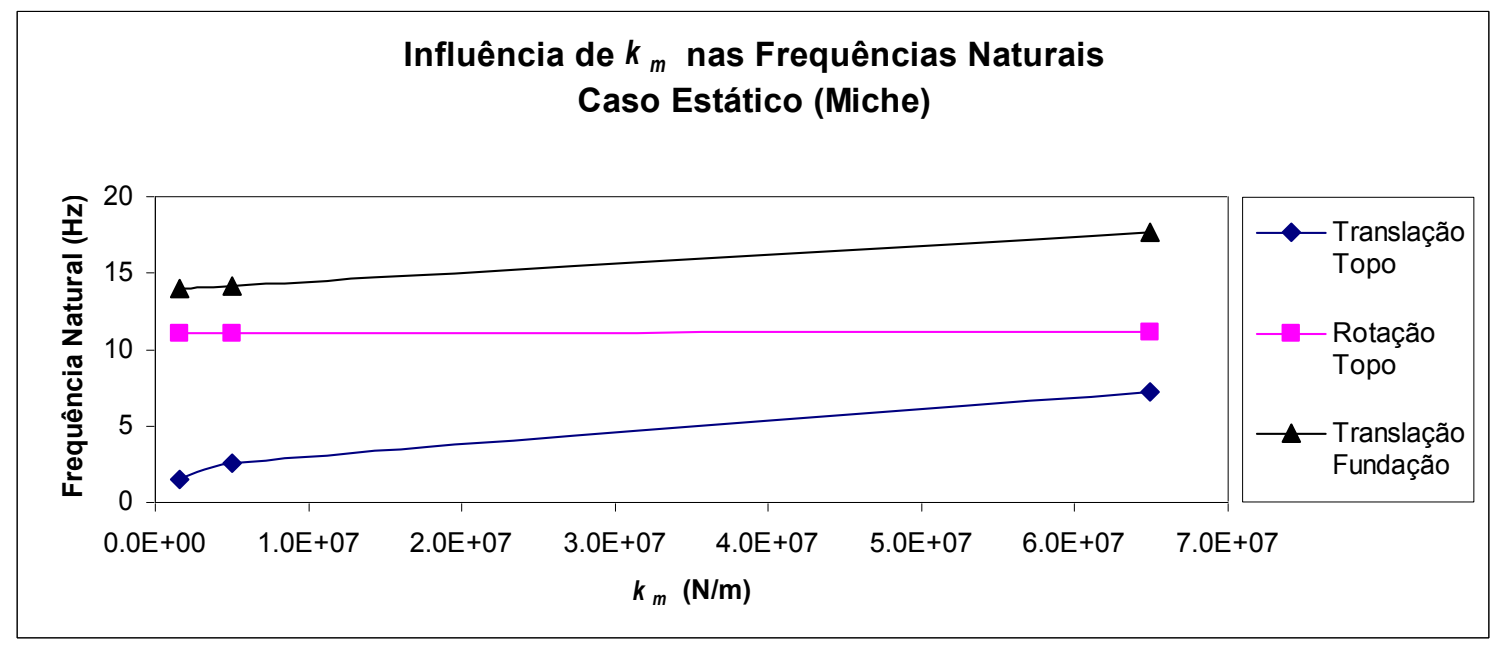

Gráfico 4-1 - Curva Freqüência Natural versus $\boldsymbol{k}_{\boldsymbol{m}}$ - Caso Estático 


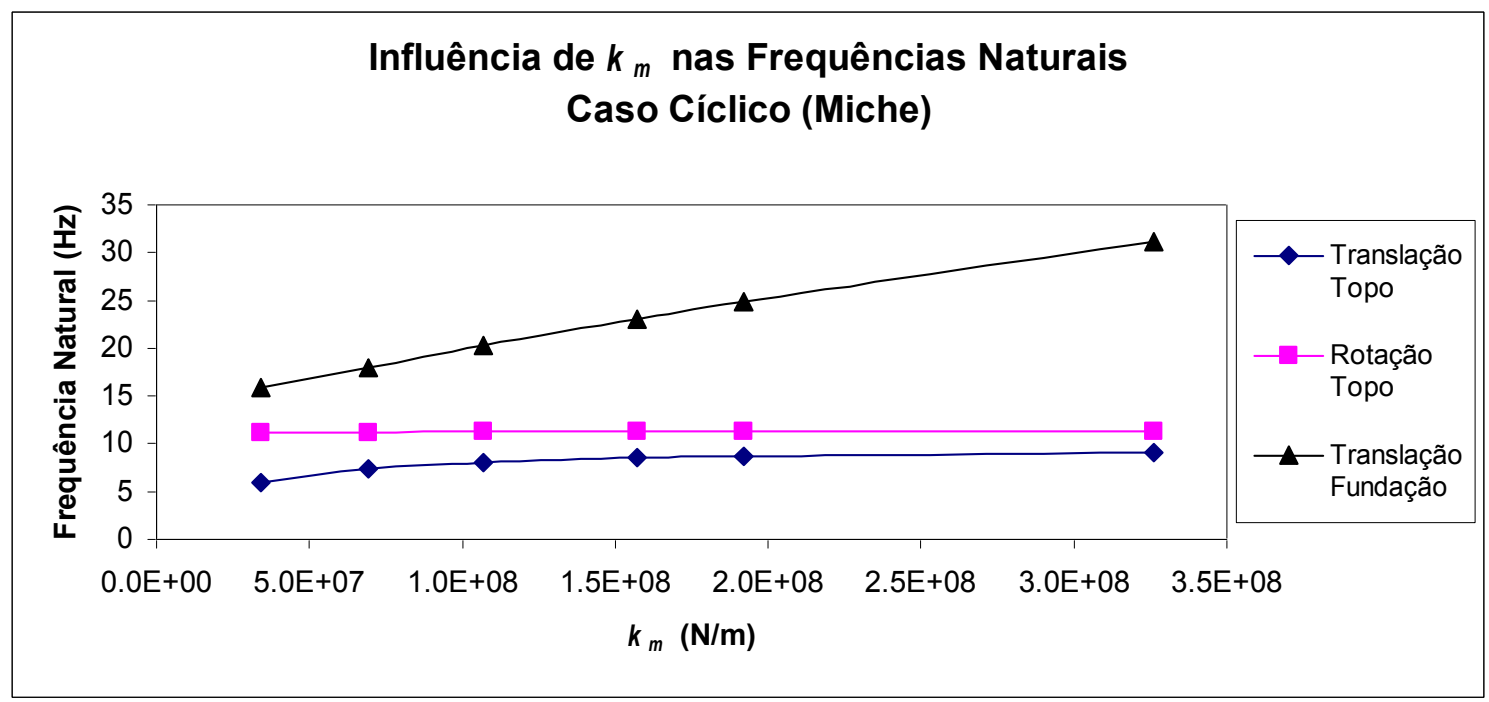

Gráfico 4-2 - Curva Freqüência Natural versus km - Caso Cíclico (Miche)

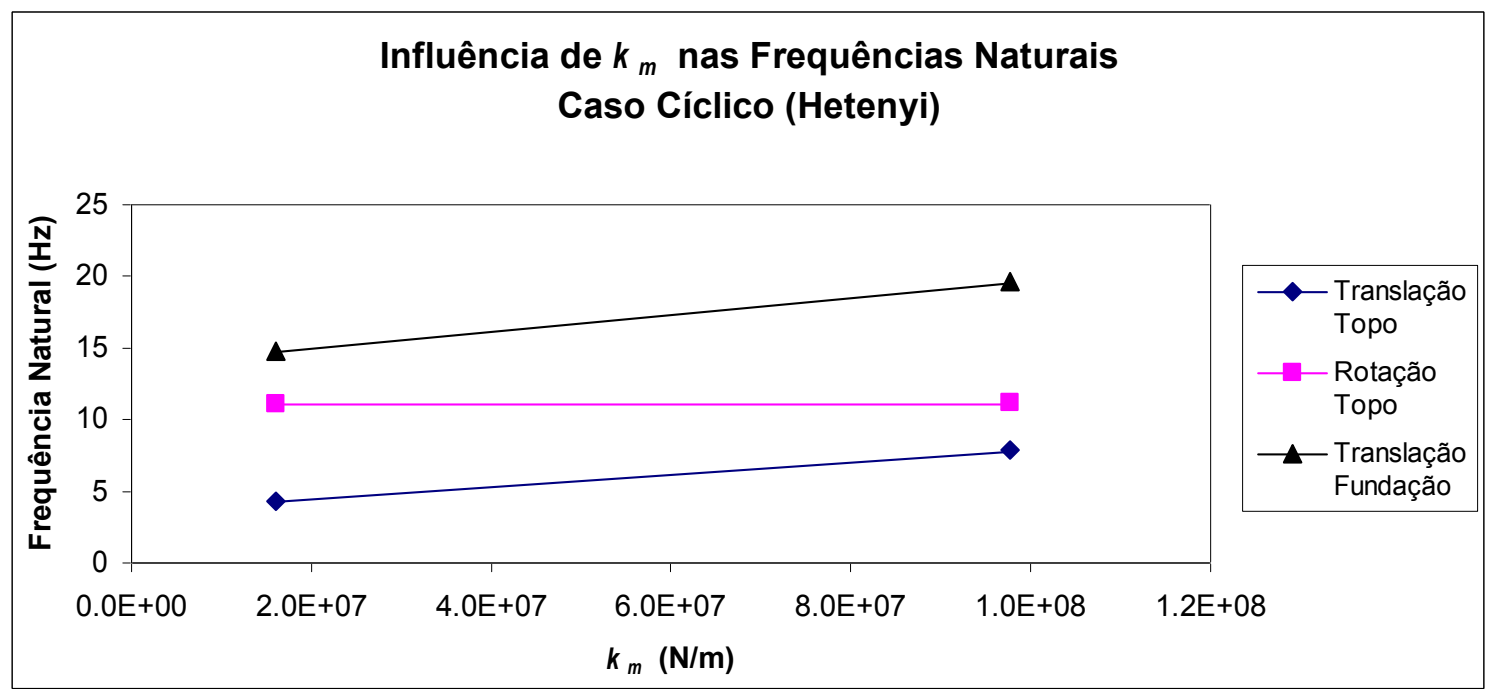

Gráfico 4-3 - Curva Freqüência Natural versus $\boldsymbol{k}_{m}$ - Caso Ciclico (Hetenyi)

As curvas mostradas no Gráfico 4-2 e no Gráfico 4-3 são desenhadas simultaneamente, conforme indicado no Gráfico 4-4. 


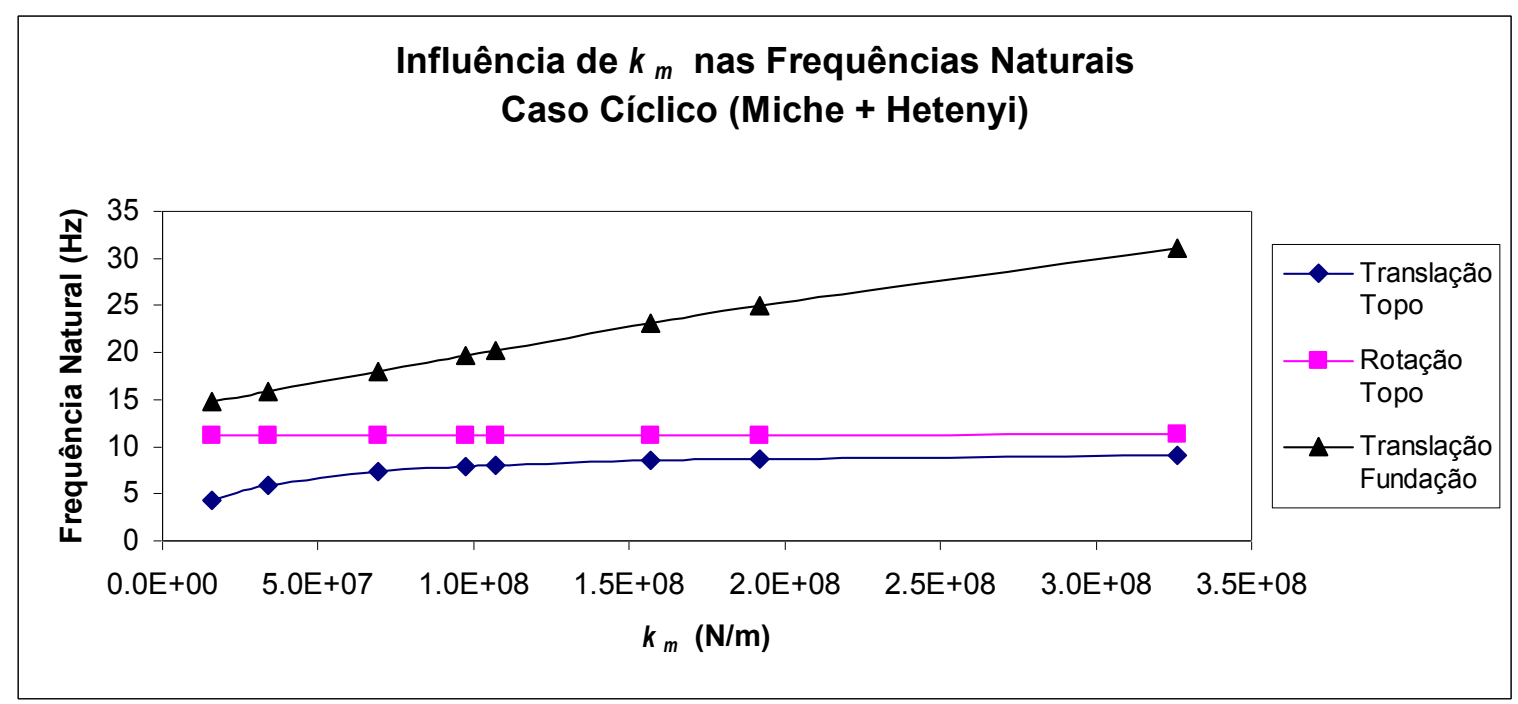

Gráfico 4-4 - Curva Freqüência Natural versus $\boldsymbol{k}_{\boldsymbol{m}}$ - Caso Cíclico - (Miche e

\section{Hetenyi)}

O Gráfico 4-4 mostra que os pontos das curvas Freqüência Natural versus $k_{m}$ correspondentes aos valores de coeficiente de mola constantes com a profundidade recaíram sobre as curvas correspondentes aos valores de coeficiente de mola variáveis com a profundidade, mostrando assim a mesma tendência de variação.

Dentro do intervalo de $16000 \mathrm{kN} / \mathrm{m}$ a $326000 \mathrm{kN} / \mathrm{m}$, as freqüências naturais correspondentes à rotação da laje de apoio dos equipamentos praticamente não sofrem influência do coeficiente de mola, seja ele estático ou cíclico, seja ele constante ou variável com a profundidade. A freqüência natural correspondente a esse modo de vibração é de aproximadamente $11.0 \mathrm{~Hz}$.

Dentro do intervalo de $16000 \mathrm{kN} / \mathrm{m}$ a $326000 \mathrm{kN} / \mathrm{m}$, as freqüências naturais correspondentes à translação da laje de apoio dos equipamentos apresenta maior variação até o valor de $k_{m}$ igual a $97000 \mathrm{kN} / \mathrm{m}$. A partir desse valor e até o limite superior do intervalo analisado do coeficiente de mola, as freqüências naturais sofrem pequena variação, cerca de 14\%, atingindo valor aproximado de $8 \mathrm{~Hz}$.

As duas freqüências notáveis identificadas nos dois parágrafos imediatamente anteriores estão situadas no intervalo de +- $20 \%$ da freqüência de operação do compressor tratado no presente estudo. Uma vez que é sabido sobre os excessos de velocidade de vibração medidas na estrutura estudada, tendo suas partes superiores excitadas sob condições de amplificação consideráveis, pode-se inferir que o modelo simplificado de interação solo-estrutura foi capaz de dar satisfatoriamente indícios de potencial ocorrência de condições de ressonância do sistema avaliado. 
As freqüências naturais correspondentes à translação das fundações sofrem influência significativamente maior em relação às demais freqüências, crescendo aproximadamente de forma linear em função do coeficiente de mola. Essa constatação permite ao projetista lançar mão de alguma estratégia de enrijecimento do solo nos primeiros metros de profundidade de modo a forçar a freqüência natural do sistema a se afastar da freqüência de excitação dos equipamentos dinâmicos. 


\section{5 \\ Modelo numérico-computacional desenvolvido no $A B A Q U S \circledR$}

Neste capítulo será apresentado o modelo numérico-computacional de Elementos Finitos em 3 dimensões do sistema estrutura-solo-equipamento estudado. O modelo foi desenvolvido com base nos elementos disponíveis no programa de análise por elementos finitos $A B A Q U S^{\circledR}$.

Conforme trata o item 3.4 sobre instrumentação, o modelo numéricocomputacional precisa ser calibrado. O processo de calibração do modelo desenvolvido no presente capítulo está apresentado no capitulo 6 seguinte.

Os resultados obtidos a partir do modelo elaborado em elementos finitos serão também comparados com os resultados obtidos a partir dos modelos simplificados massa-mola.

\section{1. Características do modelo numérico-computacional}

Um sistema físico é representado por um modelo numérico-computacional tendo como premissa fundamental a sua compatibilidade com o respectivo protótipo. É fato que para cada representação de um sistema físico por um modelo qualquer, um conjunto de aproximações é feita e, para cada uma delas, a qualidade dos resultados é diretamente influenciada.

De uma forma geral, a modelagem numérico-computacional de um problema de interação estrutura-solo-equipamento não depende apenas dos parâmetros dos elementos do sistema, mas também do tipo de análise desenvolvida (BHATIA, 2008). O Método dos Elementos Finitos (MEF) permite a modelagem da máquina, estrutura, fundação e solo como um conjunto e, conseqüentemente, o comportamento do modelo tende a se tornar o mais próximo do comportamento do seu protótipo, resultando assim em maior confiabilidade.

A estrutura ou superestrutura de suporte dos equipamentos mecânicos foi modelada com dois tipos distintos de elementos. Dada sua característica massiva, as bases propriamente ditas foram modeladas com elementos tipo C3D4 (sólidos 
tetraédricos lineares de 4 nós). Já os pilares e as vigas de travamento no nível das fundações foram modelados com elementos lineares de viga do tipo B31.

As fundações em estacas e sua interação com o solo são modeladas considerando as estacas como elementos lineares de viga e o solo como um conjunto de molas lineares atuando nas duas direções perpendiculares às estacas, cujas constantes são invariantes com a direção em que se deformam e independentes da freqüência de excitação ao qual o solo possa estar submetido. Na direção vertical, as estacas são consideradas fixas. O elemento utilizado para representar as molas é o elemento de conexão SPRING1, o qual possui um dos nós fixo e o outro deslocável. Assim, o solo é considerado um componente essencialmente elástico, sem massa e sem amortecimento.

$\mathrm{Na}$ modelagem dos equipamentos, uma preocupação imediata é a representação do sistema mecânico de tal forma que sua massa seja adequadamente considerada e o correspondente centro de gravidade se ajuste com o do protótipo ou modelo físico. Assim, a modelagem dos equipamentos leva em conta a concentração de suas massas nos respectivos centros de gravidade e a sua ligação com a estrutura através de elementos rígidos de vigas (BHATIA, 2008).

O sistema mecânico, ou seja, o compressor, o motor elétrico e os acessórios são considerados no modelo através de dois tipos de carregamento, um estático e um dinâmico, aplicados em seus centros de gravidade. O carregamento estático corresponde ao peso do compressor, do motor elétrico e dos acessórios em geral, enquanto o carregamento dinâmico corresponde às forças e aos momentos (ou torque) transientes devidos ao compressor alternativo.

Além da participação como carregamento, o sistema mecânico também influencia o comportamento dinâmico do modelo uma vez que ele contribui com a matriz de massa do sistema de equações de movimento. Portanto, para efetivar essa contribuição, foram aplicadas nos centros de gravidade dos equipamentos mecânicos suas respectivas massas. Nesse caso, são utilizados os elementos do tipo MASS, ao qual estão associados 3 graus de liberdade à translação. As massas dos equipamentos estão apresentadas na Tabela 5-1.

Tabela 5-1 - Massas concentradas correspondentes aos equipamentos mecânicos

\begin{tabular}{|l|c|}
\hline \multicolumn{1}{|c|}{ Componentes } & Massa $\mathbf{( k g )}$ \\
\hline Compressor & 10000 \\
Suporte Cilíndrico 1 & 18000 \\
Suporte Cilíndrico 2 & 18000 \\
SKID & 7163 \\
Motor Elétrico & 7000 \\
\hline
\end{tabular}


A Figura 5-1 mostra o aspecto geral do modelo do sistema Estrutura-FundaçãoSolo-Equipamento desenvolvido.

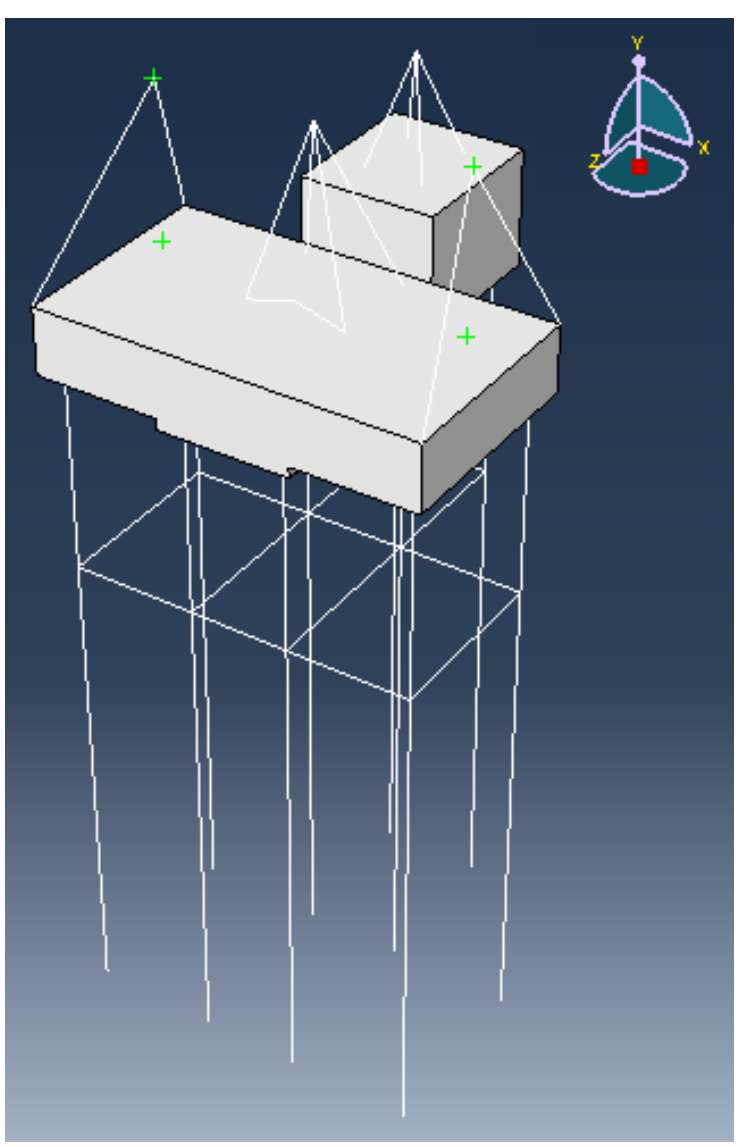

(a)

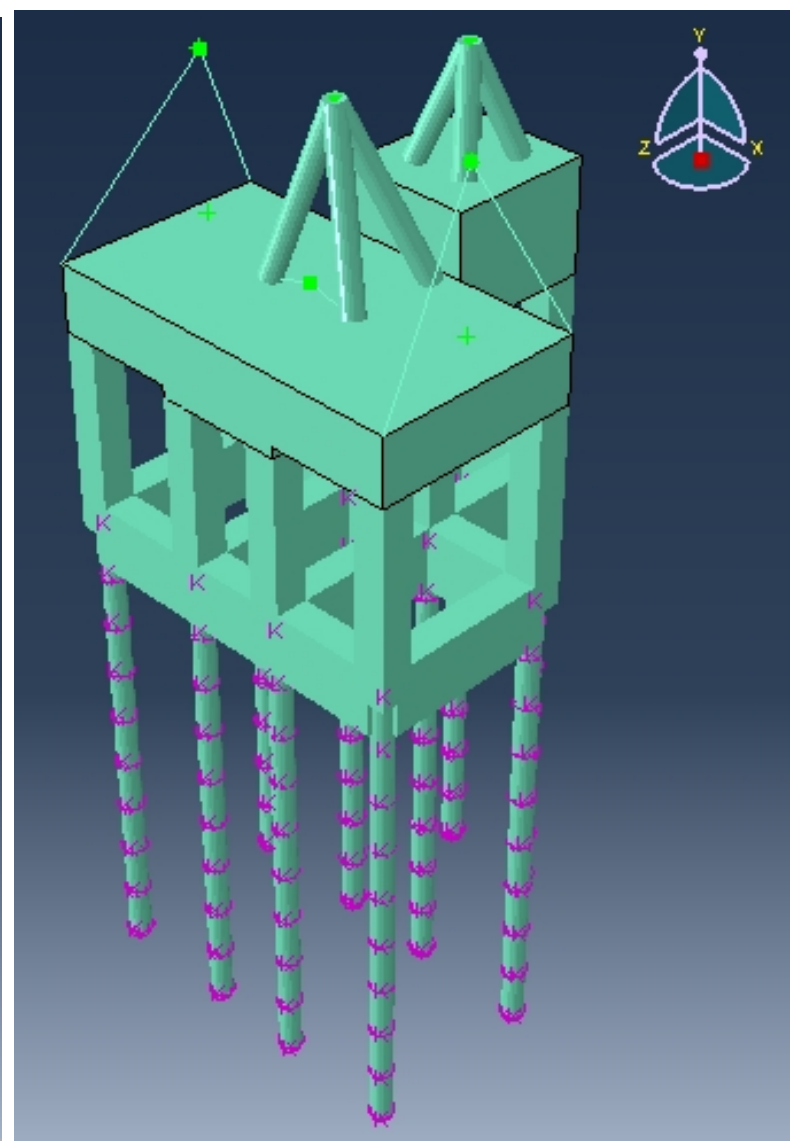

(b)

Figura 5-1 - (a) Modelo 3D do sistema Estrutura-Fundação-Solo-Equipamento feito no software $A B A Q U S \circledR$ (b) Modelo renderizado

Os principais dados de entrada do modelo estão apresentados na Tabela 5-2.

Tabela 5-2 - Dados gerais do modelo computacional em $A B A Q U S \circledR$

\begin{tabular}{|c|c|c|c|c|c|}
\hline \multirow{3}{*}{ Compondentes } & \multirow{3}{*}{ Sub-Componentes } & \multicolumn{3}{|c|}{ Geometria (m) } & \multirow{3}{*}{$\begin{array}{l}\text { Tipo de } \\
\text { Elemento }\end{array}$} \\
\hline & & \multicolumn{2}{|c|}{ Seção } & \multirow[b]{2}{*}{ Diâmetro } & \\
\hline & & $\begin{array}{c}\text { Menor } \\
\text { Dimensão }\end{array}$ & $\begin{array}{c}\text { Maior } \\
\text { Dimensão }\end{array}$ & & \\
\hline \multirow{3}{*}{ Estrutura } & Grelha (Fundações) & 0.6 & 1.2 & - & Viga \\
\hline & \begin{tabular}{|l|} 
Pilares \\
\end{tabular} & 0.6 & 0.6 & - & Viga \\
\hline & Bases & - & - & - & $\begin{array}{l}\text { Sólido Tetraédrico } \\
\text { Linear de } 4 \text { nós }\end{array}$ \\
\hline \multirow{2}{*}{ Fundações } & Estacas & - & - & 0.4 & Viga \\
\hline & Solo & - & - & - & Mola Linear \\
\hline
\end{tabular}




\begin{tabular}{|c|c|c|c|c|c|c|}
\hline \multirow{2}{*}{ Compondentes } & \multirow{2}{*}{ Sub-Componentes } & \multirow{2}{*}{ Material } & \multicolumn{4}{|c|}{ Propriedades Físicas } \\
\hline & & & $\begin{array}{c}\text { Módulo de } \\
\text { Elasticidade }\left(\mathrm{N} / \mathrm{m}^{2}\right)\end{array}$ & $\begin{array}{c}\text { Coeficiente de } \\
\text { Poisson }\end{array}$ & $\begin{array}{c}\text { Peso Específico } \\
\left(\mathrm{N} / \mathrm{m}^{3}\right)\end{array}$ & $\begin{array}{c}\text { Constante de } \\
\text { Mola (N/m) }\end{array}$ \\
\hline \multirow[b]{3}{*}{ Estrutura } & Grelha (Fundações) & \multirow{4}{*}{$\begin{array}{l}\text { Concreto } \\
\text { Armado }\end{array}$} & \multirow{4}{*}{21287367145.8} & \multirow{4}{*}{0.2} & \multirow{4}{*}{25000} & \multirow{4}{*}{-} \\
\hline & Pilares & & & & & \\
\hline & Bases & & & & & \\
\hline \multirow{2}{*}{ Fundações } & Estacas & & & & & \\
\hline & Solo & - & - & - & - & Ver testes \\
\hline
\end{tabular}

No modelo constitutivo do concreto, uma vez que as tensões desenvolvidas na estrutura devidas às condições normais de operação de um equipamento dinâmico são de ordem inferior (BHATIA, 2008), considerou-se que o valor do módulo de elasticidade é independente das deformações, ou seja, adotou-se o módulo de elasticidade estática.

Nesse contexto, o módulo de elasticidade utilizado no modelo foi calculado conforme formulação proposta na norma ABNT NBR 6118 (2007), em função da resistência característica do concreto $f_{c k}$.

$$
E=4760 \sqrt{f c k}
$$

O valor do coeficiente de Poisson foi adotado como sendo 0,2, que corresponde a um valor típico utilizado em projetos de engenharia, principalmente quando as tensões e deformações se relacionam entre si de forma linear (ABNT NBR 6118, 2007). De forma semelhante, o peso especifico do concreto armado adotado, $25 \mathrm{kN} / \mathrm{m}^{3}$, também é um valor típico.

Para a taxa de amortecimento $\xi$ do sistema (incluindo equipamento e fundações), a norma alemã DIN 4024 Part 1 (1988) orienta a utilizar o valor 0,02 quando informações precisas desse parâmetro não estão disponíveis. Esse valor foi empregado no modelo estudado.

\section{2.}

\section{Teste de malha}

Como uma primeira verificação do modelo estudado, foram realizados testes para validação do tamanho da malha e do passo de tempo. Este teste de malha foi realizado com intenção de definir qual seria o maior tamanho de malha que fornecesse os mesmos resultados de uma malha mais refinada. Ou seja, a malha tem o grau de refinamento requerido para não alterar o resultado da resposta dinâmica. Além disso, a malha não deveria ser computacionalmente dispendiosa, de forma a não inviabilizar a simulação. 
O deslocamento na direção $\mathrm{x}$ em dois nós do modelo foi utilizado como parâmetro de teste da qualidade da malha.

$\mathrm{Na}$ Tabela 5-3 estão apresentados os tipos e quantidades de elementos finitos resultantes do teste de refinamento da malha considerada.

Tabela 5-3 - Tipos e quantidade de elementos finitos utilizados para análise modal

\begin{tabular}{|c|c|c|c|}
\hline $\begin{array}{c}\text { Tipo de } \\
\text { Elemento }\end{array}$ & Nomenclatura & $\begin{array}{c}\text { Graus de } \\
\text { Liberdade Total }\end{array}$ & Quantidade \\
\hline Sólido & C3D4 & 3 & 11460 \\
\hline Viga & B31 & 12 & 629 \\
\hline Mola & SPRING1 & 1 & 199 \\
\hline Massa & MASS & 3 & 5 \\
\hline
\end{tabular}

No caso do procedimento para extração das freqüências naturais de vibração e determinação dos respectivos modos de vibração, o maior grau de refinamento da malha não influenciou os resultados. Possivelmente esse comportamento seja devido à grande rigidez de todos os elementos do sistema estrutural.

Assim, para as analises de vibração livre, utilizou-se o modelo com uma malha de elementos finitos menos densa, conforme mostra a Tabela 5-4.

Tabela 5-4 - Tipos e quantidade de elementos finitos utilizados para extração das freqüências naturais e determinação dos modos de vibração do modelo

\begin{tabular}{|c|c|c|c|}
\hline $\begin{array}{c}\text { Tipo de } \\
\text { Elemento }\end{array}$ & Nomenclatura & $\begin{array}{c}\text { Graus de } \\
\text { Liberdade Total }\end{array}$ & Quantidade \\
\hline Sólido & C3D4 & 3 & 3115 \\
\hline Viga & B31 & 12 & 397 \\
\hline Mola & SPRING1 & 1 & 199 \\
\hline Massa & MASS & 3 & 5 \\
\hline
\end{tabular}

Pode-se verificar que, com uma redução de densidade de malha de aproximadamente $70 \%$, a variação percentual entre os autovalores calculados com a malha escolhida para a análise modal e aqueles calculados com a malha indicada na Tabela 5-4 não ultrapassou $0,5 \%$. 


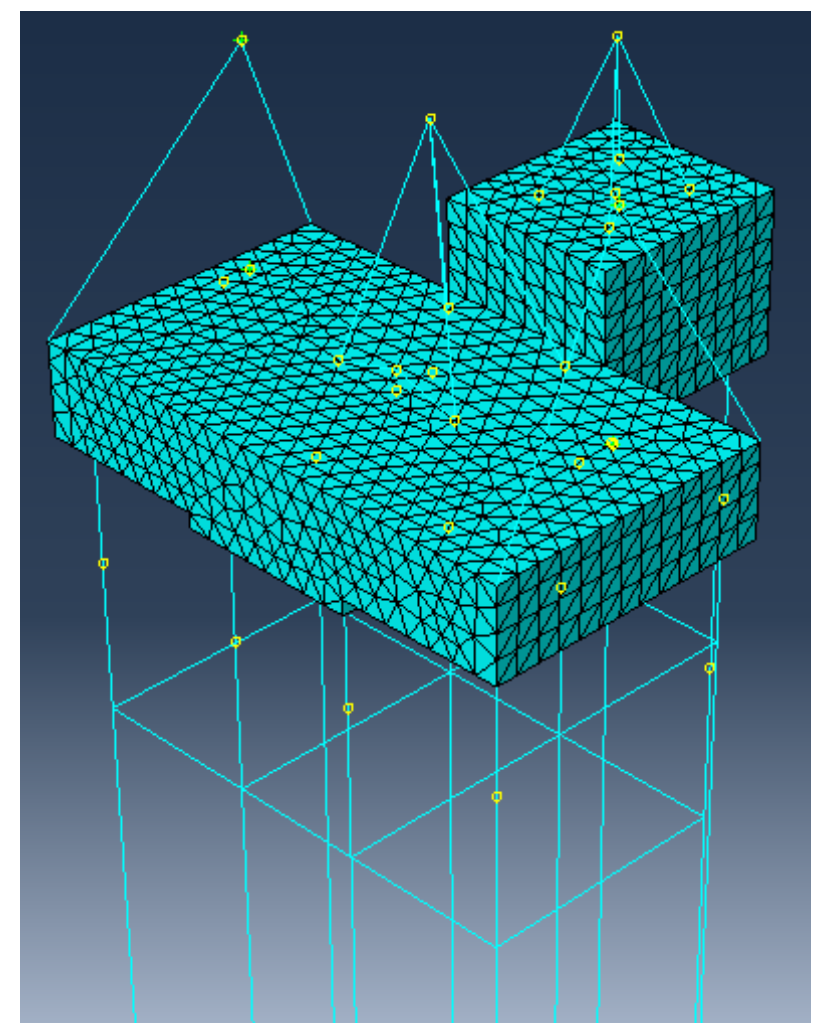

Figura 5-2 - Aspecto geral da malha de elementos finitos gerada para o modelo

\section{3. \\ Definição do passo de tempo}

Após definir o tamanho da malha, deve ser realizada a avaliação do passo de tempo. Para tanto, foi utilizada a malha escolhida para análise modal, conforme o item anterior. Foram realizados testes com três passos de tempo diferentes: $0,005 \mathrm{~s}, 0,0025 \mathrm{~s}$ e $0,00125 \mathrm{~s}$.

A escolha dos três tamanhos do passo de tempo está baseada no período da excitação da vibração forçada de modo que cada um deles corresponde a aproximadamente $5 \%, 2,5 \%$ e $1 \%$ do tamanho do período.

Da mesma forma como é feito no teste de malha, o parâmetro de teste para escolha do tamanho do passo foi o deslocamento na direção $\mathrm{x}$ em dois pontos do modelo. Como resultado, foi definido como passo de tempo $0,0025 \mathrm{~s}$.

\section{4.}

\section{Carregamentos envolvidos}

Conforme já apresentado em itens anteriores, os carregamentos envolvidos no problema são de duas naturezas: estática e dinâmica. 


\subsection{1.}

\section{Carregamento estático}

O carregamento estático aqui é considerado como sendo o peso de todos os componentes do sistema Estrutura-Equipamento. Nesse sentido, o carregamento estático devido aos elementos estruturais é levado em conta no modelo de forma automática uma vez que o $A B A Q U S \AA$ calcula o peso próprio de cada um deles diretamente em função dos dados de geometria e peso especifico do material.

A contribuição dos equipamentos no carregamento estático se dá pela inserção da respectiva força peso no centro de gravidade de cada um deles.

\subsection{2.}

\section{Carregamento dinâmico}

Como visto no item 2.5.1, o problema estudado envolve um sistema submetido a um vetor força de excitação $\underline{F}(t)$ e a um vetor torque de excitação $\underline{\tau}(t)$ causados pelo movimento alternativo dos pistões do compressor. Esses vetores são aplicados no centro de gravidade do compressor. As equações (5-2) e (5-3) representam matematicamente as cargas de excitação do problema estudado.

$$
\begin{aligned}
& \vec{F}(t)=\vec{F}_{01} \cos \omega t+\vec{F}_{02} \cos 2 \omega t \\
& \vec{\tau}(t)=\vec{\tau}_{01} \cos \omega t+\vec{\tau}_{02} \cos 2 \omega t
\end{aligned}
$$

Essas cargas de excitação são aplicadas diretamente no centro de gravidade do compressor, de modo que a força $\underline{F}(t)$ age em um plano horizontal segundo a direção $\mathrm{x}$ do sistema de coordenadas global do modelo e o torque $\underline{\tau}(t)$ atua tanto no plano horizontal como também no vertical. O torque resulta do fato da barra de conexão entre a manivela e o pistão ser excêntrica em relação ao eixo do pistão, tanto no plano que o contém como também fora dele.

As forças e os torques gerados pelo compressor alternativo do estudo são dados fornecidos pelo fabricante do equipamento. As amplitudes das cargas de excitação primárias e secundárias, bem como as correspondentes freqüências de excitação estão apresentadas a seguir.

$$
F_{0 X 1}=17865 \mathrm{~N} \quad \text { (Amplitude da força de excitação primária horizontal) }
$$


$F_{0 \times 2}=2923 \mathrm{~N} \quad$ (Amplitude da força de excitação secundária horizontal)

$$
\omega=9,83 \mathrm{~Hz}
$$

Para o torque $\underline{\tau}(t)$, as amplitudes da excitação atingem os seguintes valores.

$\tau_{0 X 1}=31667 N . m$ (Amplitude do torque de excitação primário horizontal)

$\tau_{0 \times 2}=3620 N . m$ (Amplitude do torque de excitação secundário horizontal)

$\tau_{0 Y 1}=9542 \mathrm{~N} . m$ (Amplitude do torque de excitação primário vertical)

$\tau_{0 Y 2}=0 N . m$ (Amplitude do torque de excitação secundário vertical)

No caso do torque, a freqüência de excitação também é de $9,83 \mathrm{~Hz}$.

A definição da excitação no $A B A Q U S{ }^{\circledR}$ apresenta uma peculiaridade no sentido em que a função matemática que representa a sua forma de variação no domínio do tempo deve ser dada por uma série de Fourier.

Como dado de entrada, é necessário fornecer os valores dos coeficientes $a_{m}$ e $b_{m}$ das séries de Fourier de cosseno e de seno, respectivamente, que representam a função de excitação. Uma vez que a excitação é representada por uma função seno, tem-se diretamente os coeficientes $\mathrm{a}_{\mathrm{m}}$ e $\mathrm{b}_{\mathrm{m}}$, conforme a Tabela 5-5.

Tabela 5-5 - Coeficientes das séries de Fourier de seno e cosseno para a força de excitação

\begin{tabular}{|c|c|c|}
\hline $\mathbf{m}$ & $\mathbf{a}_{\mathbf{m}}$ & $\mathbf{b}_{\mathbf{m}}$ \\
\hline $\mathbf{0}$ & 0 & - \\
\hline $\mathbf{1}$ & 0 & 0 \\
\hline $\mathbf{2}$ & 0 & 1 \\
\hline
\end{tabular}

5.5 .

\section{Analise dinâmica por Superposição Modal}

A análise dinâmica transiente fornece a resposta de um modelo como uma função do tempo baseada em um dado carregamento dependente do tempo. A resposta da estrutura é baseada em um conjunto de modos de vibração do sistema, os quais são extraídos a partir de uma análise de vibração livre prévia e, em seguida, combinados.

Para sistemas lineares, a análise dinâmica por superposição modal implica em muito menos esforço computacional do que métodos de integração direta de todo o sistema de equações. Além disso, sendo o sistema linear e representado corretamente pelos seus modos de vibração, o método de superposição modal é preciso pois a 
integração executada é exata sempre que as funções de carregamento dinâmico variarem linearmente no intervalo de tempo. Nesse sentido, a escolha do tamanho do passo no tempo deve ser consistente com essa condição.

O $A B A Q U S \circledR$ permite que se escolha o número de modos de vibração que se deseja utilizar na análise por superposição modal. Inicialmente, uma vez que não se tinha sensibilidade do número mínimo de modos necessários para promover uma análise adequada, escolheu-se 20 modos que foram obtidos através de um procedimento de extração das freqüências naturais do sistema estrutural analisado.

Para consideração do amortecimento do sistema em uma analise linear por superposição modal, o $A B A Q U S{ }^{\circledR}$ permite a escolha entre quatro tipos: fração do amortecimento critico, amortecimento de Rayleigh, amortecimento modal compósito e amortecimento estrutural. No presente estudo, o amortecimento é considerado em cada modo de vibração do modelo como uma fração do amortecimento crítico, de sorte que contribui somente com os elementos da diagonal do sistema de equações.

A análise dinâmica realizada considera que o sistema apresenta condições iniciais nulas, tanto em relação aos deslocamentos como em relação às velocidades.

No capitulo seguinte a análise dinâmica por superposição modal é então executada de modo a subsidiar o estudo dos parâmetros do problema investigado.

Destaca-se que os estudos estão baseados na avaliação do sistema quando este está sob vibração livre e vibração forcada. 


\section{6 \\ Estudos paramétricos}

Esse capítulo se propõe a descrever os estudos paramétricos realizados a partir do modelo de elementos finitos do sistema interativo estrutura-solo-equipamento-fundação, e dos modelos simplificados massa-mola, além de analisar a influência dos parâmetros identificados no comportamento dinâmico desse sistema.

Dentre os componentes do sistema interativo, a estrutura e o equipamento são aqueles que possuem características bem definidas e de fácil controle, não sendo aqui objetos de análise de sensibilidade. Diferentemente, o solo é o componente que carrega as maiores incertezas em suas características, exigindo assim atenção especial na consideração de suas propriedades em modelos matemáticos analíticos ou numéricos de modo a fazê-los representativos.

Em projetos de fundações de máquinas, ou até mesmo em análises estáticas de estruturas que interagem com o solo, coeficiente de mola linear $k$ é o parâmetro de engenharia mais amplamente utilizado. Isso se deve à sua fácil implementação em modelos simplificados massa-mola e também em modelos de elementos finitos.

Alguns dos principais aspectos que estão relacionados à incorreta interpretação do solo como elemento do sistema são:

- Dados não representativos do subsolo local;

- Falta de conhecimento do nível de deformações ao qual o solo está submetido;

- Falta de dados de ensaios dinâmicos de campo;

- Utilização de parâmetros correlacionados inadequadamente com parâmetros estáticos;

- Inerente heterogeneidade do material.

Assim, uma análise adequada de um problema com tal nível de complexidade preferencialmente se faz para intervalos de valores dentro dos quais são obtidas as melhores estimativas dos parâmetros.

Primeiramente, utilizando-se o modelo de elementos finitos desenvolvido, é avaliada a resposta do sistema para o caso em que não há interação entre a estrutura e o 
solo, ou seja, as fundações são consideradas indeslocáveis. Em seguida, avalia-se a resposta do sistema para cada um dos coeficientes de mola retroanalisados no item 3.3.

Como visto no item 3.4, as velocidades efetivas medidas em campo estão organizadas esquematicamente em retângulos. A esse esquema adiciona-se outra coluna, agora também representando as velocidades efetivas calculadas do modelo de elementos finitos, conforme mostra a Figura 6-1 abaixo. Dessa forma, a primeira linha representa os valores medidos e calculados de velocidade efetiva dos pontos altos $(\mathrm{Pa})$, no topo de cada pilar, e a segunda linha representa os valores medidos e calculados de velocidade efetiva dos pontos baixos $(P b)$, à 0,10 do nível do terreno.

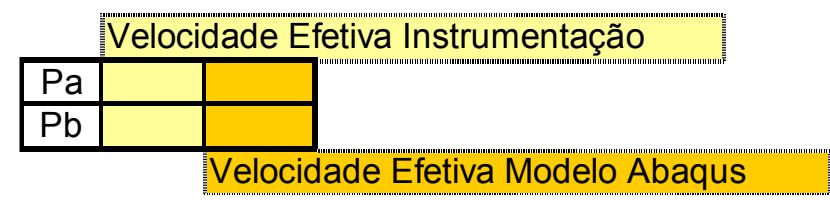

Figura 6-1 - Legenda para a apresentação dos resultados

Para melhor entendimento e visualização, a Figura 6-2 mostra novamente o projeto da estrutura estudada.
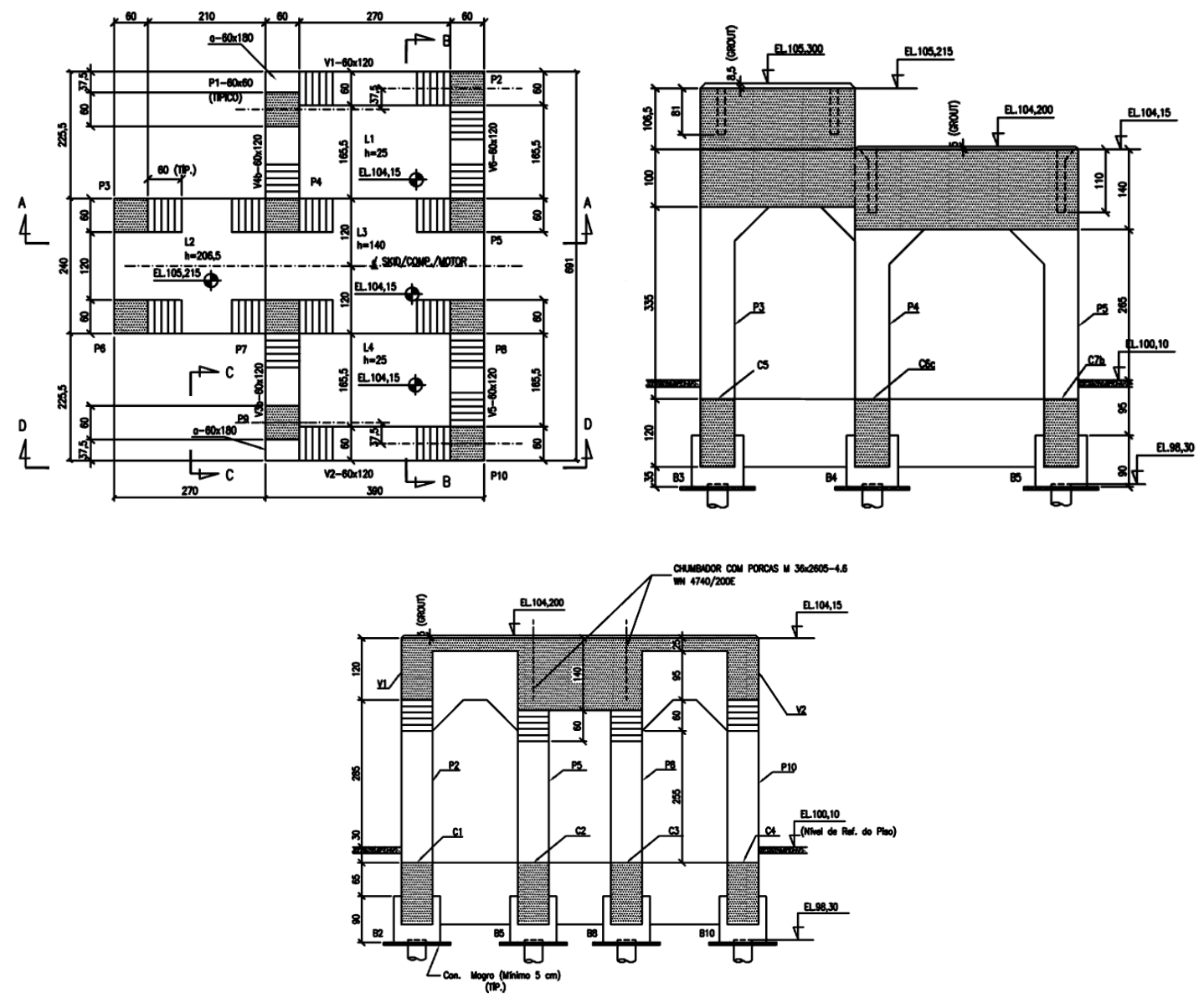

Figura 6-2 - Planta e cortes da estrutura de suporte do compressor 
A magnitude do erro entre os valores medidos e os valores calculados é definida pela equação.

$$
\text { Erro }=\frac{\text { menor }\left(V_{\text {calculada }}, V_{\text {medida }}\right)}{\text { maior }\left(V_{\text {calculada }}, V_{\text {medida }}\right)} \times 100
$$

A medida do erro foi calculada em cada uma das simulações, para cada ponto de controle da estrutura (pontos de medição de velocidade efetiva). A partir das medidas individuais do erro, foram calculados os erros médios correspondentes aos pontos de controle $P a$ e aos pontos de controle $P b$, além do erro médio global correspondente a todos os pontos de controle.

Barkan (1962) realizou vários testes de campo para determinação do coeficiente de mola $k_{m}$ do solo no caso de fundações diretas, e também testes dinâmicos de campo para determinação das freqüências de ressonância dos mesmos tipos de fundações. Utilizando em um modelo massa-mola não-amortecido os valores dos coeficientes de mola determinados em campo, ele calculou as freqüências de ressonância para o sistema e as comparou com as freqüências de ressonância medidas em campo. Barkan (1962) então concluiu que as freqüências calculadas a partir do modelo massa-mola resultaram dentro de um intervalo de $85 \%$ a $121 \%$ da magnitude da freqüência ressonante medida em campo, intervalo esse considerado por ele aceitável do ponto de vista do ajuste entre o modelo e o protótipo.

No presente trabalho, apesar da grandeza dinâmica utilizada para avaliação da resposta dos modelos não ser a freqüência ressonante, e sim as velocidades efetivas de vibração, considera-se como aceitável um erro percentual da mesma ordem de grandeza daquele considerado por Barkan (1962), ou seja, $\pm 20 \%$ do valor medido.

$\mathrm{Na}$ apresentação dos resultados, os valores destacados na cor verde são aqueles que atendem ao limite aceitável estabelecido para o erro. Ao contrário, os valores destacados em vermelho correspondem àqueles que não estão dentro dos limites aceitáveis.

\section{1.}

\section{Teste 1: modelo com base indeslocável}

A Figura 6-3 apresenta a comparação entre as velocidades medidas e calculadas para o compressor. 


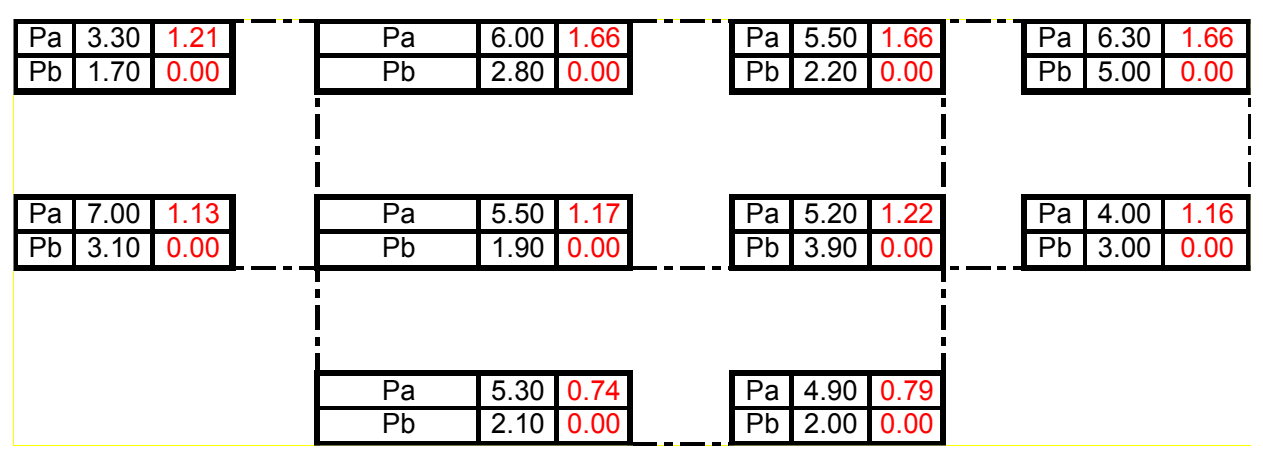

Figura 6-3 - Velocidade Efetiva de Vibração $(\mathrm{mm} / \mathrm{s})$

A Tabela 6-1 apresenta as freqüências naturais correspondentes a cada um dos 10 primeiros modos de vibração.

\section{Tabela 6-1 - Freqüências naturais calculadas}

\begin{tabular}{|c|c|}
\hline $\begin{array}{c}\text { Modos de } \\
\text { Vibração }\end{array}$ & $\begin{array}{c}\text { Frequências } \\
\text { Naturais }(\mathbf{H z})\end{array}$ \\
\hline $\mathbf{1}$ & 5.14 \\
\hline $\mathbf{2}$ & 5.28 \\
\hline $\mathbf{3}$ & 6.92 \\
\hline $\mathbf{4}$ & 40.25 \\
\hline $\mathbf{5}$ & 42.09 \\
\hline $\mathbf{6}$ & 42.43 \\
\hline $\mathbf{7}$ & 47.01 \\
\hline $\mathbf{8}$ & 49.89 \\
\hline $\mathbf{9}$ & 52.31 \\
\hline $\mathbf{1 0}$ & 52.31 \\
\hline
\end{tabular}

Como mostra Figura 6-4 dos erros percentuais, é clara a não convergência entre os resultados medidos e calculados, o que confirma a necessidade de se considerar o solo no modelo de modo a gerar resultados minimamente coerentes. Mesmo os pontos mais altos da estrutura, onde em tese a indeslocabilidade da base teria menor influência, não ficam bem representados.

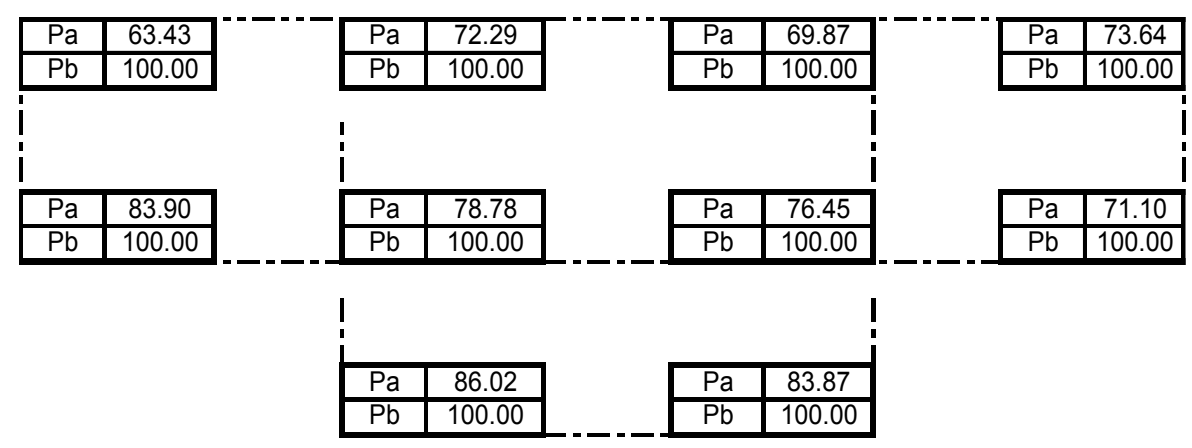

\begin{tabular}{|c|c|c|c|}
\cline { 2 - 4 } \multicolumn{1}{c|}{} & Global & $\mathbf{P a}$ & $\mathbf{P b}$ \\
\hline Erro Medio & 87.97 & 75.93 & 100.00 \\
\hline
\end{tabular}

Figura 6-4 - Erros percentuais - Velocidade efetiva Medida x Velocidade efetiva calculada 


\section{2.}

\section{Teste 2: modelo com $\boldsymbol{k}_{\boldsymbol{m}}$ estático e variável com a profundidade}

Os valores de $n_{h}$ e $k_{m}$ retroanalisados para o caso dito estático foram apresentados na Tabela 3-8 e na Tabela 3-9.

A seguir são realizadas as avaliações relativas às respostas do sistema aos valores da Constante do Coeficiente de Reação Horizontal $\left(n_{h}\right)$ e conseqüentemente do coeficiente de mola $\left(k_{m}\right)$, retroanalisados a partir dos ensaios de carregamento horizontal de campo E-11, E-16 e E-03, utilizando-se o método de Miche (1930).

\subsection{1.}

\section{Ensaio E-11}

A Figura 6-5 apresenta a comparação entre as velocidades medidas e calculadas considerando o valor do parâmetro do solo $n_{h}=64945.9630 \mathrm{kN} / \mathrm{m}^{3}$, e a Figura $6-12$ resume os erros percentuais correspondentes.

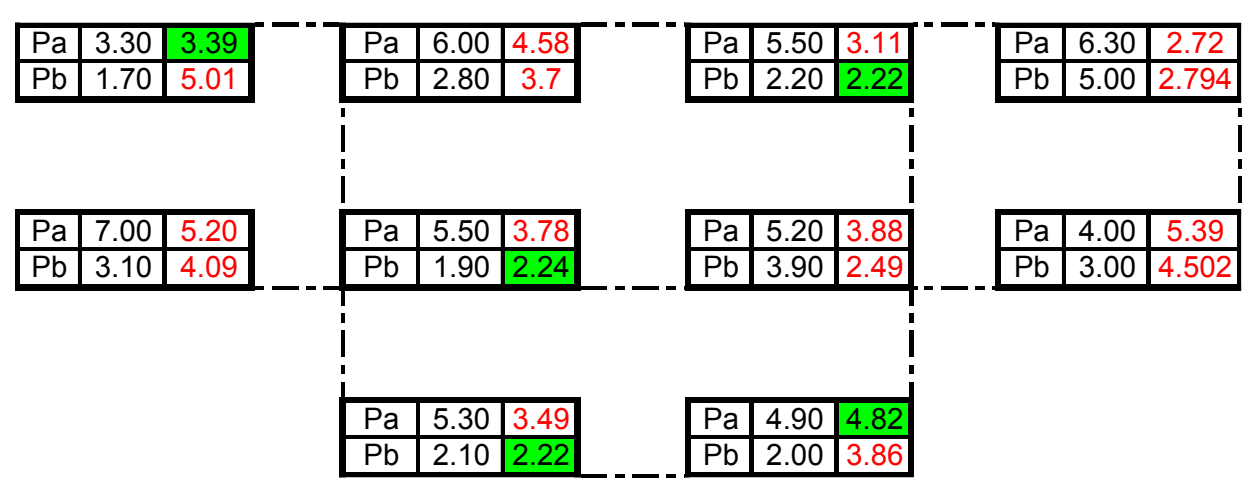

Figura 6-5 - Velocidade Efetiva de Vibração $(\mathrm{mm} / \mathrm{s})-n_{h}=64945.9630 \mathrm{kN} / \mathrm{m}^{3}$

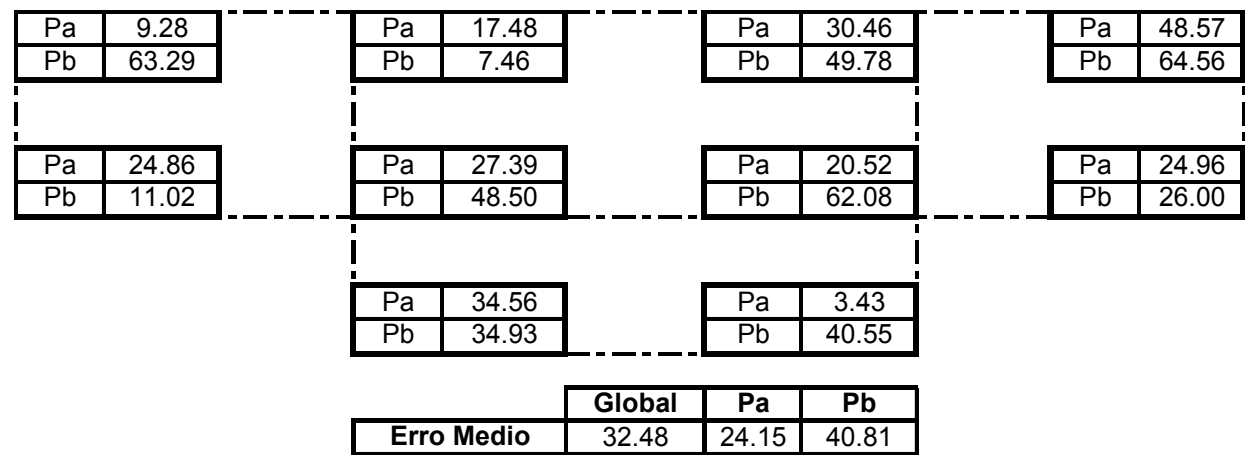

Figura 6-6 - Erros percentuais $-n_{h}=64945.9630 \mathrm{kN} / \mathrm{m}^{3}$

As freqüências naturais correspondentes aos dez primeiros modos de vibração são as seguintes. 
Tabela 6-2 - Freqüências naturais de vibração $-n_{h}=64945.9630 \mathrm{kN} / \mathrm{m}^{3}$

\begin{tabular}{|c|c|}
\hline $\begin{array}{c}\text { Modos de } \\
\text { Vibração }\end{array}$ & $\begin{array}{c}\text { Frequências } \\
\text { Naturais }(\mathbf{H z})\end{array}$ \\
\hline $\mathbf{1}$ & 4.18 \\
\hline $\mathbf{2}$ & 4.32 \\
\hline $\mathbf{3}$ & 6.18 \\
\hline $\mathbf{4}$ & 17.36 \\
\hline $\mathbf{5}$ & 19.98 \\
\hline $\mathbf{6}$ & 20.37 \\
\hline $\mathbf{7}$ & 21.55 \\
\hline $\mathbf{8}$ & 21.73 \\
\hline $\mathbf{9}$ & 23.90 \\
\hline $\mathbf{1 0}$ & 37258.00 \\
\hline \multicolumn{2}{|r}{} \\
\hline
\end{tabular}

\subsection{2.}

\section{Ensaio E-16}

A Figura 6-7 apresenta a comparação entre as velocidades medidas e calculadas considerando o valor do parâmetro do solo $n_{h}=5087.9877 \mathrm{kN} / \mathrm{m}^{3}$, e a Figura $6-8$ resume os erros percentuais correspondentes.

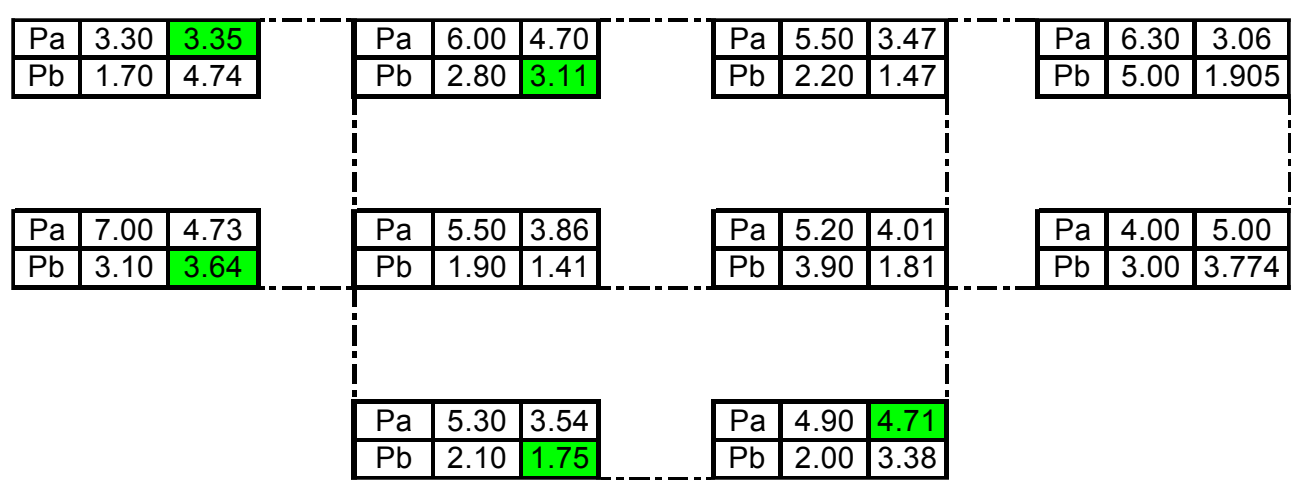

Figura 6-7 - Velocidade Efetiva de Vibração $(\mathrm{mm} / \mathrm{s})-n_{h}=5087.9877 \mathrm{kN} / \mathrm{m}^{3}$

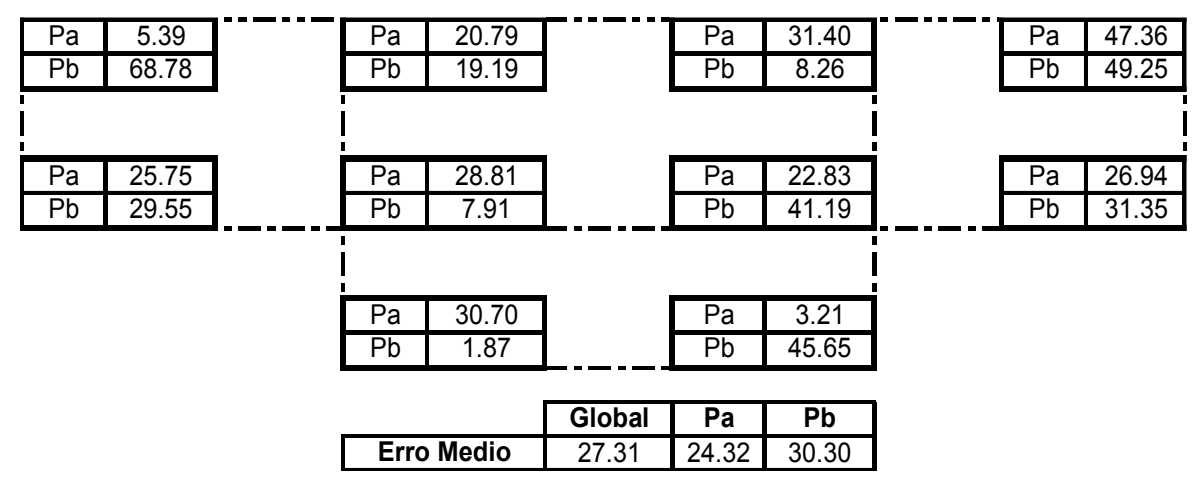

Figura 6-8 - Erros percentuais $-n_{h}=5087.9877 \mathrm{kN} / \mathrm{m}^{3}$ 
As freqüências naturais correspondentes aos dez primeiros modos de vibração são as seguintes.

Tabela 6-3 - Freqüências naturais de vibração $-n_{h}=5087.9877 \mathrm{kN} / \mathrm{m}^{3}$

\begin{tabular}{|c|c|}
\hline $\begin{array}{c}\text { Modos de } \\
\text { Vibração }\end{array}$ & $\begin{array}{c}\text { Frequências } \\
\text { Naturais } \mathbf{( H z})\end{array}$ \\
\hline $\mathbf{1}$ & 3.30 \\
\hline $\mathbf{2}$ & 3.40 \\
\hline $\mathbf{3}$ & 4.61 \\
\hline $\mathbf{4}$ & 10.53 \\
\hline $\mathbf{5}$ & 10.66 \\
\hline $\mathbf{6}$ & 12.66 \\
\hline $\mathbf{7}$ & 17.37 \\
\hline $\mathbf{8}$ & 20.35 \\
\hline $\mathbf{9}$ & 21.20 \\
\hline $\mathbf{1 0}$ & 31.27 \\
\hline
\end{tabular}

\subsection{3.}

\section{Ensaio E-03}

A Figura 6-9 apresenta a comparação entre as velocidades medidas e calculadas considerando o valor do parâmetro do solo $n_{h}=1624.9799 \mathrm{kN} / \mathrm{m}^{3}$, e a Figura 6-10 resume os erros percentuais correspondentes.

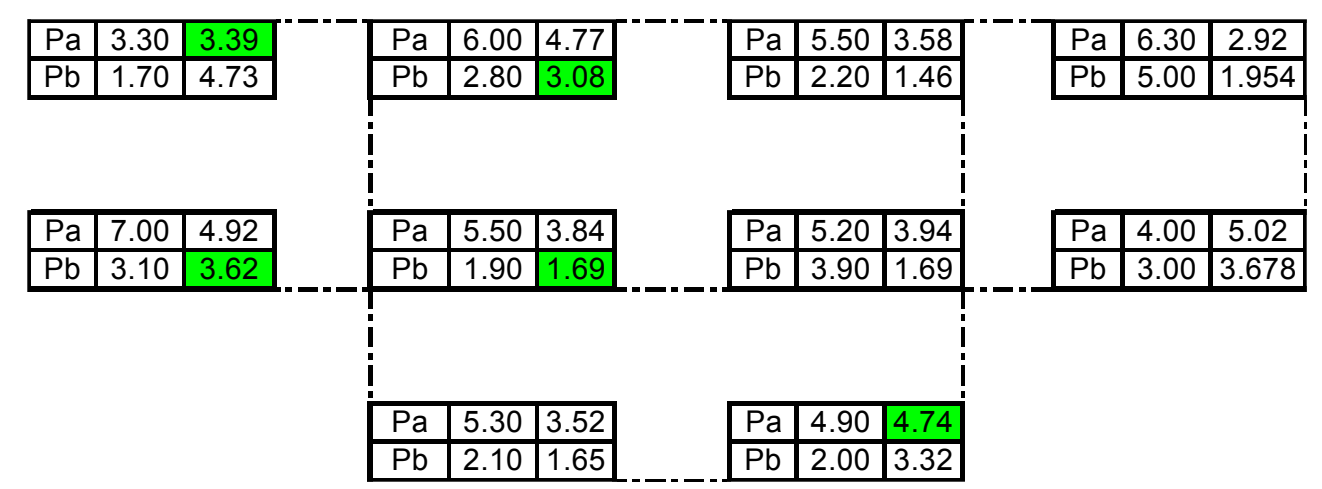

Figura 6-9 - Velocidade Efetiva de Vibração $(\mathrm{mm} / \mathrm{s})-n_{h}=1624.9799 \mathrm{kN} / \mathrm{m}^{3}$

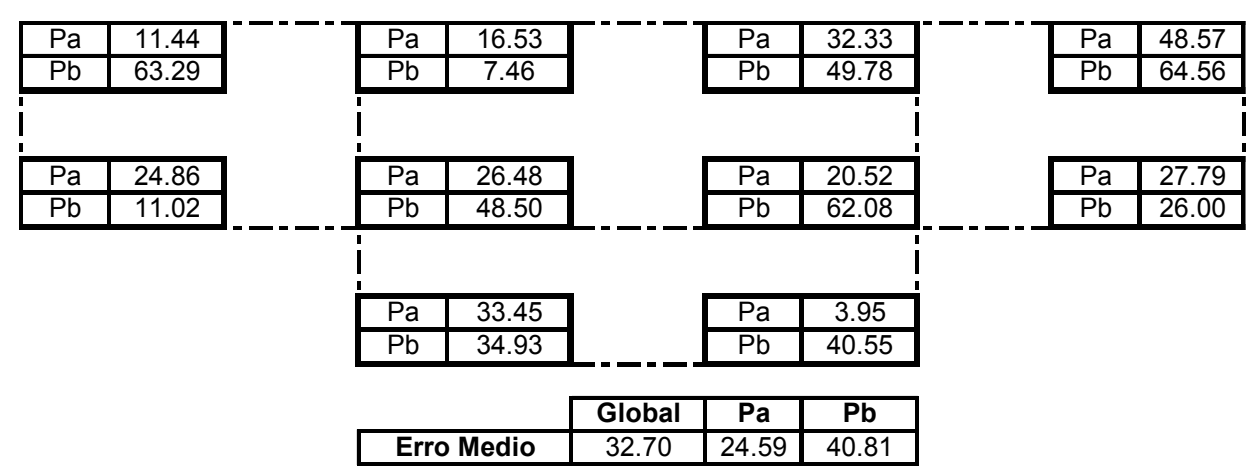

Figura 6-10 - Erros percentuais $-n_{h}=1624.9799 \mathrm{kN} / \mathrm{m}^{3}$ 
As freqüências naturais correspondentes aos dez primeiros modos de vibração são as seguintes.

Tabela 6-4 - Freqüências naturais de vibração $-n_{h}=1624.9799 \mathrm{kN} / \mathrm{m}^{3}$

\begin{tabular}{|c|c|}
\hline $\begin{array}{c}\text { Modos de } \\
\text { Vibração }\end{array}$ & $\begin{array}{c}\text { Frequências } \\
\text { Naturais }(\mathrm{Hz})\end{array}$ \\
\hline $\mathbf{1}$ & 2.62 \\
\hline $\mathbf{2}$ & 2.68 \\
\hline $\mathbf{3}$ & 3.52 \\
\hline $\mathbf{4}$ & 8.86 \\
\hline $\mathbf{5}$ & 8.98 \\
\hline $\mathbf{6}$ & 11.12 \\
\hline $\mathbf{7}$ & 17.37 \\
\hline $\mathbf{8}$ & 20.34 \\
\hline $\mathbf{9}$ & 21.18 \\
\hline $\mathbf{1 0}$ & 28.27 \\
\hline
\end{tabular}

\subsection{4.}

\section{Análise dos resultados}

Neste item, todos os resultados apresentados em 6.2.1, 6.2.2 e 6.2.3 são então interpretados, tanto em termo das velocidades efetivas como em termos das freqüências naturais.

Os erros percentuais correspondentes a cada um dos testes realizados estão resumidos a seguir, considerando os dados dos ensaios E-11, E-16 e E-03, respectivamente.

Tabela 6-5 - Resumo dos erros percentuais

\begin{tabular}{|c|c|c|c|}
\hline Local de & \multicolumn{3}{|c|}{ Erros Médios Percentuais } \\
\cline { 2 - 4 } Avaliação & $\mathrm{E}-11$ & $\mathrm{E}-16$ & $\mathrm{E}-\mathbf{0 3}$ \\
\hline $\mathrm{Pa}$ & 24.15 & 24.32 & 24.59 \\
\hline $\mathrm{Pb}$ & 40.81 & 30.30 & 40.81 \\
\hline Global & 32.48 & 27.31 & 32.70 \\
\hline
\end{tabular}

Os erros globais médios dos pontos altos $P a$ e dos pontos baixos $P b$ resultaram maiores que o admissível. Contudo, vê-se que em alguns casos individuais os erros percentuais entre os dados medidos e os dados calculados resultaram ora dentro dos limites admissíveis, sendo que em certas situações muito menores que o erro máximo limite, ora extremamente divergentes. A partir de critérios adequados de estatística, a eliminação dos resultados individuais que apresentaram muita discrepância entre os dados medidos e calculados poderá mostrar um melhor ajuste entre o modelo e a realidade. 
A análise dos números mostrados na Tabela 6-5 permite concluir que as velocidades obtidas pelo modelo de elementos finitos tiveram melhor aproximação em relação às velocidades medidas em campo para os pontos da estrutura correspondentes ao topo dos pilares. Além disso, para esses mesmos pontos e entre os ciclos de carregamento, houve pouca variação dos erros percentuais das velocidades efetivas, o que indica a menor suscetibilidade dos pontos mais altos da estrutura às variações das condições do solo.

Nos gráficos a seguir, as curvas das velocidades efetivas medidas em campo (linhas pretas) e calculadas (linhas rosa) através do modelo de elementos finitos estão desenhadas simultaneamente em função do parâmetro $n_{h}$ do solo, parâmetro esse retroanalisado a partir dos dois ensaios E-11, E-16 e E-03.

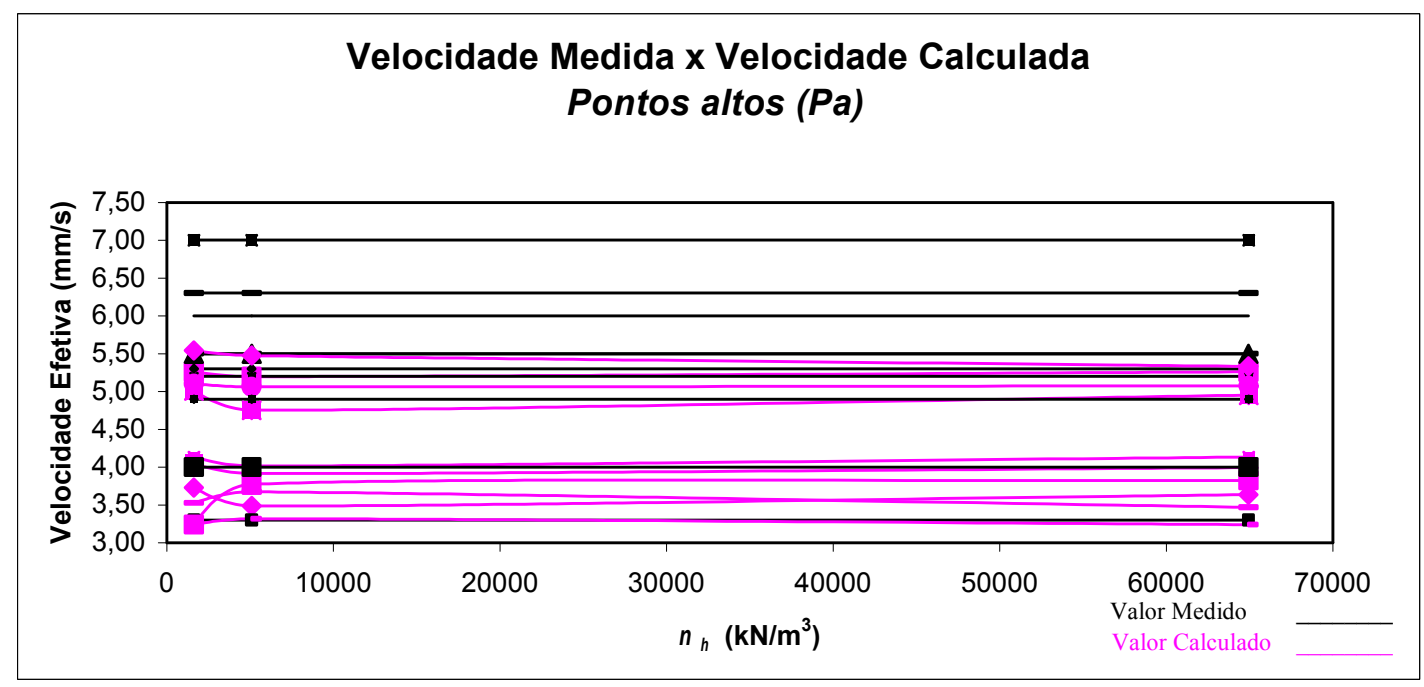

Gráfico 6-1 - Curvas Velocidades Efetivas versus $n_{h}-$ Pontos $P_{a}$

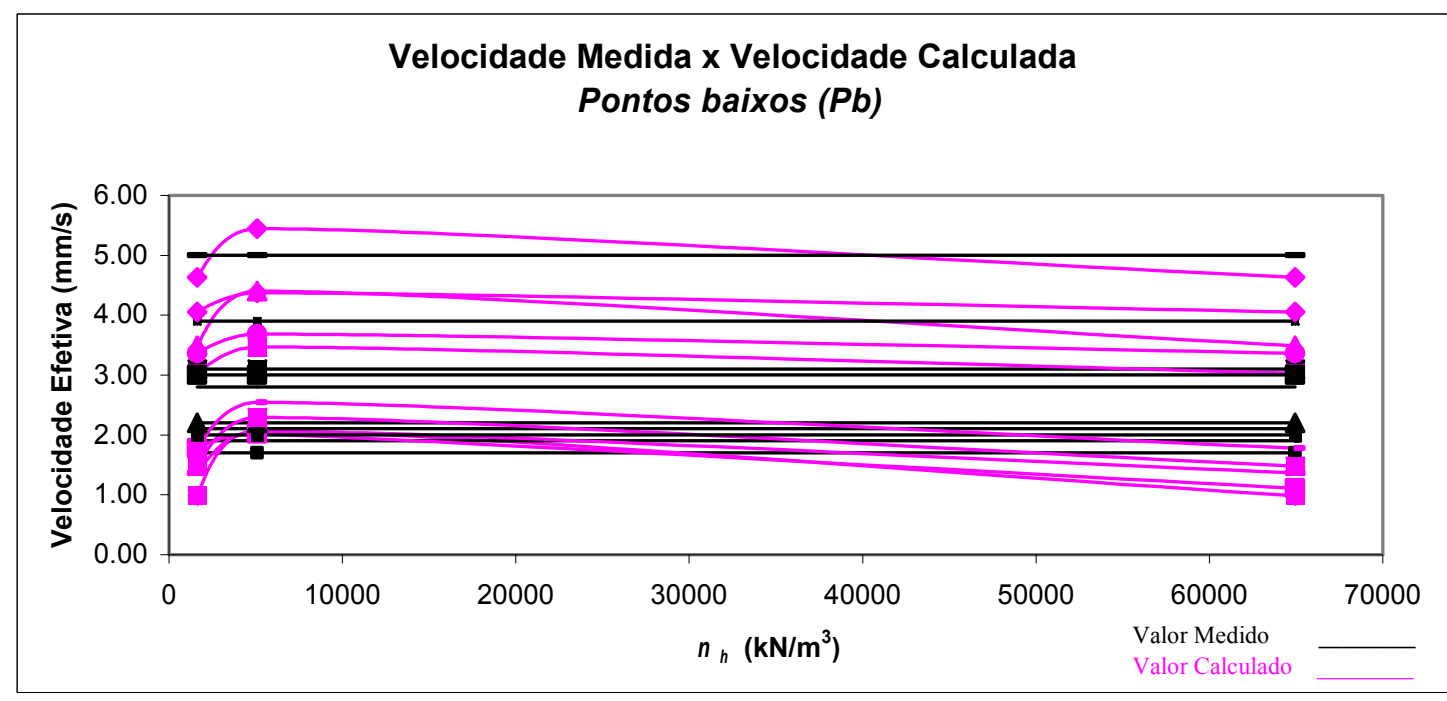

Gráfico 6-2 - Curvas Velocidades Efetivas versus $\boldsymbol{n}_{h}-$ Pontos $\boldsymbol{P}_{\boldsymbol{b}}$ 
O Gráfico 6-1 se refere aos pontos altos da estrutura, próximos da laje de apoio do compressor. Dele se observa que as velocidades calculadas se enquadram em dois limites estreitos bem distintos, o primeiro entre as velocidades efetivas de $3.2 \mathrm{~mm} / \mathrm{s}$ e $4.0 \mathrm{~mm} / \mathrm{s}$, e o segundo entre $5 \mathrm{~mm} / \mathrm{s}$ e $5.5 \mathrm{~mm} / \mathrm{s}$, considerando os valores de $n_{h}$ entre $1600 \mathrm{kN} / \mathrm{m}^{3}$ e $65000 \mathrm{kN} / \mathrm{m}^{3}$. Para valores de $n_{h}$ mais baixos, aproximadamente entre $1600 \mathrm{kN} / \mathrm{m}^{3}$ e $5000 \mathrm{kN} / \mathrm{m}^{3}$, as velocidades efetivas apresentam maior variabilidade, e para valores superiores a $5000 \mathrm{kN} / \mathrm{m}^{3}$, observa-se uma tendência de menor influência de $n_{h}$ na resposta dinâmica do sistema.

O Gráfico 6-2 se refere aos pontos baixos da estrutura, próximos do nível do terreno. Dele se observa que para valores de $n_{h}$ dentro do intervalo aproximado de 1600 $\mathrm{kN} / \mathrm{m}^{3}$ a $5000 \mathrm{kN} / \mathrm{m}^{3}$, as velocidades efetivas calculadas apresentam um tendência de crescimento, passando a serem maiores do que as velocidades efetivas medidas. Em se aumentando o valor do parâmetro $n_{h}$, as velocidades efetivas calculadas tendem para valores inferiores aos medidos. Assim, no primeiro intervalo de valores de $n_{h}$ o método de Miche (1930) proporciona velocidades efetivas superestimadas, e no segundo intervalo, o método proporciona velocidades efetivas subestimadas.

O comportamento das freqüências naturais em relação ao parâmetro do solo $n_{h}$ é então analisado a partir dos resultados resumidos na Tabela 6-6 e Gráfico 6-3.

Tabela 6-6 - Freqüências naturais em função dos valores de $\boldsymbol{n}_{\boldsymbol{h}}$

\begin{tabular}{|c|c|c|c|c|}
\hline \multirow{2}{*}{$\begin{array}{c}\text { Modos de } \\
\text { Vibração }\end{array}$} & \multicolumn{3}{|c|}{ ENSAIOS } & \multirow{2}{*}{$\begin{array}{c}\text { Variação } \\
\text { (\%) }\end{array}$} \\
\cline { 2 - 4 } & \multicolumn{2}{|c|}{ FREQUÉNCIAS NATURAIS (Hz) } & \\
\hline $\mathbf{1}$ & 4.18 & 3.30 & 2.62 & 37.31 \\
\hline $\mathbf{2}$ & 4.32 & 3.40 & 2.68 & 37.94 \\
\hline $\mathbf{3}$ & 6.18 & 4.61 & 3.52 & 43.12 \\
\hline $\mathbf{4}$ & 17.36 & 10.53 & 8.86 & 48.94 \\
\hline $\mathbf{5}$ & 19.98 & 10.66 & 8.98 & 55.04 \\
\hline $\mathbf{6}$ & 20.37 & 12.66 & 11.12 & 45.42 \\
\hline $\mathbf{7}$ & 21.55 & 17.37 & 17.37 & 19.43 \\
\hline $\mathbf{8}$ & 21.73 & 20.35 & 20.34 & 6.40 \\
\hline $\mathbf{9}$ & 23.90 & 21.20 & 21.18 & 11.39 \\
\hline $\mathbf{1 0}$ & 37.26 & 31.27 & 28.27 & 24.13 \\
\hline
\end{tabular}

\begin{tabular}{|l|l|l|l|}
\hline $\mathrm{n}_{\mathrm{h}}\left(\mathbf{k N} / \mathbf{m}^{3}\right)$ & 64945.9631 & 5087.9878 & 1624.9800 \\
\hline
\end{tabular}




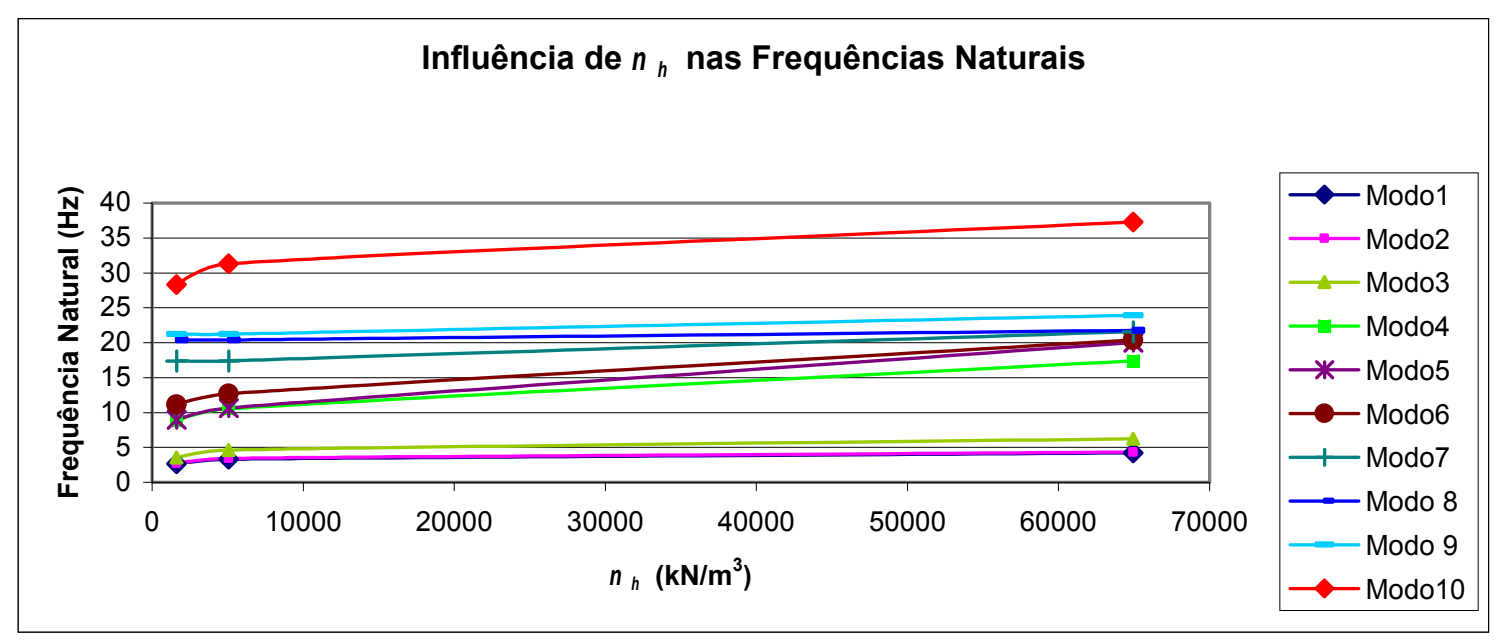

Gráfico 6-3 - Curva Freqüência Natural versus nh

Para os valores de $n_{h}$ (estático) dentro do intervalo típico do solo estudado, observa-se que as freqüências naturais apresentam variação significativa. Praticamente, apenas as freqüências naturais correspondentes aos modos 8 e 9 apresentaram variação inferior a $20 \%$, permitindo assim inferir que o parâmetro $n_{h}$ obtido sob condições estáticas não é adequado para representar o solo em modelos quando se pretende obter os autovalores do sistema interativo estrutura-fundação-solo.

\section{3.}

\section{Teste 3: modelo com $\boldsymbol{k}_{\boldsymbol{m}}$ cíclico e variável com a profundidade}

A seguir estão apresentadas as avaliações relativas às respostas do sistema aos valores da Constante do Coeficiente de Reação Horizontal $\left(n_{h}\right)$ e conseqüentemente do coeficiente de mola $\left(k_{m}\right)$ retroanalisados a partir dos ensaios de carregamento horizontal de campo E-16 e E-03, utilizando-se o método de Miche (1930). Primeiramente são tratados os dados obtidos do ensaio E-16 e em seguida os obtidos do ensaio E-03. A apresentação desses dados está organizada de tal modo que os ciclos de carregamento foram tratados separadamente em Ciclos de Ida e Ciclos de Volta. 


\subsection{1.}

\section{Ensaio E-16}

\subsubsection{1.}

\section{Ciclo de ida}

O ciclo de ida corresponde ao valor de $n_{h}=157227.3290 \mathrm{kN} / \mathrm{m}^{3}$ e coeficientes de mola reapresentados novamente abaixo. Este é o ciclo que resultou no menor valor de $n_{h}$.

Tabela 6-7 - Ensaio E-16 - Ciclo de Ida $-k_{m}$ para $n_{h}=157227.3290 \mathrm{kN} / \mathrm{m}^{3}$

\begin{tabular}{|c|c|}
\multicolumn{2}{c}{ Ciclo Ida - Menor Valor } \\
\hline $\mathbf{Z}$ & $\mathbf{k}_{\mathrm{m}}(\mathbf{k N} / \mathbf{m})$ \\
\hline $\mathbf{1}$ & $1.572273 \mathrm{E}+05$ \\
\hline $\mathbf{2}$ & $3.144547 \mathrm{E}+05$ \\
\hline $\mathbf{3}$ & $4.716820 \mathrm{E}+05$ \\
\hline $\mathbf{4}$ & $6.289093 \mathrm{E}+05$ \\
\hline $\mathbf{5}$ & $7.861366 \mathrm{E}+05$ \\
\hline $\mathbf{6}$ & $9.433640 \mathrm{E}+05$ \\
\hline $\mathbf{7}$ & $1.100591 \mathrm{E}+06$ \\
\hline $\mathbf{8}$ & $1.257819 \mathrm{E}+06$ \\
\hline $\mathbf{9}$ & $1.415046 \mathrm{E}+06$ \\
\hline $\mathbf{1 0}$ & $1.572273 \mathrm{E}+06$ \\
\hline
\end{tabular}

A Figura 6-11 apresenta a comparação entre as velocidades medidas e calculadas e a Figura 6-12 resume os erros percentuais correspondentes.

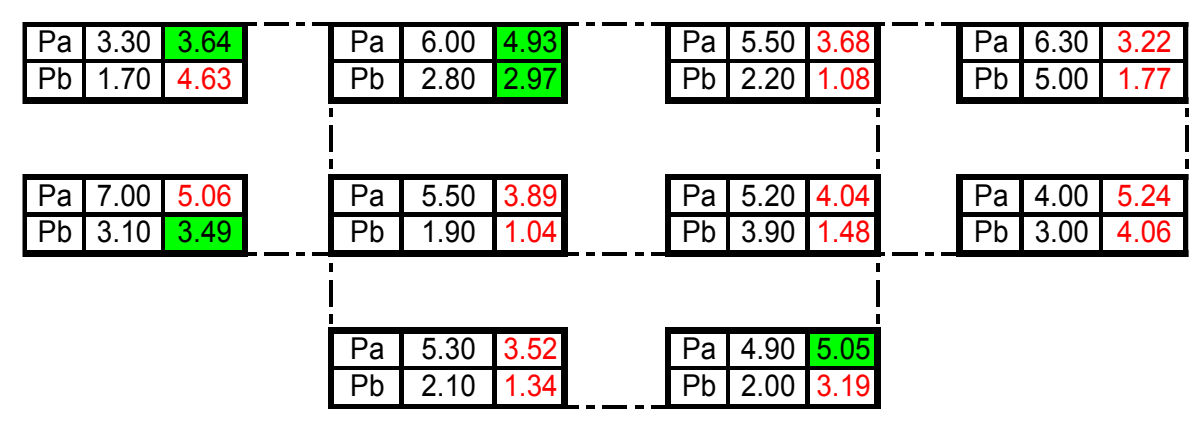

Figura 6-11 - Velocidade Efetiva de Vibração $(\mathrm{mm} / \mathrm{s})$ - Ciclo Ida Menor 


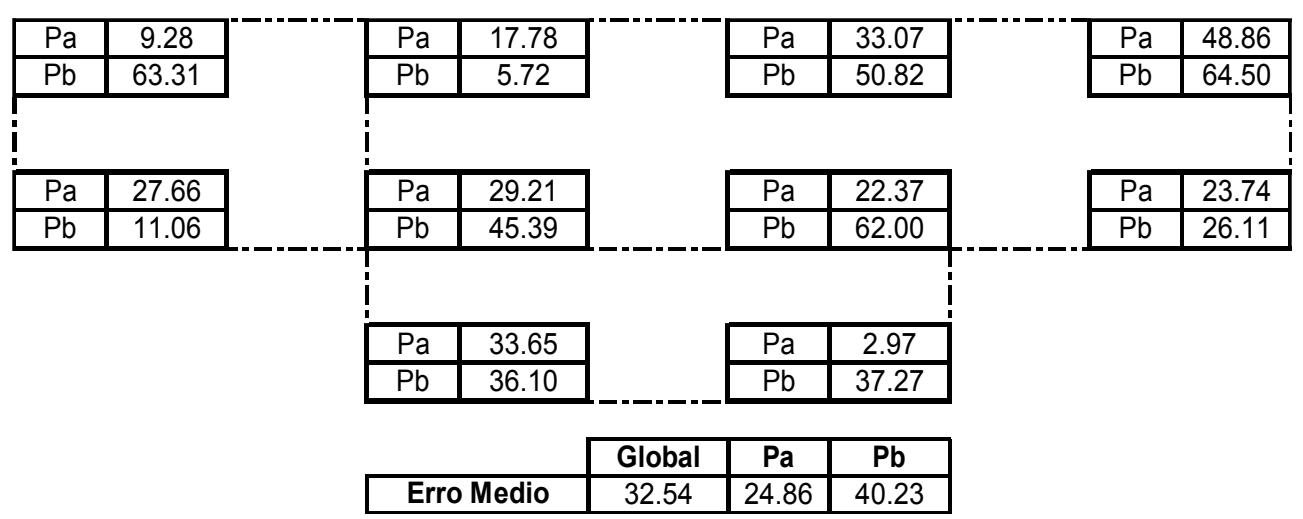

Figura 6-12 - Erros percentuais - Ciclo Ida Menor

As freqüências naturais correspondentes aos dez primeiros modos de vibração são as seguintes.

Tabela 6-8 - Freqüências naturais de vibração - Ciclo Ida Menor

\begin{tabular}{|c|c|}
\hline $\begin{array}{c}\text { Modos de } \\
\text { Vibração }\end{array}$ & $\begin{array}{c}\text { Frequências } \\
\text { Naturais }(\mathrm{Hz})\end{array}$ \\
\hline 1 & 4.31 \\
\hline 2 & 4.46 \\
\hline 3 & 6.39 \\
\hline 4 & 17.37 \\
\hline 5 & 20.28 \\
\hline 6 & 21.12 \\
\hline 7 & 28.35 \\
\hline 8 & 28.76 \\
\hline 9 & 32.11 \\
\hline 10 & 38.00 \\
\hline
\end{tabular}

Em seguida, são apresentados os demais casos correspondentes aos outros valores de $n_{h}$ retroanalisados.

Tabela 6-9 - Ensaio E-16 - Ciclo de Ida $-k_{m}$ para $n_{h}=191974.2753 \mathrm{kN} / \mathrm{m}^{3}$

Ciclo Ida - Maior Valor

\begin{tabular}{|c|c|}
\hline $\mathbf{Z}$ & $\mathbf{k}_{\mathbf{m}} \mathbf{( k N / \mathbf { m } )}$ \\
\hline $\mathbf{1}$ & $1.919743 \mathrm{E}+05$ \\
\hline $\mathbf{2}$ & $3.839486 \mathrm{E}+05$ \\
\hline $\mathbf{3}$ & $5.759228 \mathrm{E}+05$ \\
\hline $\mathbf{4}$ & $7.678971 \mathrm{E}+05$ \\
\hline $\mathbf{5}$ & $9.598714 \mathrm{E}+05$ \\
\hline $\mathbf{6}$ & $1.151846 \mathrm{E}+06$ \\
\hline $\mathbf{7}$ & $1.343820 \mathrm{E}+06$ \\
\hline $\mathbf{8}$ & $1.535794 \mathrm{E}+06$ \\
\hline $\mathbf{9}$ & $1.727768 \mathrm{E}+06$ \\
\hline $\mathbf{1 0}$ & $1.919743 \mathrm{E}+06$ \\
\hline
\end{tabular}




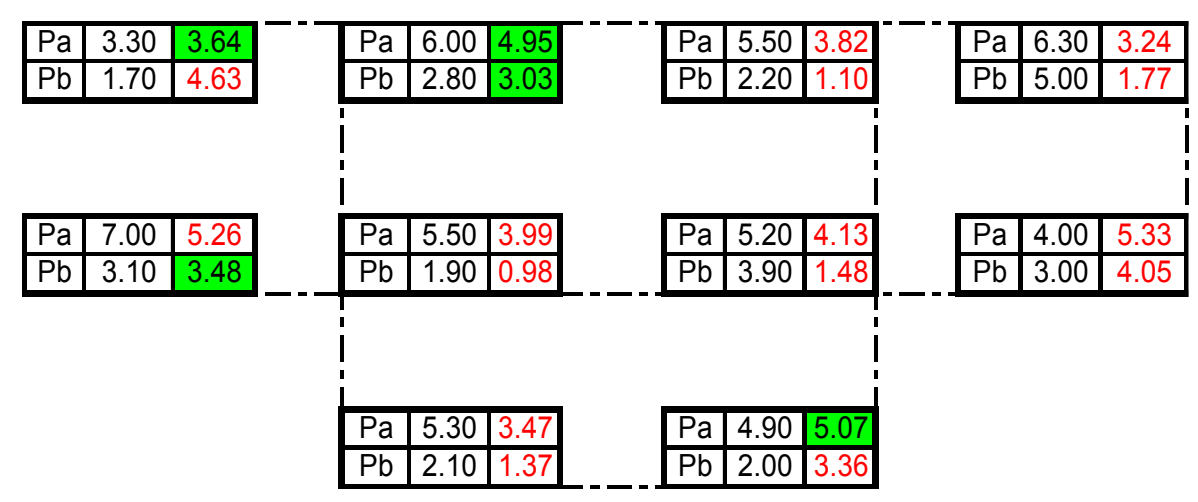

Figura 6-13 - Velocidade Efetiva de Vibração (mm/s) - Ciclo Ida Maior

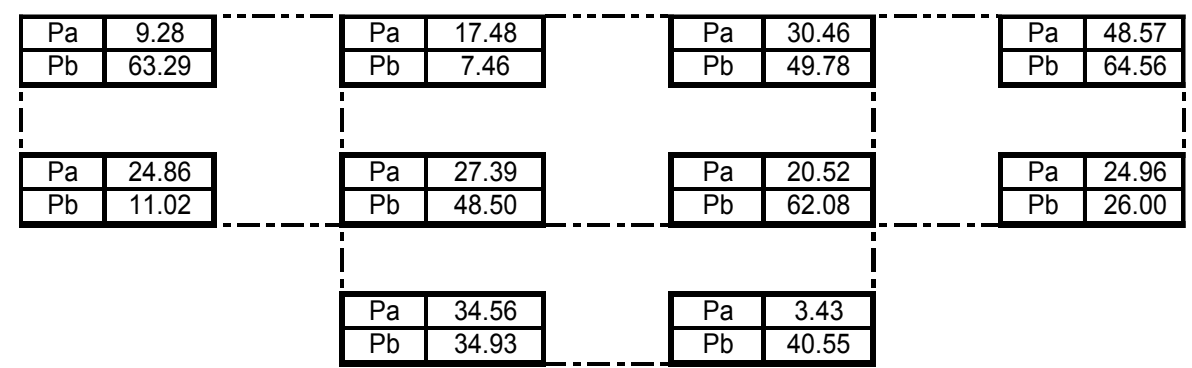

\begin{tabular}{|c|c|c|c|}
\cline { 2 - 4 } \multicolumn{1}{c|}{} & Global & $\mathrm{Pa}$ & $\mathrm{Pb}$ \\
\hline Erro Medio & 32.48 & 24.15 & 40.81 \\
\hline
\end{tabular}

Figura 6-14 - Erros percentuais - Ciclo Ida Maior

As freqüências naturais correspondentes aos dez primeiros modos de vibração são as seguintes.

Tabela 6-10 - Freqüências naturais de vibração - Ciclo Ida Maior

\begin{tabular}{|c|c|}
\hline $\begin{array}{c}\text { Modos de } \\
\text { Vibração }\end{array}$ & $\begin{array}{c}\text { Frequências } \\
\text { Naturais }(\mathrm{Hz})\end{array}$ \\
\hline 1 & 4.33 \\
\hline 2 & 4.48 \\
\hline 3 & 6.42 \\
\hline 4 & 17.37 \\
\hline 5 & 20.29 \\
\hline 6 & 21.13 \\
\hline 7 & 30.41 \\
\hline 8 & 30.87 \\
\hline 9 & 34.42 \\
\hline 10 & 38.00 \\
\hline
\end{tabular}




\subsubsection{2.}

\section{Ciclo de volta}

Tabela 6-11 - Ensaio E-16 - Ciclo de Volta $-k_{m}$ para $n_{h}=69712.6988 \mathrm{kN} / \mathrm{m}^{3}$

Ciclo Volta - Menor Valor

\begin{tabular}{|c|c|}
\hline $\mathbf{Z}$ & $\mathbf{k}_{\mathbf{m}}(\mathbf{k N} / \mathbf{m})$ \\
\hline $\mathbf{1}$ & $6.971270 \mathrm{E}+04$ \\
\hline $\mathbf{2}$ & $1.394254 \mathrm{E}+05$ \\
\hline $\mathbf{3}$ & $2.091381 \mathrm{E}+05$ \\
\hline $\mathbf{4}$ & $2.788508 \mathrm{E}+05$ \\
\hline $\mathbf{5}$ & $3.485635 \mathrm{E}+05$ \\
\hline $\mathbf{6}$ & $4.182762 \mathrm{E}+05$ \\
\hline $\mathbf{7}$ & $4.879889 \mathrm{E}+05$ \\
\hline $\mathbf{8}$ & $5.577016 \mathrm{E}+05$ \\
\hline $\mathbf{9}$ & $6.274143 \mathrm{E}+05$ \\
\hline $\mathbf{1 0}$ & $6.971270 \mathrm{E}+05$ \\
\hline
\end{tabular}

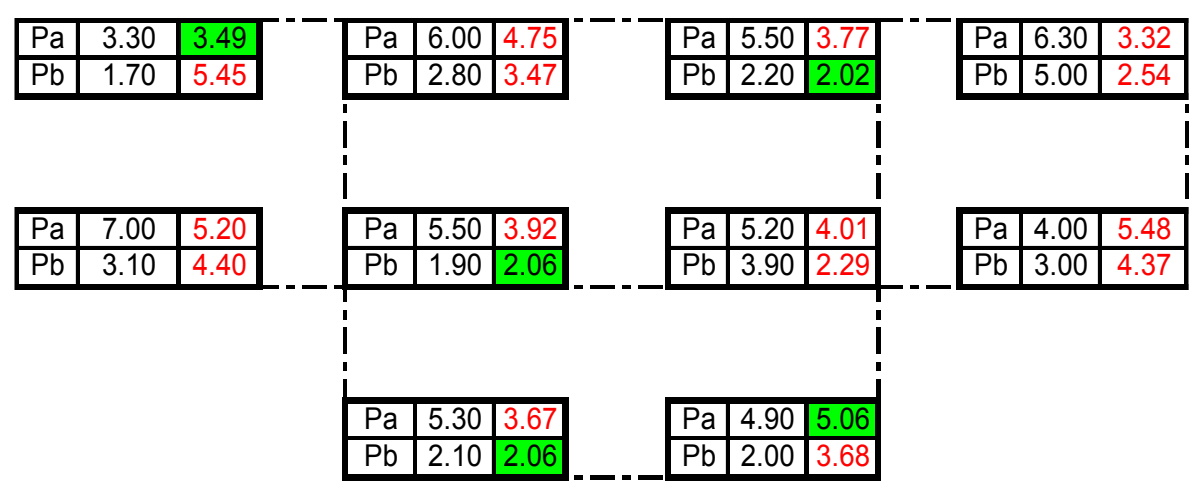

Figura 6-15 - Velocidade Efetiva de Vibração (mm/s)-Ciclo Volta Menor

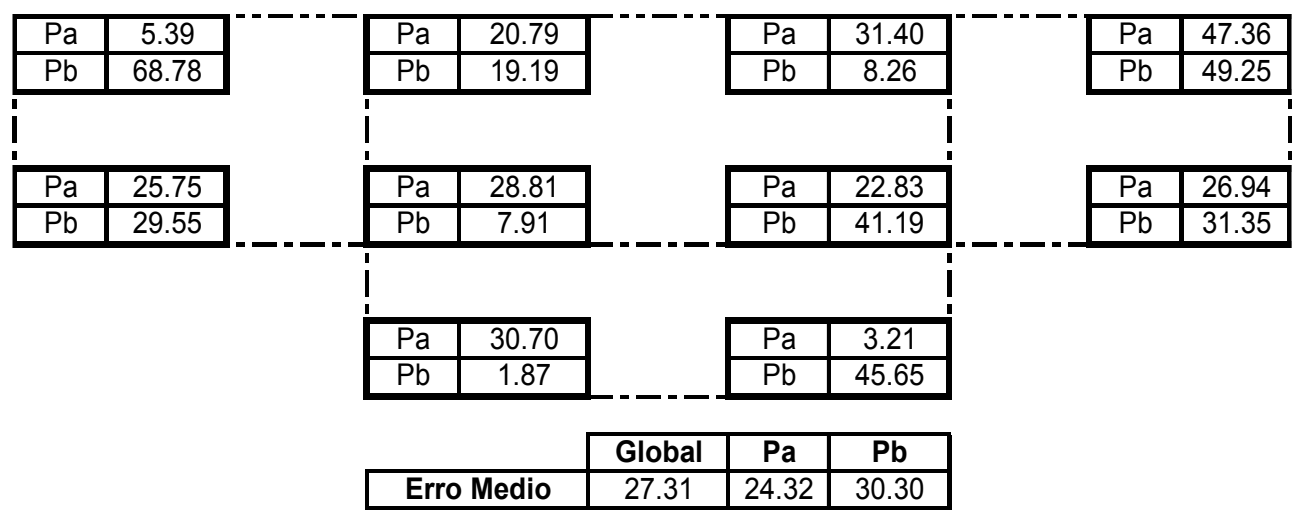

Figura 6-16 - Erros percentuais - Ciclo Volta Menor

As freqüências naturais correspondentes aos dez primeiros modos de vibração são as seguintes. 
Tabela 6-12 - Freqüências naturais de vibração - Ciclo Volta Menor

\begin{tabular}{|c|c|}
\hline $\begin{array}{c}\text { Modos de } \\
\text { Vibração }\end{array}$ & $\begin{array}{c}\text { Frequências } \\
\text { Naturais }(\mathrm{Hz})\end{array}$ \\
\hline 1 & 4.20 \\
\hline 2 & 4.34 \\
\hline 3 & 6.20 \\
\hline 4 & 17.36 \\
\hline 5 & 20.07 \\
\hline 6 & 20.61 \\
\hline 7 & 21.96 \\
\hline 8 & 21.99 \\
\hline 9 & 24.45 \\
\hline 10 & 37.58 \\
\hline
\end{tabular}

Tabela 6-13 - Ensaio E-16 - Ciclo de Volta $-k_{m}$ para $n_{h}=107239.9282 \mathrm{kN} / \mathrm{m}^{3}$

Ciclo Volta - Maior Valor

\begin{tabular}{|c|c|}
\hline $\mathbf{Z}$ & $\mathbf{k}_{\mathbf{m}}(\mathbf{k N} / \mathbf{m})$ \\
\hline $\mathbf{1}$ & $1.072399 \mathrm{E}+05$ \\
\hline $\mathbf{2}$ & $2.144799 \mathrm{E}+05$ \\
\hline $\mathbf{3}$ & $3.217198 \mathrm{E}+05$ \\
\hline $\mathbf{4}$ & $4.289597 \mathrm{E}+05$ \\
\hline $\mathbf{5}$ & $5.361996 \mathrm{E}+05$ \\
\hline $\mathbf{6}$ & $6.434396 \mathrm{E}+05$ \\
\hline $\mathbf{7}$ & $7.506795 \mathrm{E}+05$ \\
\hline $\mathbf{8}$ & $8.579194 \mathrm{E}+05$ \\
\hline $\mathbf{9}$ & $9.651594 \mathrm{E}+05$ \\
\hline $\mathbf{1 0}$ & $1.072399 \mathrm{E}+06$ \\
\hline
\end{tabular}

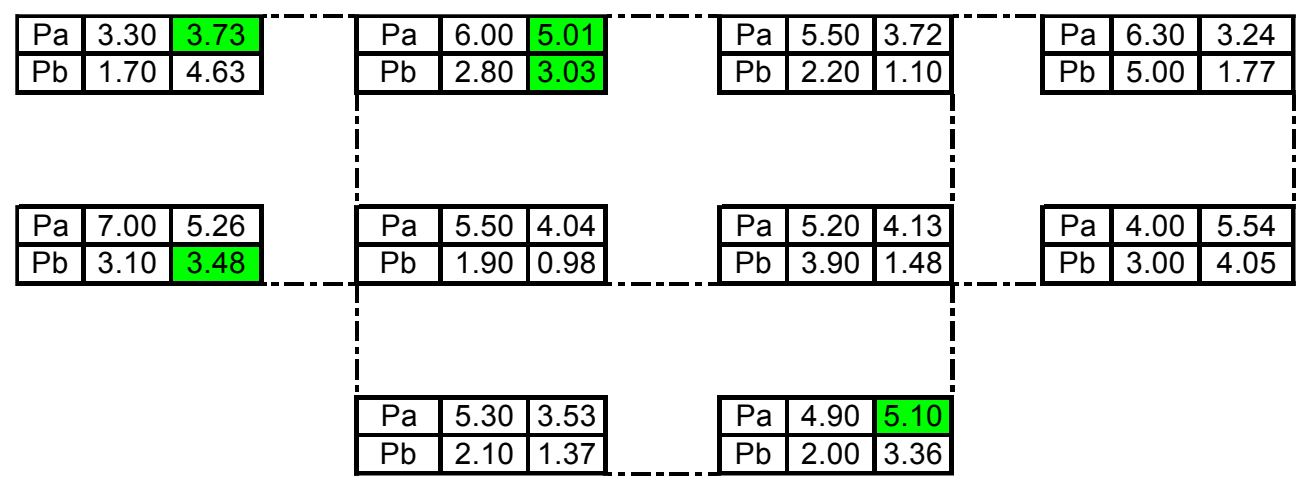

Figura 6-17 - Velocidade Efetiva de Vibração (mm/s)-Ciclo Volta Maior 


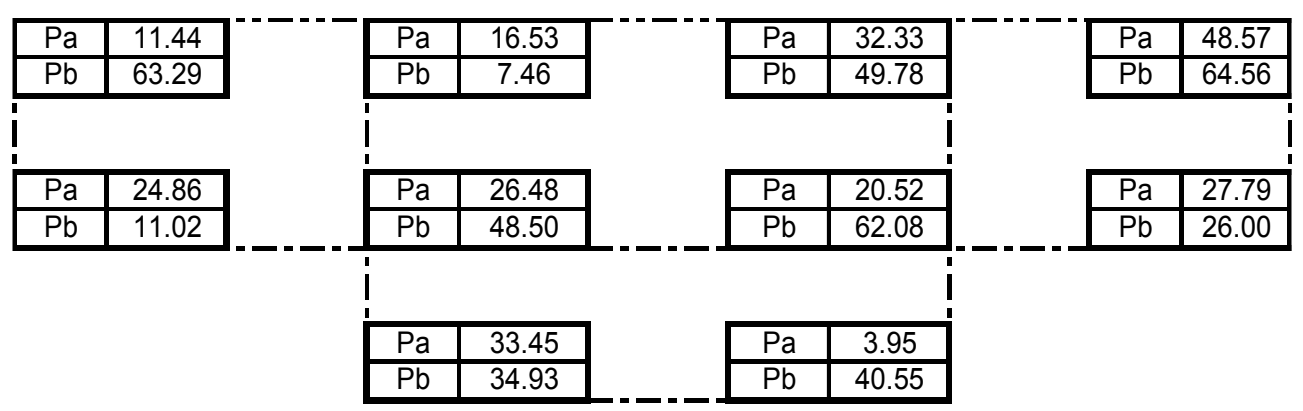

\begin{tabular}{|c|c|c|c|}
\cline { 2 - 4 } & Global & $\mathbf{P a}$ & $\mathbf{P b}$ \\
\hline Erro Medio & 32.70 & 24.59 & 40.81 \\
\hline
\end{tabular}

Figura 6-18 - Erros percentuais - Ciclo Volta Maior

As freqüências naturais correspondentes aos dez primeiros modos de vibração são as seguintes.

Tabela 6-14 - Freqüências naturais de vibração - Ciclo Volta Maior

\begin{tabular}{|c|c|}
\hline $\begin{array}{c}\text { Modos de } \\
\text { Vibração }\end{array}$ & $\begin{array}{c}\text { Frequências } \\
\text { Naturais }(\mathrm{Hz})\end{array}$ \\
\hline 1 & 4.26 \\
\hline 2 & 4.41 \\
\hline 3 & 6.31 \\
\hline 4 & 17.36 \\
\hline 5 & 20.24 \\
\hline 6 & 21.05 \\
\hline 7 & 24.89 \\
\hline 8 & 25.20 \\
\hline 9 & 28.17 \\
\hline 10 & 37.99 \\
\hline
\end{tabular}

\subsection{2.}

\section{Ensaio E-03}

A seguir está apresentada a avaliação da resposta do sistema aos valores do coeficiente de mola retroanalisados a partir do ensaio de carregamento horizontal de campo E-03. Somente serão avaliados o menor coeficiente de mola dos ciclos de ida e o maior coeficiente de mola dos ciclos de volta uma vez que os demais valores de coeficiente de mola se aproximam muito daqueles já avaliados no item 6.3.1.

\subsubsection{1.}

\section{Ciclo de ida}

O ciclo de ida corresponde ao valor de $n_{h}=34222.4094 \mathrm{kN} / \mathrm{m}^{3}$ e coeficientes de mola reapresentados novamente abaixo. Este é o ciclo que resultou no menor valor de $n_{h}$. 
Tabela 6-15 - Ensaio E-03 - Ciclo de Ida $-k_{m}$ para $n_{h}=34222.4094 \mathrm{kN} / \mathrm{m}^{3}$

Ciclo Ida - Menor Valor

\begin{tabular}{|c|c|}
\hline $\mathbf{Z}$ & $\mathbf{k}_{\mathbf{m}}(\mathbf{k N} / \mathbf{m})$ \\
\hline $\mathbf{1}$ & $3.422241 \mathrm{E}+04$ \\
\hline $\mathbf{2}$ & $6.844482 \mathrm{E}+04$ \\
\hline $\mathbf{3}$ & $1.026672 \mathrm{E}+05$ \\
\hline $\mathbf{4}$ & $1.368896 \mathrm{E}+05$ \\
\hline $\mathbf{5}$ & $1.711120 \mathrm{E}+05$ \\
\hline $\mathbf{6}$ & $2.053345 \mathrm{E}+05$ \\
\hline $\mathbf{7}$ & $2.395569 \mathrm{E}+05$ \\
\hline $\mathbf{8}$ & $2.737793 \mathrm{E}+05$ \\
\hline $\mathbf{9}$ & $3.080017 \mathrm{E}+05$ \\
\hline $\mathbf{1 0}$ & $3.422241 \mathrm{E}+05$ \\
\hline
\end{tabular}

A Figura 6-19 apresenta a comparação entre as velocidades medidas e calculadas.

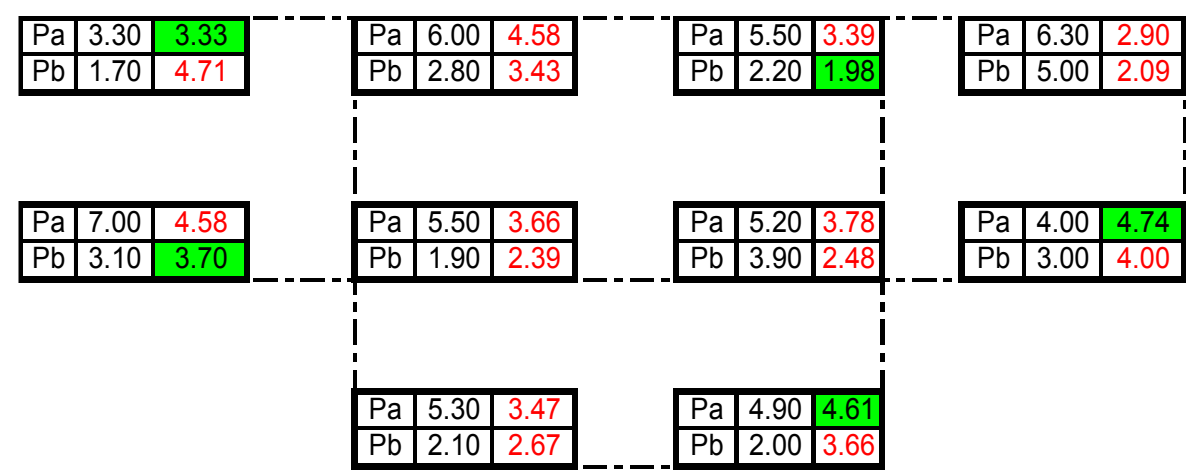

Figura 6-19 - Velocidade Efetiva de Vibração (mm/s) - Ciclo Ida Menor

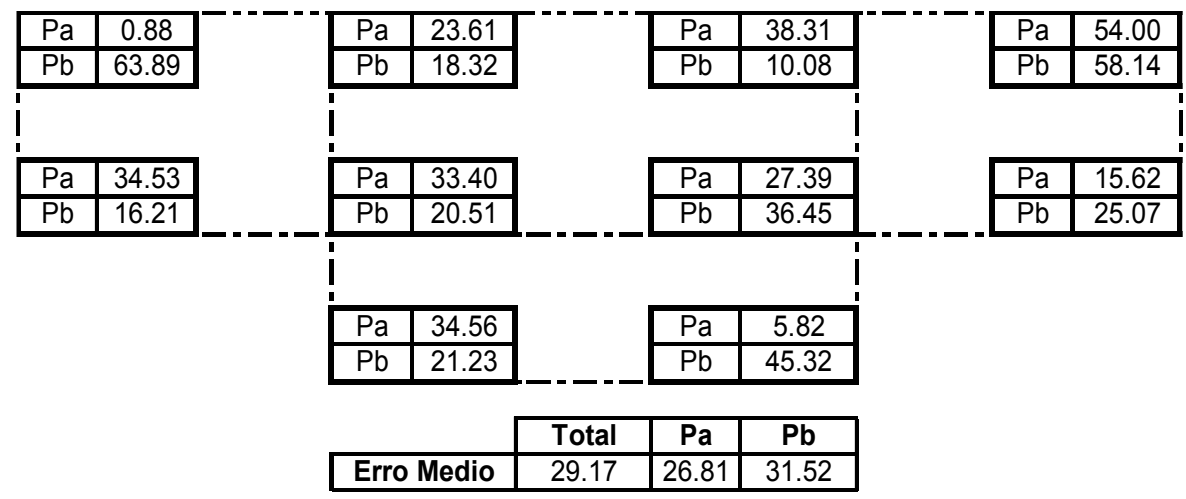

Figura 6-20 - Erros percentuais - Ciclo Ida Menor

As freqüências naturais correspondentes aos dez primeiros modos de vibração são as seguintes. 
Tabela 6-16 - Freqüências naturais de vibração - Ciclo Ida Menor

\begin{tabular}{|c|c|}
\hline $\begin{array}{c}\text { Modos de } \\
\text { Vibração }\end{array}$ & $\begin{array}{c}\text { Frequências } \\
\text { Naturais }(\mathrm{Hz})\end{array}$ \\
\hline 1 & 4.05 \\
\hline 2 & 4.18 \\
\hline 3 & 5.95 \\
\hline 4 & 16.98 \\
\hline 5 & 17.13 \\
\hline 6 & 17.42 \\
\hline 7 & 19.60 \\
\hline 8 & 20.45 \\
\hline 9 & 21.29 \\
\hline 10 & 34.90 \\
\hline
\end{tabular}

\subsubsection{2.}

\section{Ciclo de volta}

Tabela 6-17 - Ensaio E-03 - Ciclo de Volta $-k_{m}$ para $n_{h}=326398.0336 \mathrm{kN} / \mathrm{m}^{3}$

Ciclo Volta - Maior Valor

\begin{tabular}{|c|c|}
\hline $\mathbf{Z}$ & $\mathbf{k}_{\mathbf{m}}(\mathbf{k N} / \mathbf{m})$ \\
\hline $\mathbf{1}$ & $3.263980 \mathrm{E}+05$ \\
\hline $\mathbf{2}$ & $6.527961 \mathrm{E}+05$ \\
\hline $\mathbf{3}$ & $9.791941 \mathrm{E}+05$ \\
\hline $\mathbf{4}$ & $1.305592 \mathrm{E}+06$ \\
\hline $\mathbf{5}$ & $1.631990 \mathrm{E}+06$ \\
\hline $\mathbf{6}$ & $1.958388 \mathrm{E}+06$ \\
\hline $\mathbf{7}$ & $2.284786 \mathrm{E}+06$ \\
\hline $\mathbf{8}$ & $2.611184 \mathrm{E}+06$ \\
\hline $\mathbf{9}$ & $2.937582 \mathrm{E}+06$ \\
\hline $\mathbf{1 0}$ & $3.263980 \mathrm{E}+06$ \\
\hline
\end{tabular}

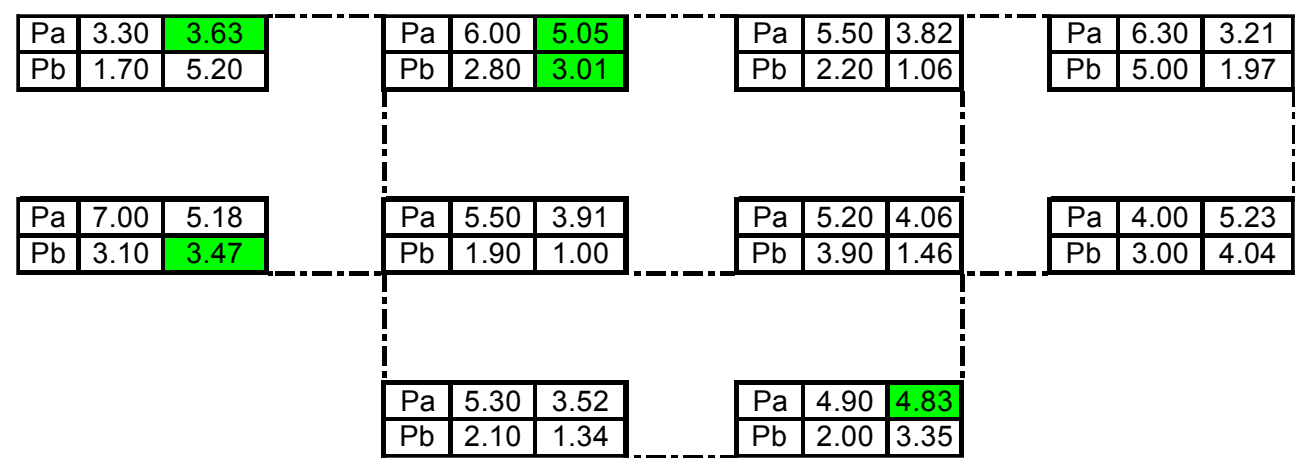

Figura 6-21 - Velocidade Efetiva de Vibração ( $\mathrm{mm} / \mathrm{s})$ - Ciclo Volta Maior 


\begin{tabular}{|l|l|l|l|l|l|l|}
\hline $\mathrm{Pa}$ & 9.14 \\
\hline $\mathrm{Pb}$ & 67.29 \\
\hline
\end{tabular}

Figura 6-22 - Erros percentuais - Ciclo Volta Maior

As freqüências naturais correspondentes aos dez primeiros modos de vibração são as seguintes.

Tabela 6-18 - Freqüências naturais de vibração - Ciclo Volta Maior

\begin{tabular}{|c|c|}
\hline $\begin{array}{c}\text { Modos de } \\
\text { Vibração }\end{array}$ & $\begin{array}{c}\text { Frequências } \\
\text { Naturais }(\mathrm{Hz})\end{array}$ \\
\hline 1 & 4.38 \\
\hline 2 & 4.53 \\
\hline 3 & 6.49 \\
\hline 4 & 17.37 \\
\hline 5 & 20.31 \\
\hline 6 & 21.16 \\
\hline 7 & 36.79 \\
\hline 8 & 37.46 \\
\hline 9 & 38.02 \\
\hline 10 & 41.50 \\
\hline
\end{tabular}

\subsection{3.}

\section{Análise dos resultados}

Neste item, todos os resultados apresentados em 6.3.1 e 6.3 .2 são então interpretados, tanto em termo das velocidades efetivas como em termos das freqüências naturais.

Os erros percentuais correspondentes a cada um dos testes realizados estão resumidos na Tabela 6-19 e na Tabela 6-20, considerando os dados dos ensaios E-16 e E-03, respectivamente. 
Tabela 6-19 - Resumo dos erros percentuais - Ensaio E-16

\begin{tabular}{|c|c|c|c|c|}
\hline Local de & \multicolumn{4}{|c|}{ Erros Médios Percentuais por Ciclo } \\
\cline { 2 - 5 } Avaliação & Ida menor & Ida Maior & Volta Menor & Volta Maior \\
\hline $\mathbf{P a}$ & 24.86 & 24.15 & 24.32 & 24.59 \\
\hline $\mathrm{Pb}$ & 40.23 & 38.74 & 30.30 & 40.81 \\
\hline Global & 32.54 & 31.44 & 27.31 & 32.70 \\
\hline
\end{tabular}

Tabela 6-20 - Resumo dos erros percentuais - Ensaio E-03

\begin{tabular}{|c|c|c|}
\hline Local de & \multicolumn{2}{|c|}{ Erros Médios Percentuais por Ciclo } \\
\cline { 2 - 3 } Avaliação & Ida menor & Volta Maior \\
\hline $\mathbf{P a}$ & 26.81 & 24.01 \\
\hline $\mathrm{Pb}$ & 31.52 & 40.99 \\
\hline Global & 29.17 & 32.50 \\
\hline
\end{tabular}

Os erros globais médios dos pontos altos $P a$ e dos pontos baixos $P b$ resultaram maiores que o admissível. Contudo, vê-se que em alguns casos individuais os erros percentuais entre os dados medidos e os dados calculados resultaram ora dentro dos limites admissíveis, sendo que em certas situações muito menores que o erro máximo limite, ora extremamente divergentes. A partir de critérios adequados de estatística, a eliminação dos resultados individuais que apresentaram muita discrepância entre os dados medidos e calculados poderá mostrar um melhor ajuste entre o modelo e a realidade.

A análise dos números mostrados na Tabela 6-19 e na Tabela 6-20 permite concluir que as velocidades obtidas pelo modelo de elementos finitos tiveram melhor aproximação em relação às velocidades medidas em campo para os pontos da estrutura correspondentes ao topo dos pilares. Além disso, para esses mesmos pontos e entre os ciclos de carregamento, houve pouca variação dos erros percentuais das velocidades efetivas, o que indica a menor suscetibilidade dos pontos mais altos da estrutura às variações das condições do solo.

Nos gráficos abaixo as curvas das velocidades efetivas medidas em campo (linhas pretas) e calculadas (linhas rosa) através do modelo de elementos finitos estão desenhadas simultaneamente em função do parâmetro $n_{h}$ do solo, retroanalisado a partir dos dois ensaios E-03 e E-16. 


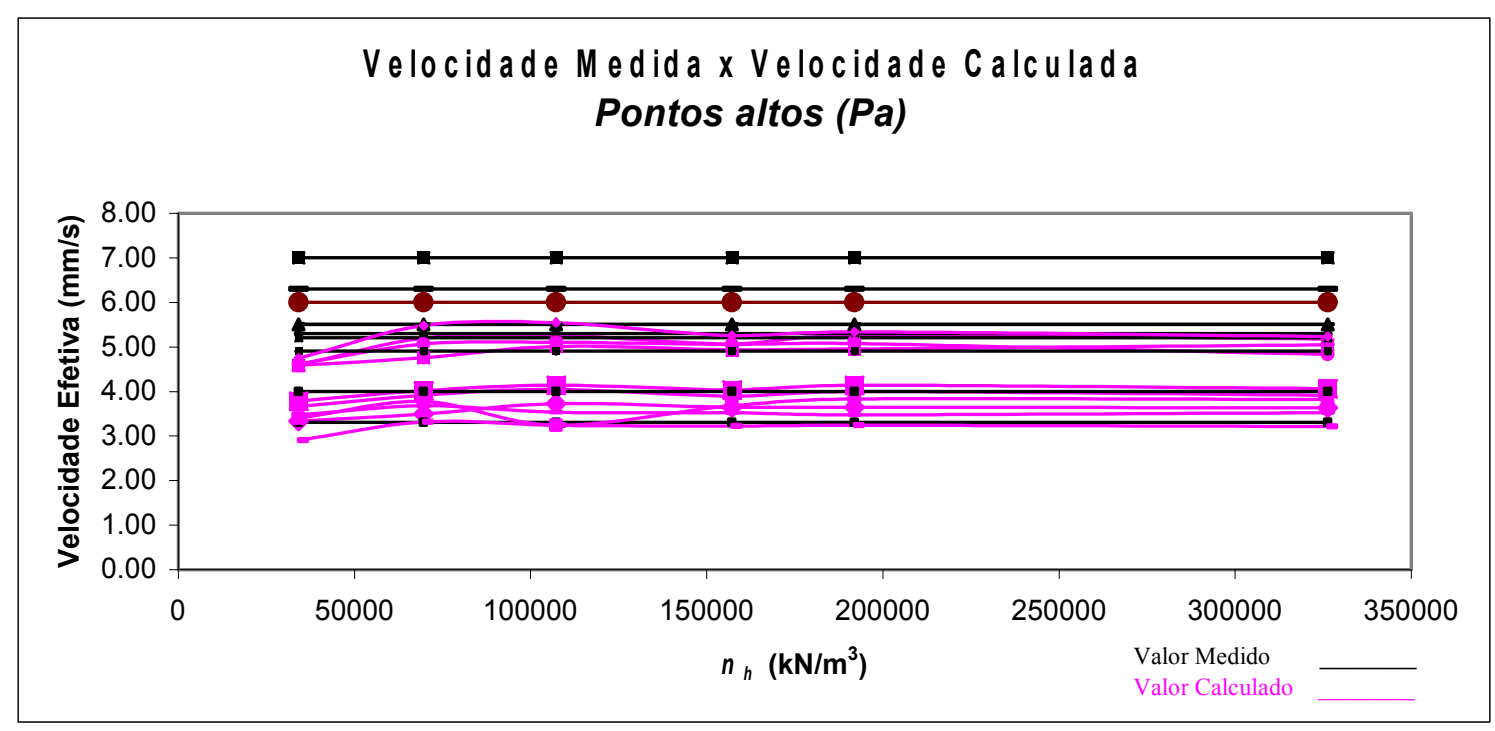

Gráfico 6-4 - Curvas Velocidades Efetivas versus $\boldsymbol{n}_{\boldsymbol{h}}-$ Pontos $\boldsymbol{P}_{\boldsymbol{a}}$

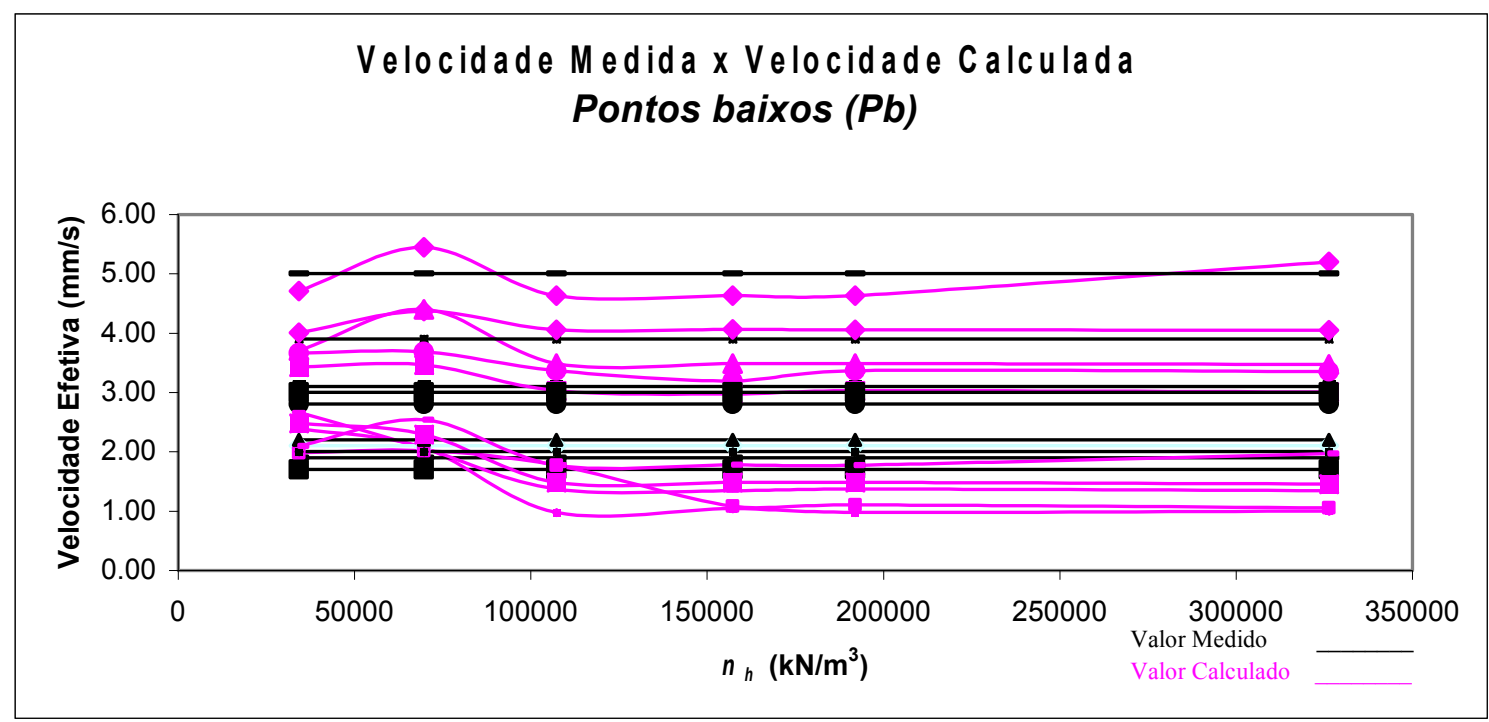

\section{Gráfico 6-5 - Curvas Velocidades Efetivas versus $n_{h}-$ Pontos $P_{b}$}

O Gráfico 6-4 se refere aos pontos altos da estrutura, próximos da laje de apoio do compressor. Dele se observa que as velocidades calculadas estão predominantemente subestimadas para valores do parâmetro $n_{h}$ dentro do intervalo analisado de 34000 $\mathrm{kN} / \mathrm{m}^{3}$ a $326000 \mathrm{kN} / \mathrm{m}^{3}$.

O Gráfico 6-5 se refere aos pontos baixos da estrutura, próximos do nível do terreno. Dele se observa que para valores de $n_{h}$ dentro do intervalo aproximado de $34000 \mathrm{kN} / \mathrm{m}^{3}$ a $80000 \mathrm{kN} / \mathrm{m}^{3}$, as velocidades efetivas calculadas são maiores que as velocidades efetivas medidas em campo. A partir desse valor do parâmetro do solo, ora as velocidades efetivas calculadas predominantemente são maiores que as velocidades efetivas medidas, ora ocorre o contrário. 
O comportamento das freqüências naturais em relação ao parâmetro do solo $n_{h}$ é então analisado a partir dos resultados resumidos na Tabela 6-21 e Gráfico 6-6, referentes ao ensaio E-16, e no Gráfico 6-7 e Tabela 6-22, referentes ao ensaio E-03.

Tabela 6-21 - Freqüências naturais em função dos valores de $\boldsymbol{n}_{\boldsymbol{h}}$ - Ensaio E-16

\begin{tabular}{|c|c|c|c|c|c|}
\hline \multirow{3}{*}{$\begin{array}{l}\text { Modos de } \\
\text { Vibração }\end{array}$} & \multicolumn{4}{|c|}{ Ciclos - Ensaio E-16 } & \multirow{3}{*}{$\begin{array}{c}\text { Variação } \\
(\%)\end{array}$} \\
\hline & Ida menor & Ida Maior & Volta Menor & Volta Maior & \\
\hline & \multicolumn{4}{|c|}{ Frequências Naturais (Hz) } & \\
\hline 1 & 4.31 & 4.33 & 4.20 & 4.26 & 3.15 \\
\hline 2 & 4.46 & 4.48 & 4.34 & 4.41 & 3.18 \\
\hline 3 & 6.39 & 6.42 & 6.20 & 6.31 & 3.35 \\
\hline 4 & 17.37 & 17.37 & 17.36 & 17.36 & 0.02 \\
\hline 5 & 20.28 & 20.29 & 20.07 & 20.24 & 1.09 \\
\hline 6 & 21.12 & 21.13 & 20.61 & 21.05 & 2.47 \\
\hline 7 & 28.35 & 30.41 & 21.96 & 24.89 & 27.78 \\
\hline 8 & 28.76 & 30.87 & 21.99 & 25.20 & 28.78 \\
\hline 9 & 32.11 & 34.42 & 24.45 & 28.17 & 28.98 \\
\hline 10 & 38.00 & 38.00 & 37.58 & 37.99 & 1.12 \\
\hline
\end{tabular}

\begin{tabular}{|l|l|l|l|l|}
\hline $\mathbf{n}_{\mathrm{h}}\left(\mathbf{k N} / \mathbf{m}^{3}\right)$ & 157227.3290 & 191974.2753 & 69712.6988 & 107239.9283 \\
\hline
\end{tabular}

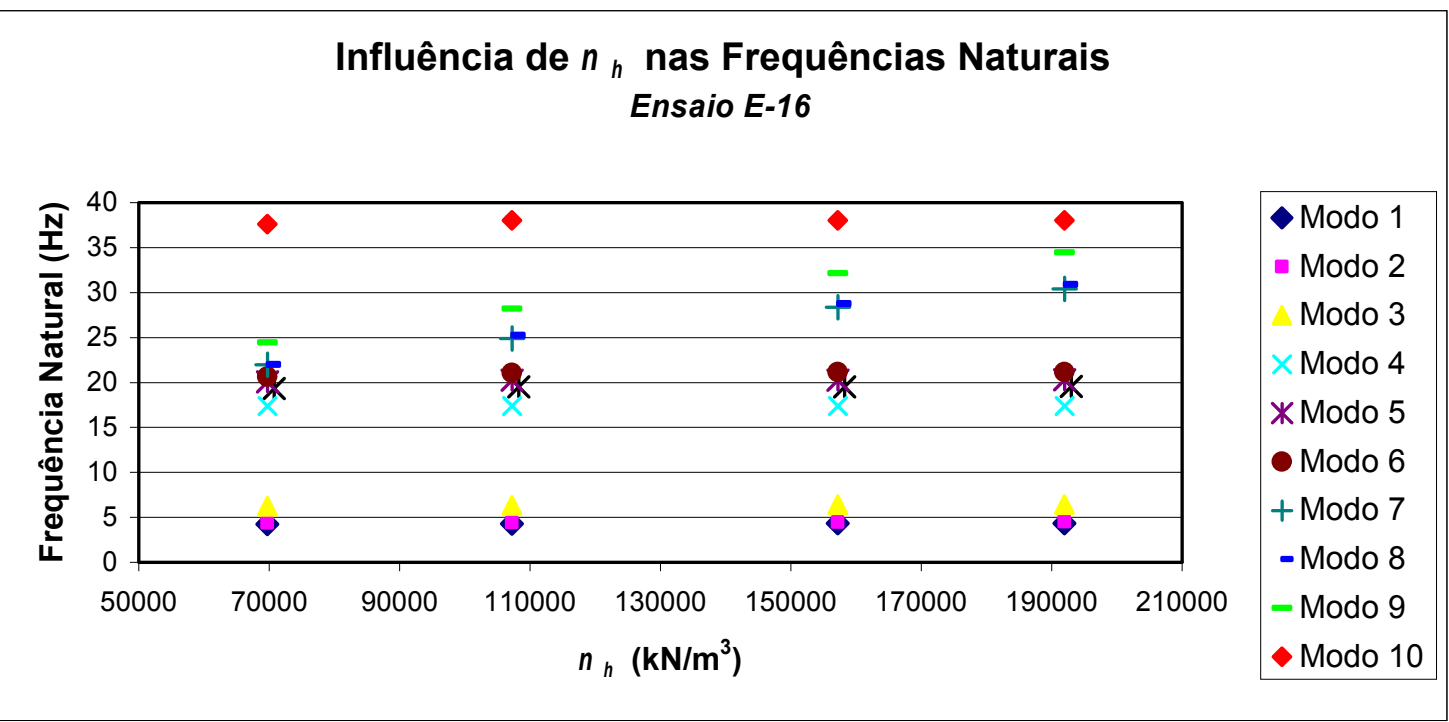

Gráfico 6-6 - Curva Freqüência Natural versus $\boldsymbol{n}_{\boldsymbol{h}}$ - Ensaio E-16

Para os seis primeiros modos de vibração, a variação percentual das freqüências naturais não foi superior a 3,5\% quando se varia o valor de $n_{h}$ de aproximadamente $64 \%$, ou seja, quando $n_{h}$ está entre $69000 \mathrm{kN} / \mathrm{m}^{3}$ e $192000 \mathrm{kN} / \mathrm{m}^{3}$. Em contrapartida, a variação percentual das freqüências naturais a partir do sétimo modo de vibração, quando se varia o valor de $n_{h}$, foi de aproximadamente $28 \%$.

Conclui-se que a verificação da condição de ressonância para compressores alternativos com freqüência de operação até $20 \mathrm{~Hz}$, instalados nos solos estudados no 
presente trabalho, será firme e confiável uma vez que a maioria dos códigos normativos e a boa prática de engenharia de fundações de máquinas exigem a defasagem mínima de $20 \%$ entre a freqüência de operação dos equipamentos e a freqüência natural do sistema estrutural de suporte.

Em relação ao comportamento das freqüências naturais em função do parâmetro do solo $n_{h}$, retroanalisado a partir dos resultados do ensaio E-03, verifica-se a mesma tendência observada anteriormente, conforme se observa da Tabela 6-22 e do Gráfico 6-7.

Tabela 6-22 - Freqüências naturais em função dos valores de $n_{h}$ - Ensaio E-03

\begin{tabular}{|c|c|c|c|}
\hline \multirow{2}{*}{$\begin{array}{c}\text { Modos de } \\
\text { Vibração }\end{array}$} & \multicolumn{2}{|c|}{ Ciclos - Ensaio E-03 } & Variação \\
\cline { 2 - 3 } & Ida menor & Volta Maior & \multirow{2}{*}{\begin{tabular}{c} 
I) \\
\cline { 2 - 3 }
\end{tabular}} \\
\hline $\mathbf{1}$ & 4.05 & 4.38 & 7.58 \\
\hline $\mathbf{2}$ & 4.18 & 4.53 & 7.66 \\
\hline $\mathbf{3}$ & 5.95 & 6.49 & 8.30 \\
\hline $\mathbf{4}$ & 16.98 & 17.37 & 2.21 \\
\hline $\mathbf{5}$ & 17.13 & 20.31 & 15.67 \\
\hline $\mathbf{6}$ & 17.42 & 21.16 & 17.69 \\
\hline $\mathbf{7}$ & 19.60 & 36.79 & 46.73 \\
\hline $\mathbf{8}$ & 20.45 & 37.46 & 45.41 \\
\hline $\mathbf{9}$ & 21.29 & 38.02 & 44.01 \\
\hline $\mathbf{1 0}$ & 34.90 & 41.50 & 15.92 \\
\hline \multicolumn{3}{|c|}{} \\
\hline $\mathbf{n}_{\mathbf{h}} \mathbf{( k N / \mathbf { m } ^ { 3 } \mathbf { ) }}$ & 34222.4094 & 326398.0336 & 89.52 \\
\hline
\end{tabular}

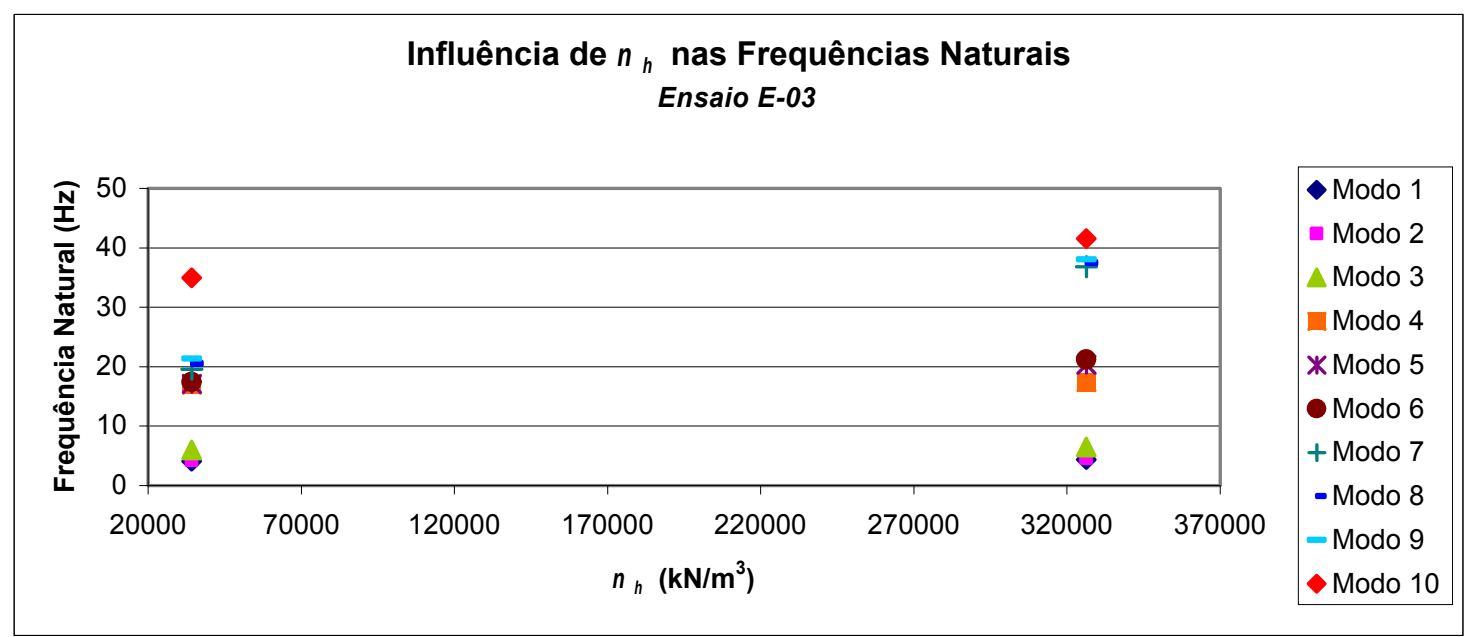

Gráfico 6-7 - Curva Freqüência Natural versus $n_{h}$ - Ensaio E-03

Para os seis primeiros modos de vibração, a variação percentual das freqüências naturais não foi superior a $18 \%$ quando se varia o valor de $n_{h}$ de aproximadamente $89 \%$, ou seja, quando $n_{h}$ está entre $34000 \mathrm{kN} / \mathrm{m}^{3}$ e $327000 \mathrm{kN} / \mathrm{m}^{3}$. Entre esses modos, os quatro primeiros evidenciam menores variações, não ultrapassando $8.3 \%$ 
Em contrapartida, a variação percentual das freqüências naturais a partir do sétimo modo de vibração, quando se varia o valor de $n_{h}$, foi de aproximadamente $45 \%$.

Conclui-se novamente que a verificação da condição de ressonância para compressores alternativos com freqüência de operação até $20 \mathrm{~Hz}$, instalados nos solos estudados no presente trabalho, será firme e confiável uma vez que a maioria dos códigos normativos e a boa prática de engenharia de fundações de máquinas exigem a defasagem mínima de $20 \%$ entre a freqüência de operação dos equipamentos e a freqüência natural do sistema estrutural de suporte.

\section{4 .}

\section{Teste 4: modelo com $k_{m}$ cíclico e constante com a profundidade}

\subsection{1. Ensaio E-03}

A seguir está apresentada a avaliação da resposta do sistema aos valores do coeficiente de mola retroanalisados a partir do ensaio de carregamento horizontal e do método de Hetenyi (1930). Uma vez que os resultados obtidos no item 6.3 mostram-se convergentes entre si ao se utilizar os dados do ensaio de campo E-03 e E-16, adota-se para efeito dos testes apenas os dados referentes ao ensaio E-03. Diferentemente do que foi feito para o caso em que o parâmetro do solo é variável com a profundidade, aqui somente serão avaliados os menores e maiores valores da propriedade elástica do subsolo, o que corresponde ao menor valor do ciclo de ida e ao maior valor do ciclo de volta.

\subsubsection{1. \\ Ciclo de ida}

O ciclo de ida corresponde ao valor do coeficiente de mola $k_{m}=16093.5988 \mathrm{kN} / \mathrm{m}$ reapresentado novamente abaixo. Este é o ciclo que resultou no menor valor de $k_{m}$. 
Tabela 6-23 - Ensaio E-03 - Ciclo de Ida $-k_{m}=16093.5988 \mathrm{kN} / \mathrm{m}$

Ciclo Ida - Menor Valor

\begin{tabular}{|c|c|}
\hline $\mathbf{Z}$ & $\mathbf{k}_{\mathbf{m}}(\mathbf{k N} / \mathbf{m})$ \\
\hline $\mathbf{1}$ & $1.609360 \mathrm{E}+04$ \\
\hline $\mathbf{2}$ & $1.609360 \mathrm{E}+04$ \\
\hline $\mathbf{3}$ & $1.609360 \mathrm{E}+04$ \\
\hline $\mathbf{4}$ & $1.609360 \mathrm{E}+04$ \\
\hline $\mathbf{5}$ & $1.609360 \mathrm{E}+04$ \\
\hline $\mathbf{6}$ & $1.609360 \mathrm{E}+04$ \\
\hline $\mathbf{7}$ & $1.609360 \mathrm{E}+04$ \\
\hline $\mathbf{8}$ & $1.609360 \mathrm{E}+04$ \\
\hline $\mathbf{9}$ & $1.609360 \mathrm{E}+04$ \\
\hline $\mathbf{1 0}$ & $1.609360 \mathrm{E}+04$ \\
\hline
\end{tabular}

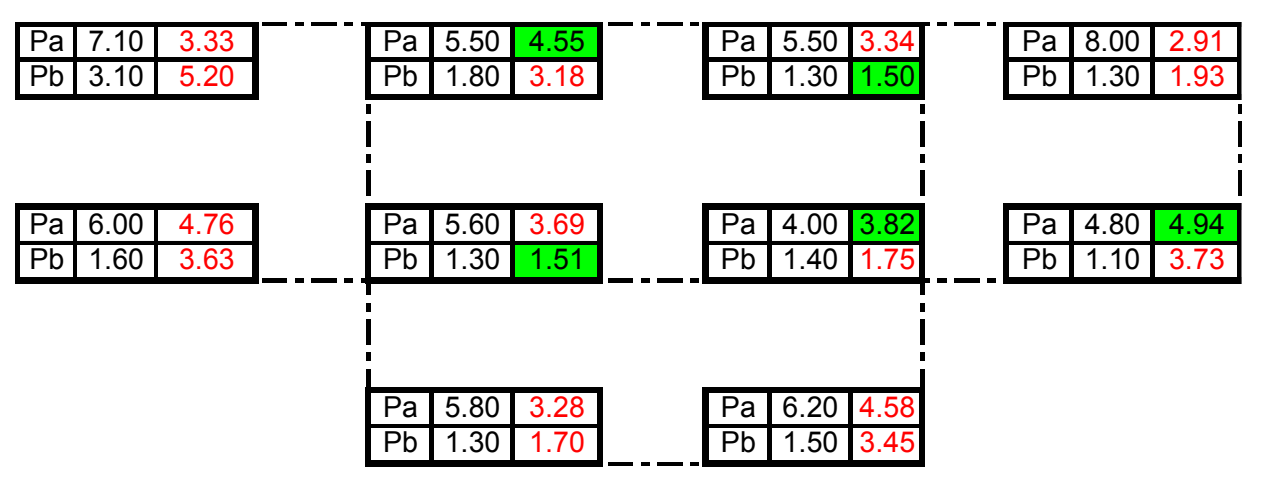

Figura 6-23 - Velocidade Efetiva de Vibração $(\mathrm{mm} / \mathrm{s})$ - Ciclo Ida Menor

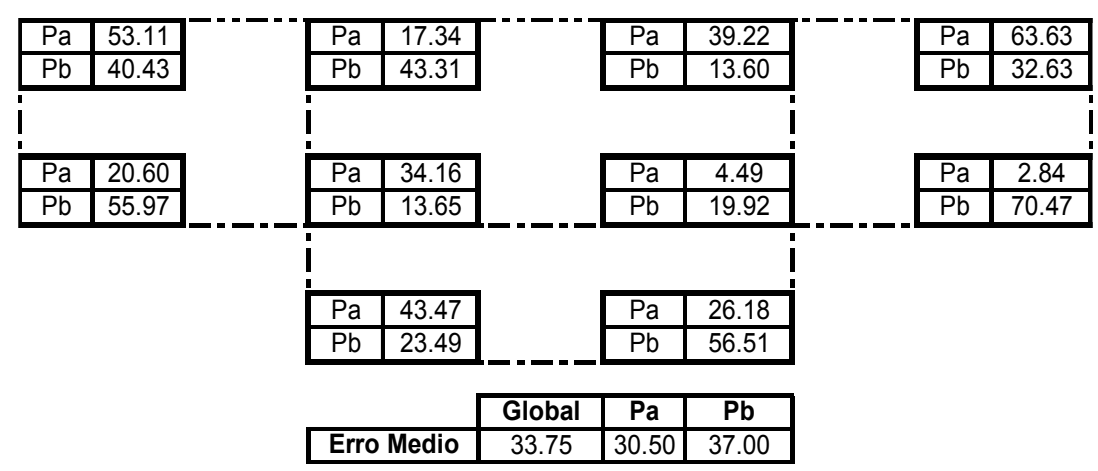

Figura 6-24 - Erros percentuais - Ciclo Ida Menor

As freqüências naturais correspondentes aos dez primeiros modos de vibração são as seguintes. 
Tabela 6-24 - Freqüências naturais de vibração - Mola Constante - Ciclo Ida Menor

\begin{tabular}{|c|c|}
\hline $\begin{array}{c}\text { Modos de } \\
\text { Vibração }\end{array}$ & $\begin{array}{c}\text { Frequências } \\
\text { Naturais }(\mathrm{Hz})\end{array}$ \\
\hline 1 & 3.70 \\
\hline 2 & 3.82 \\
\hline 3 & 5.31 \\
\hline 4 & 12.39 \\
\hline 5 & 12.60 \\
\hline 6 & 14.69 \\
\hline 7 & 17.37 \\
\hline 8 & 20.37 \\
\hline 9 & 21.22 \\
\hline 10 & 32.22 \\
\hline
\end{tabular}

\subsubsection{2.}

Ciclo de volta

Tabela 6-25 - Ensaio E-03 - Ciclo de volta $-k_{m}=97769.3507 \mathrm{kN} / \mathrm{m}$

\begin{tabular}{|c|c|}
\multicolumn{2}{c}{ Ciclo Volta - Maior Valor } \\
\hline $\mathbf{Z}$ & $\mathbf{k}(\mathbf{k N} / \mathbf{m})$ \\
\hline $\mathbf{1}$ & $9.776935 \mathrm{E}+04$ \\
\hline $\mathbf{2}$ & $9.776935 \mathrm{E}+04$ \\
\hline $\mathbf{3}$ & $9.776935 \mathrm{E}+04$ \\
\hline $\mathbf{4}$ & $9.776935 \mathrm{E}+04$ \\
\hline $\mathbf{5}$ & $9.776935 \mathrm{E}+04$ \\
\hline $\mathbf{6}$ & $9.776935 \mathrm{E}+04$ \\
\hline $\mathbf{7}$ & $9.776935 \mathrm{E}+04$ \\
\hline $\mathbf{8}$ & $9.776935 \mathrm{E}+04$ \\
\hline $\mathbf{9}$ & $9.776935 \mathrm{E}+04$ \\
\hline $\mathbf{1 0}$ & $9.776935 \mathrm{E}+04$ \\
\hline
\end{tabular}

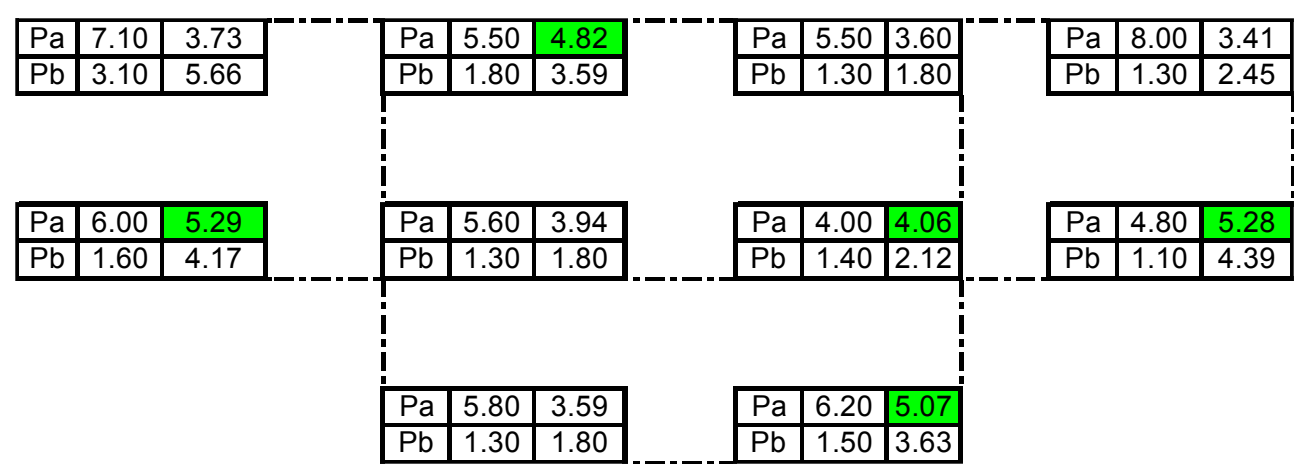

Figura 6-25 - Velocidade Efetiva de Vibração ( $\mathrm{mm} / \mathrm{s})$ - Ciclo Volta Maior 


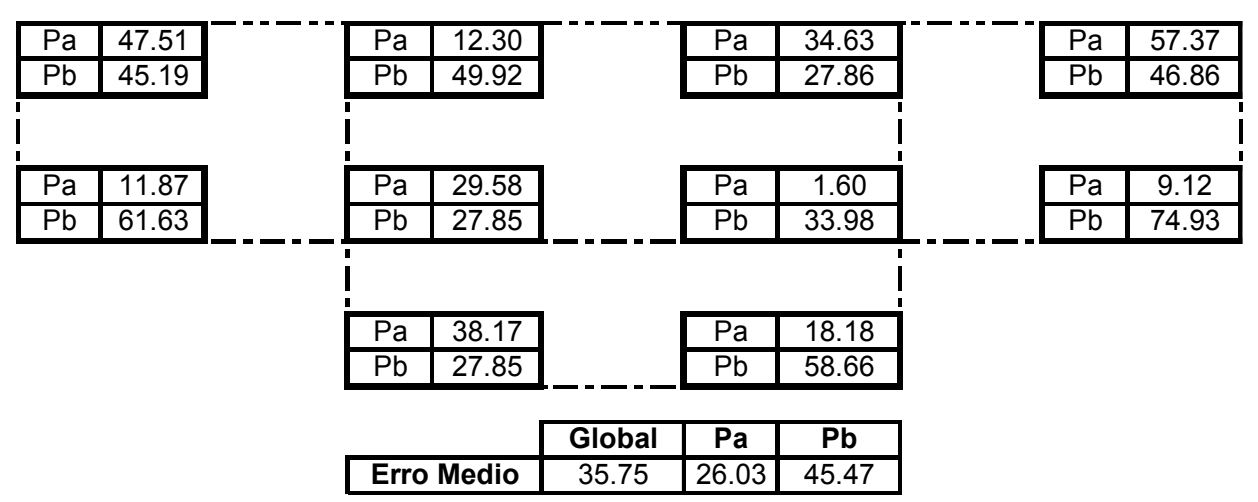

Figura 6-26 - Erros percentuais - Ciclo Volta Maior

As freqüências naturais correspondentes aos dez primeiros modos de vibração são as seguintes.

Tabela 6-26 - Freqüências naturais de vibração Mola Constante Ciclo Volta Maior

\begin{tabular}{|c|c|}
\hline $\begin{array}{c}\text { Modos de } \\
\text { Vibração }\end{array}$ & $\begin{array}{c}\text { Frequências } \\
\text { Naturais }(\mathrm{Hz})\end{array}$ \\
\hline 1 & 4.24 \\
\hline 2 & 4.38 \\
\hline 3 & 6.26 \\
\hline 4 & 17.36 \\
\hline 5 & 20.11 \\
\hline 6 & 20.79 \\
\hline 7 & 23.01 \\
\hline 8 & 23.24 \\
\hline 9 & 25.95 \\
\hline 10 & 37.97 \\
\hline
\end{tabular}

\subsection{2.}

\section{Análise dos resultados}

Neste item, todos os resultados apresentados em 6.4.1 são então interpretados, tanto em termo das velocidades efetivas como em termos das freqüências naturais.

Os erros percentuais correspondentes a cada um dos testes realizados neste item estão resumidos na tabela Tabela 6-27.

Tabela 6-27 - Resumo dos erros percentuais para cada teste

\begin{tabular}{|c|c|c|}
\hline $\begin{array}{c}\text { Local de } \\
\text { Avaliação }\end{array}$ & \multicolumn{2}{|c|}{ Erros Médios Percentuais por Ciclo } \\
\cline { 2 - 3 } & Ida menor & Volta Maior \\
\hline $\mathbf{P a}$ & 30.50 & 26.03 \\
\hline $\mathrm{Pb}$ & 37.00 & 45.47 \\
\hline Global & 33.75 & 35.75 \\
\hline
\end{tabular}

Conforme também ocorreu nos testes anteriores, os erros globais médios totais, dos pontos altos $P a$ e dos pontos baixos $P b$ resultaram maiores que o admissível, sendo 
que em alguns casos individuais, o erro percentual entre os dados medidos e os dados calculados resultaram ou dentro dos limites admissíveis, em certas situações muito menores que o erro máximo limite, e em outros casos extremamente divergentes.

Novamente as velocidades obtidas pelo modelo de elementos finitos tiveram melhor aproximação com as velocidades medidas em campo somente para os pontos da estrutura correspondentes ao topo dos pilares.

De forma geral, a magnitude dos erros foi maior nos casos em que o método de Hetenyi (1930) foi utilizado para estimativa dos coeficientes de mola, contudo não significantemente maior do que a magnitude dos erros nos casos em que a propriedade elástica do solo varia com a profundidade. Esse fato mostra que o solo influencia a resposta do sistema estrutural aos carregamentos dinâmicos até certa profundidade.

Nos gráficos abaixo as curvas das velocidades efetivas medidas em campo (linhas pretas) e calculadas (linhas rosa) através do modelo de elementos finitos estão desenhadas simultaneamente em função do parâmetro $n_{h}$ do solo, retroanalisado a partir do ensaio E-03.

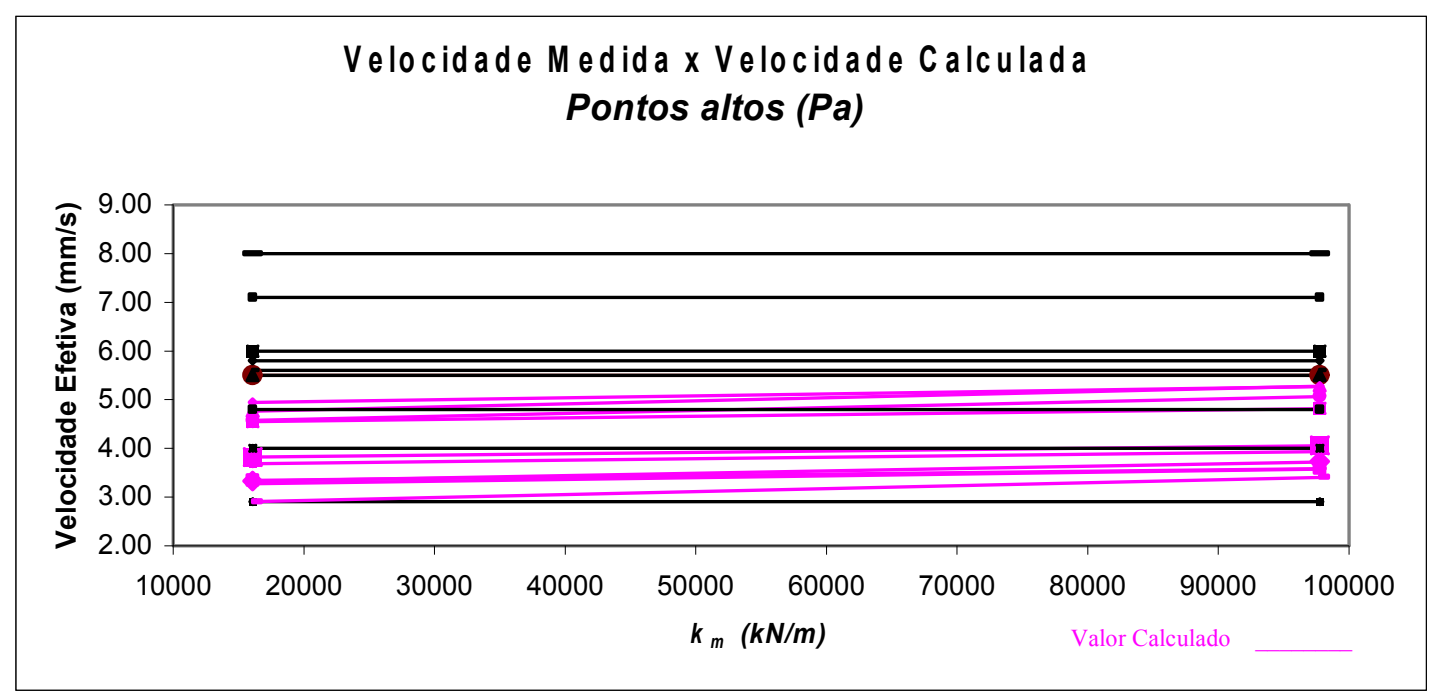

Gráfico 6-8 - Curvas Velocidades Efetivas versus $\boldsymbol{k}_{\boldsymbol{m}}$ - Pontos $\boldsymbol{P}_{\boldsymbol{a}}$ 


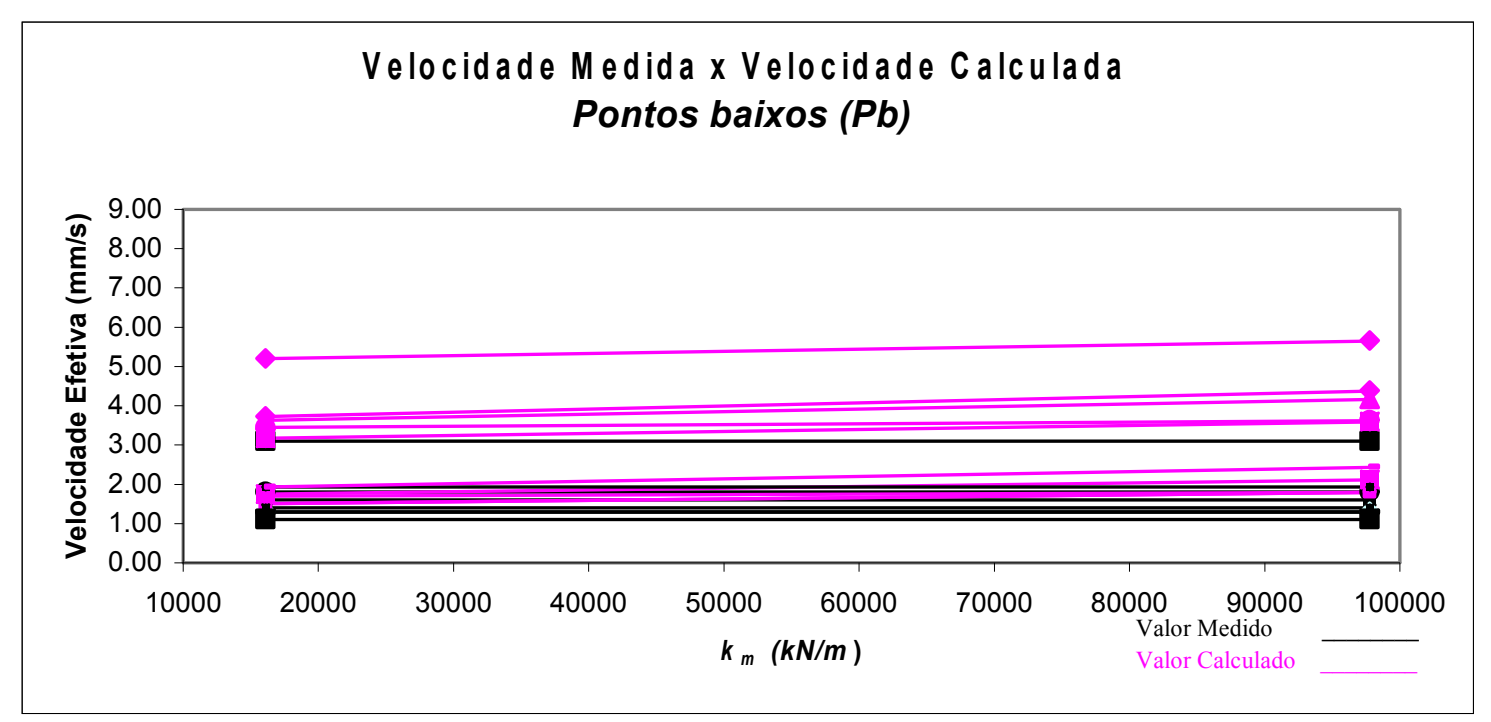

Gráfico 6-9 - Curvas Velocidades Efetivas versus $\boldsymbol{k}_{\boldsymbol{m}}-$ Pontos $\boldsymbol{P}_{\boldsymbol{b}}$

O Gráfico 6-8 se refere aos pontos altos da estrutura, próximos da laje de apoio do compressor. Dele se observa que as velocidades calculadas estão predominantemente subestimadas para valores do parâmetro $k_{m}$ dentro do intervalo analisado de 16000 $\mathrm{kN} / \mathrm{m}$ a $100000 \mathrm{kN} / \mathrm{m}$.

O Gráfico 6-9 se refere aos pontos baixos da estrutura, próximos do nível do terreno. Dele se observa que para valores de $k_{m}$ dentro do intervalo aproximado de $16000 \mathrm{kN} / \mathrm{m}$ a $100000 \mathrm{kN} / \mathrm{m}$, as velocidades efetivas calculadas são maiores que as velocidades efetivas medidas em campo.

O comportamento das freqüências naturais em relação ao parâmetro do solo $k_{m}$ é então analisado a partir dos resultados resumidos na Tabela 6-21 e Gráfico 6-6, referentes ao ensaio E-16, e no Gráfico 6-7 e Tabela 6-22, referentes ao ensaio E-03.

Tabela 6-28 - Freqüências naturais em função dos valores de $\boldsymbol{k}_{m}$

\begin{tabular}{|c|c|c|c|}
\hline \multirow{3}{*}{$\begin{array}{l}\text { Modos de } \\
\text { Vibração }\end{array}$} & \multicolumn{2}{|c|}{ Ensaio E-03 } & \multirow{3}{*}{$\begin{array}{c}\text { Variação } \\
\text { (\%) }\end{array}$} \\
\hline & Ida menor & \begin{tabular}{|l|} 
Volta Maior \\
\end{tabular} & \\
\hline & FREQUÉNCIAS I & NATURAIS (Hz) & \\
\hline 1 & 3.70 & \begin{tabular}{|c|}
4.24 \\
\end{tabular} & 12.68 \\
\hline 2 & 3.82 & 4.38 & 12.73 \\
\hline 3 & 5.31 & 6.26 & 15.22 \\
\hline$\overline{4}$ & 12.39 & 17.36 & 28.63 \\
\hline 5 & 12.60 & 20.11 & 37.32 \\
\hline 6 & 14.69 & 20.79 & 29.32 \\
\hline 7 & 17.37 & 23.01 & 24.53 \\
\hline 8 & 20.37 & 23.24 & 12.35 \\
\hline 9 & 21.22 & 25.95 & 18.25 \\
\hline 10 & 32.22 & 37.97 & 15.14 \\
\hline$k_{m}(k N / m)$ & 34222 & 326398 & \\
\hline
\end{tabular}




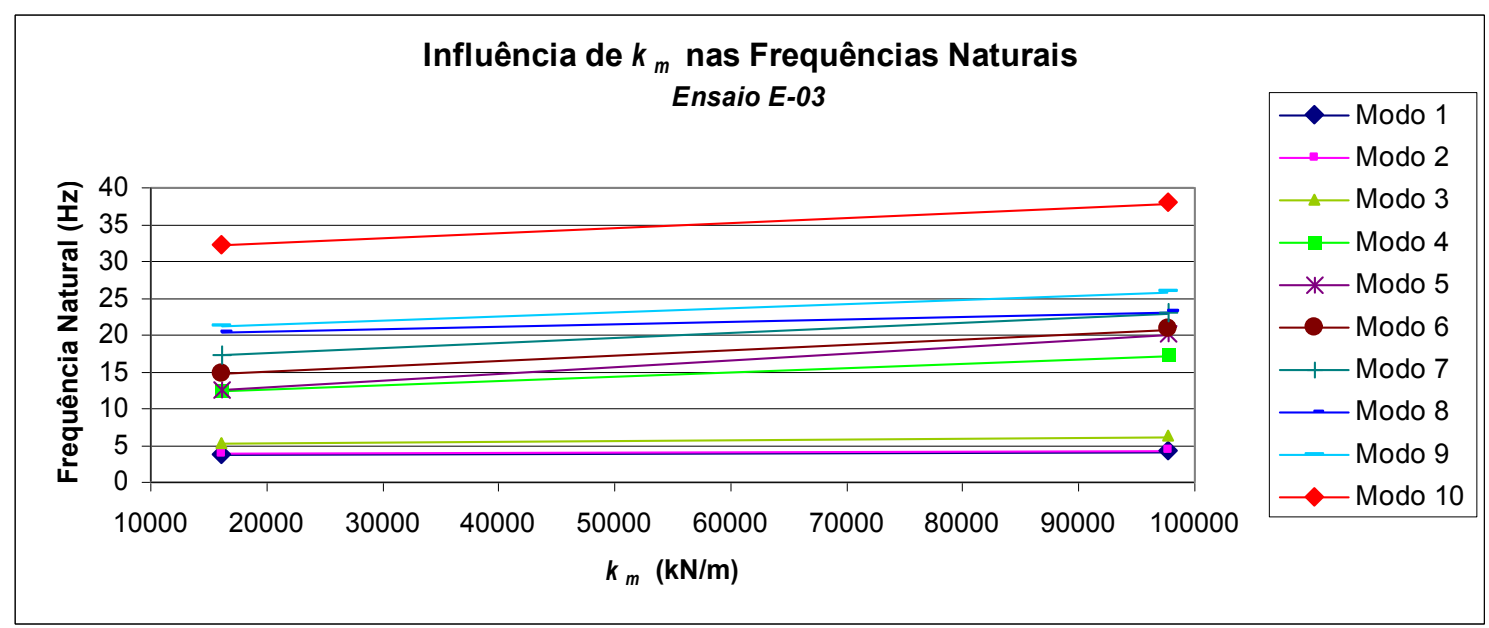

\section{Gráfico 6-10 - Curva Freqüência Natural versus $\boldsymbol{k}_{\boldsymbol{m}}$}

Para os três primeiros modos de vibração, a variação percentual das freqüências naturais não foi superior a $15,5 \%$ quando se varia o valor de $k_{m}$ de aproximadamente $84 \%$, ou seja, quando $k_{m}$ está entre $16000 \mathrm{kN} / \mathrm{m}^{3}$ e $97000 \mathrm{kN} / \mathrm{m}^{3}$. Em contrapartida, dentro desse mesmo intervalo de valores de $k_{m}$, a variação percentual das freqüências naturais entre o quarto e o sétimo modos foi superior a $24 \%$

Conclui-se que a verificação da condição de ressonância para compressores alternativos com freqüência de operação até $15 \mathrm{~Hz}$, instalados nos solos estudados no presente trabalho, será firme e confiável uma vez que a maioria dos códigos normativos e a boa prática de engenharia de fundações de máquinas exigem a defasagem mínima de $20 \%$ entre a freqüência de operação dos equipamentos e a freqüência natural do sistema estrutural de suporte.

\section{5 . \\ Comparação entre modelos numéricos simplificados e em Elementos Finitos}

Neste item as freqüências naturais obtidas a partir dos modelos simplificados são então confrontadas com as freqüências naturais obtidas do modelo em elementos finitos.

Os modelos simplificados são capazes de representar no máximo quatro graus de liberdade. O modelo de Rausch (1959) representa apenas as translações (horizontal e vertical). O modelo de Barkan pode representar as translações (horizontal e vertical) e a rotação da laje de apoio em seu próprio plano. Com o modelo proposto por Chowdhury (1984) é possível obter as translações horizontais da laje de apoio e das fundações, além de suas rotações, embora no caso estudado a rotação das fundações tenha sido desconsiderada. Portanto, de modo a permitir comparações, são consideradas do modelo 
em elementos finitos apenas as freqüências naturais correspondentes a esses modos de vibração, quais sejam modos 1,3 e 4 .

A Figura 6-27, Figura 6-28 e Figura 6-29 mostram graficamente e simultaneamente as freqüências naturais calculadas através do modelo simplificado proposto por Chowdhury (1984), e as freqüências naturais obtidas do modelo em elementos finitos. Para efeito das comparações, a escolha do modelo simplificado citado se justifica pelo fato de melhor representar a interação entre solo e estrutura, que é exatamente a mesma motivação de modelos de fundações de máquinas baseados em elementos finitos.
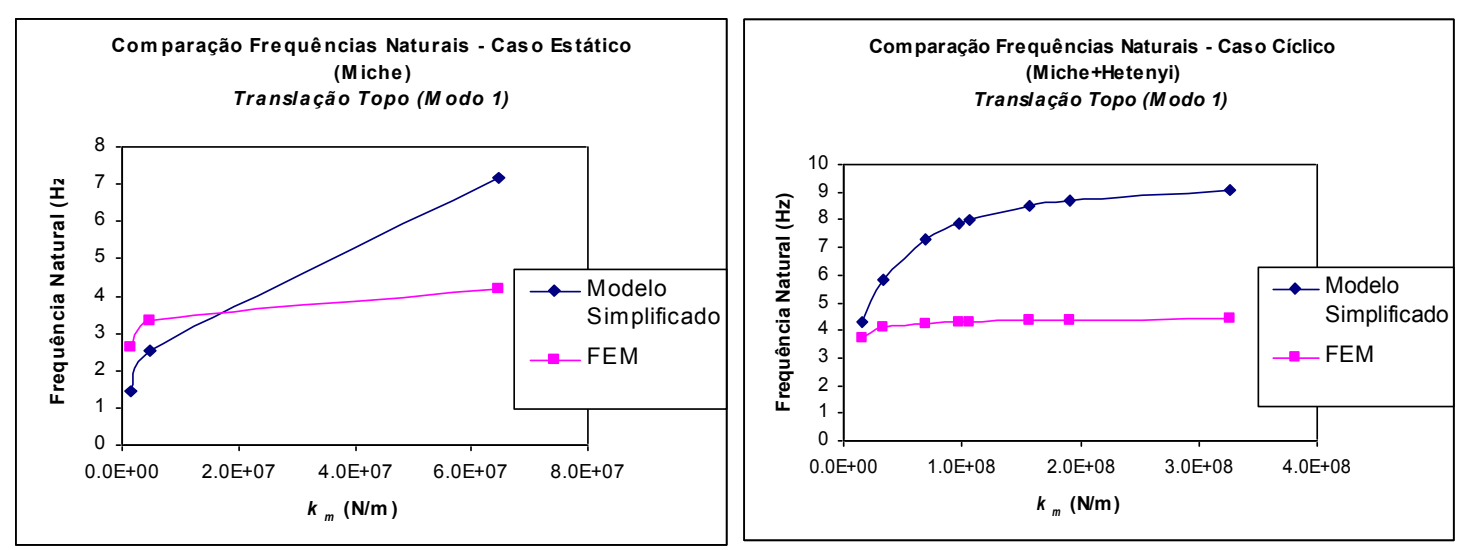

Figura 6-27 - Comparação Modelo Simplificado versus FEM - Modo 1
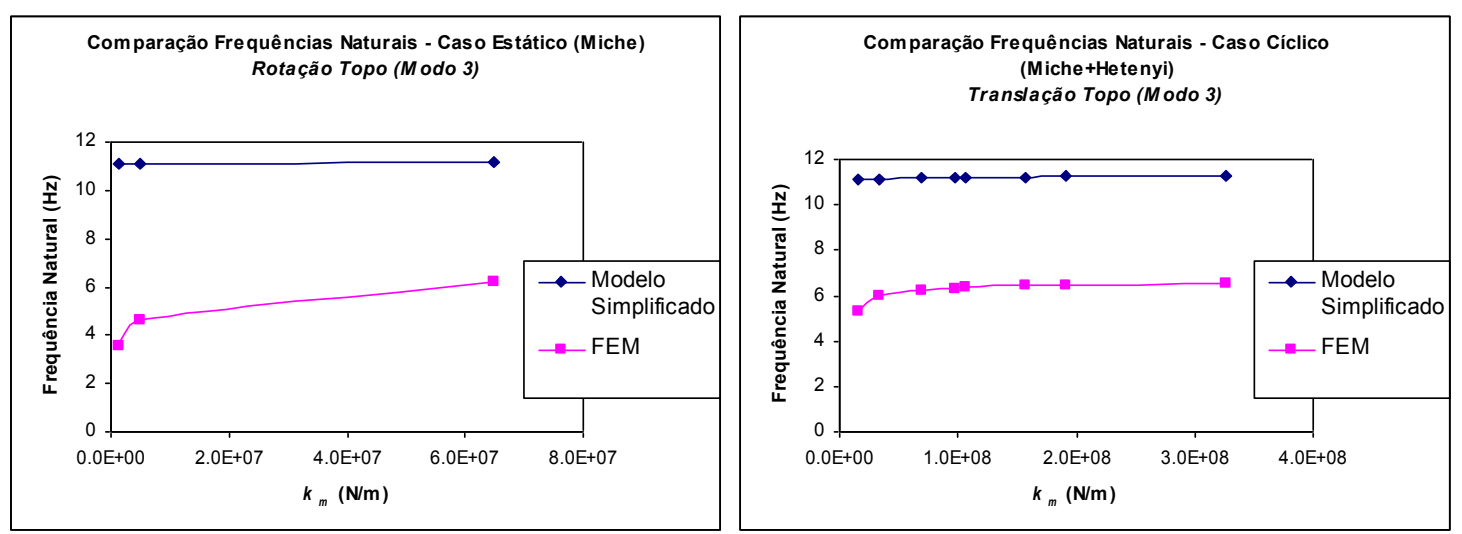

Figura 6-28 - Comparação Modelo Simplificado versus FEM - Modo 3 

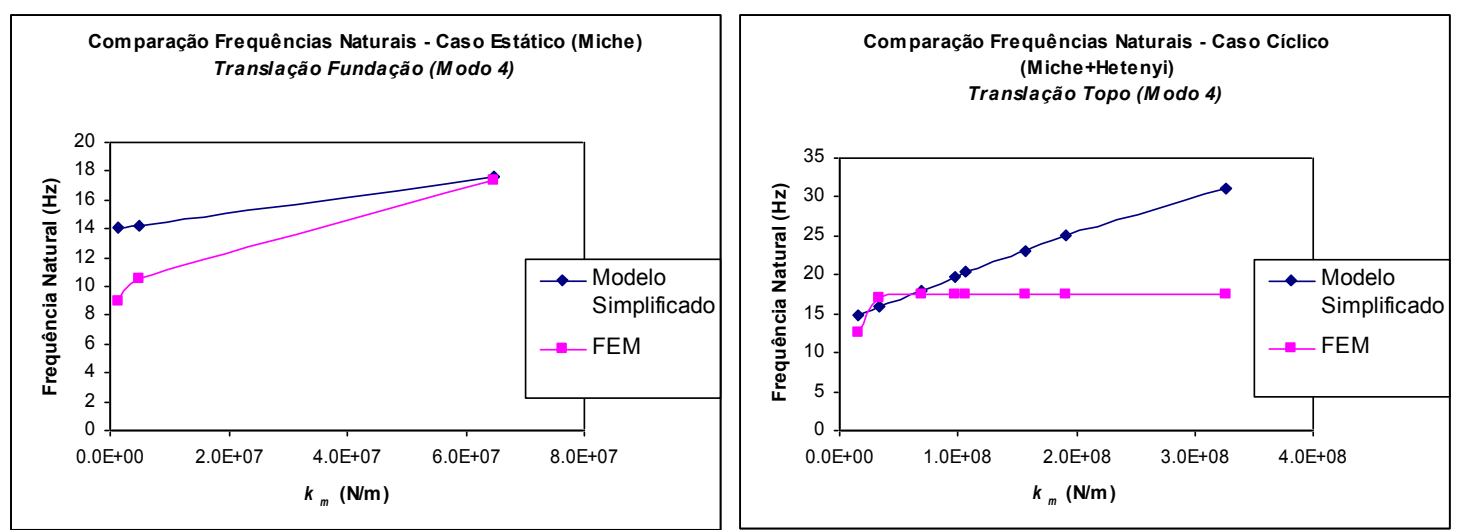

Figura 6-29 - Comparação Modelo Simplificado versus FEM - Modo 4

De forma geral, conclui-se que o modelo simplificado massa-mola fornece valores de freqüências naturais superiores aos valores obtidos com o modelo em elementos finitos para quaisquer dos modos considerados. Essa conclusão vale para o domínio do parâmetro $k_{m}$ compreendido entre $20000 \mathrm{kN} / \mathrm{m}$ e $64000 \mathrm{kN} / \mathrm{m}$, quando este é obtido por ensaio estático, e entre $69000 \mathrm{kN} / \mathrm{m}$ e $326000 \mathrm{kN} / \mathrm{m}$, quando é obtido por carregamentos cíclicos. 


\section{7 \\ Considerações finais}

\section{1.}

\section{Conclusões}

Um dos principais objetivos do presente trabalho consiste no aperfeiçoamento do processo de projeto de estruturas e fundações de máquinas. De forma geral, a maneira como o trabalho está apresentado retrata os procedimentos a serem seguidos na concepção de um sistema estrutural submetido a carregamentos dinâmicos alternativos. Portanto, sugere-se que sejam seguidos cronologicamente cada um dos passos, desde o levantamento dos dados de cada elemento constituinte do sistema de interação estruturasolo-equipamento, passando por ensaios de campo e terminando com as simulações do seu comportamento. Com o cumprimento dessas etapas, espera-se que naturalmente o comportamento do sistema após inicio de operação seja concordante, dentro de limites aceitáveis, com as previsões do inicio do empreendimento. Deve-se ressaltar que essa proposta é válida também para outros tipos de plantas industriais, que não somente plantas de refino de petróleo.

Em termos das velocidades efetivas de vibração e das freqüências naturais, são tecidas conclusões específicas acerca das modelagens desenvolvidas.

Ao se restringir no modelo de elementos finitos todos os graus de liberdade da estrutura no nível das fundações, negligenciando a influencia das deformações do solo na resposta do sistema, constata-se que a resposta do sistema aos carregamentos dinâmicos diverge significantemente da resposta medida na estrutura real.

Ao se utilizar parâmetros do solo obtidos sob condições estáticas, observa-se intervalos distintos de valores de $n_{h}$ onde a resposta dinâmica do sistema ora é superestimada e ora é subestimada. Para os valores de $n_{h}$ estático dentro do intervalo típico do solo estudado, observa-se que as freqüências naturais apresentam variação significativa. Praticamente, apenas as freqüências naturais correspondentes aos modos 8 e 9 apresentaram variação inferior a 20\%, alertando-se assim sobre a necessidade da 
determinação cuidadosa do parâmetro do solo de tal forma a não proporcionar erros de interpretação da condição de ressonância do sistema.

Ao se utilizar parâmetros do solo obtidos sob condições cíclicas, observa-se também intervalos distintos de valores de $n_{h}$ onde a resposta dinâmica pode ser sub ou superestimada. Em relação às freqüências naturais, constata-se que a partir do sétimo modo de vibração há significativa variabilidade de sua magnitude em função de $n_{h}$. Para o caso de compressores com alta freqüência de operação, a escolha do parâmetro do solo deve ser cuidadosa de modo a evitar erro de interpretação da condição de ressonância do sistema. Já os seis primeiros modos de vibração sofrem pequena variação em função do aumento da rigidez causada por carregamentos dinâmicos. Tal fato motiva a realização de ensaios de campo com maior número de ciclos de carregamento.

Em termos da representatividade dos modelos propostos por Miche e Hetenyi, observa-se que a magnitude dos erros das velocidades efetivas foi maior nos casos em que o método de Hetenyi foi utilizado para estimativa dos coeficientes de mola, contudo não significantemente maior do que a magnitude dos erros nos casos em que a propriedade elástica do solo varia com a profundidade. Esse fato mostra que o solo influencia a resposta do sistema estrutural aos carregamentos dinâmicos até certa profundidade.

De forma geral, conclui-se que o modelo simplificado massa-mola fornece valores de freqüências naturais superiores aos valores obtidos com o modelo em elementos finitos para quaisquer dos modos considerados. Essa conclusão vale para o domínio do parâmetro $k_{m}$ compreendido entre $20000 \mathrm{kN} / \mathrm{m}$ e $64000 \mathrm{kN} / \mathrm{m}$, quando este é obtido por ensaio estático, e entre $69000 \mathrm{kN} / \mathrm{m}$ e $326000 \mathrm{kN} / \mathrm{m}$, quando é obtido por carregamentos cíclicos. 


\section{2.}

\section{Recomendações para trabalhos futuros}

$\mathrm{O}$ estudo da interação entre equipamentos, estruturas, fundações e solo é um campo vasto e possui inerentemente muitas incertezas, o que muitas das vezes exige dos especialistas envolvidos no projeto desse tipo de sistema integrado assumir valores de parâmetros que podem levar ao sucesso ou ao fracasso do desempenho das máquinas de uma planta industrial qualquer.

Nesse contexto, com o objetivo de complementar os estudos realizados nessa pesquisa, sugere-se o desenvolvimento dos seguintes aspectos:

- Testar o efeito na resposta dinâmica do sistema em relação ao uso de molas nãolineares como parâmetro representante do solo. Nesse caso, deve-se utilizar um procedimento de análise dinâmica que não por superposição modal de modo permitir a incorporação dos elementos não-lineares;

- Testar o efeito na resposta dinâmica do sistema em relação ao uso de molas associadas a amortecedores viscosos como parâmetro representante do solo;

- Avaliar o efeito da degradação da rigidez do solo devido ao efeito de cargas dinâmicas;

- Avaliar a sensibilidade dos modelos massa-mola e de elementos finitos em relação à rigidez dos elementos estruturais das fundações visando à otimização de projetos;

- Testar valores retroanalisados de parâmetros do solo obtidos de ensaios com maior número de ciclos de carregamento e ciclos com nível de carregamento de serviço;

- Testar o efeito na resposta dinâmica do sistema em relação ao uso de isoladores de vibração. 


\section{8 Referencias bibliográficas}

ARYA, S. C.; O`NEILL, M. W.; PINCUS, G. Design of Structures and Foundations for Vibrating Machines, Gulf Publishing Company, USA, 4th edition, 1979.

ASSOCIAÇÃO BRASILEIRA DE NORMAS TÉCNICAS. NBR 6118: Projeto de estruturas de concreto - Procedimento, 2007.

ASSOCIAÇÃO BRASILEIRA DE NORMAS TÉCNICAS. NBR 12131: Estacas prova de carga estática - Método de ensaio, 2006.

AMERICAN SOCIETY FOR TESTING AND MATERIALS. ASTM D3966 - 07: Standard test methods for deep foundations under lateral load, 2007.

BARKAN, D. D. Dynamics of bases and foundations, Mcgraw-Hill, USA, 1962.

BHATIA, K. G. Foundations for industrial machines, D-CAD Publishers, New Delhi, 2008.

CHOWDHURY, I.; DASGUPTA, S. P. Dynamics of structure and foundation - A Unified approach, Taylor \& Francis Group, London, UK, Vol. 2, 2009.

CLOUGH, R. W.; PENZIEN, J. Dynamics of structures, New York, McGraw- Hill, 1975.

DASSAULT SYSTÈMES SIMULIA CORP. ABAQUS 6.10-1 - Documentation Collection, 2010.

GAZETAS, G. Analysis of machine foundation: State of the art. International Journal of Soil Dynamics and Earthquake Engineering, Elsevier, Volume 2, Issue 1, pp. $2-42,1983$. 
HETENYI, M. Beams on elastic foundation. University of Michigan Press, 1946.

MICHE, R. J. Investigation of piles subject to horizontal forces. Application to quay walls. Journal of the School of Engineering, n. 4, Giza, Egipt, 1930, apud Velloso, 2010.

NASCIMENTO, N. A.; PUPPI, R. F. K. Formação Guabirotuba: Algumas características e comentários sobre fundações e contenções, Anais da mesa redonda Características Geotécnicas da Formação Guabirotuba, pp. 189-195, Curitiba, 1999.

NOGAMI, T. Simplified subgrade model for three-dimensional soil-foundation interaction analysis, Soil Dynamics and Earthquake Engineering, Elsevier, Volume 15, number 7, pp. 419-429, 1996.

NOVAK, M. Dynamic stiffness and damping of piles, Canadian Geotechnical Journal, Vol. 11, pp. 574-598, 1974.

STEINWENDER, F.; NORMANN, R. Parameter adjustment of a finite element model by means of measured natural frequencies, International Journal of Pressure Vessels and Piping, Volume 27, Issue 3, pp. 179-190, 1987.

INTERNATIONAL ORGANIZATION FOR STANDARDIZATION. ISO 2372: Mechanical vibration of machines with operating speeds from 10 to $200 \mathrm{rev} / \mathrm{s}$ Basis for specifying evaluation Standards, 1974.

PRAKASH, S. Soil Dynamics, Mcgraw-Hill, USA, 1981.

RAUSCH, E. Fundamente und andere dynamisch beanspruchte baukonstructionen, Verlag, Dusseldorf, 1959.

TERZAGHI, K. Evaluation of coefficients of subgrade reaction, Geotechnique, Vol. 5, pp. 297-326, 1955. 
WU, J. Finite element modeling and experimental modal testing of a threedimensional framework, International Journal of Mechanical Sciences, Volume 46, Issue 8, pp. 1245-1266, 2004. 